\title{
Does bipartite return-to-work policy work?: An evaluation based on stakeholder's experiences in a Canadian healthcare setting
}

Citation for published version (APA):

Maiwald, K. (2014). Does bipartite return-to-work policy work?: An evaluation based on stakeholder's experiences in a Canadian healthcare setting. [Doctoral Thesis, Maastricht University]. Datawyse / Universitaire Pers Maastricht. https://doi.org/10.26481/dis.20140521km

Document status and date:

Published: 01/01/2014

DOI:

$10.26481 /$ dis. $20140521 \mathrm{~km}$

Document Version:

Publisher's PDF, also known as Version of record

\section{Please check the document version of this publication:}

- A submitted manuscript is the version of the article upon submission and before peer-review. There can be important differences between the submitted version and the official published version of record. People interested in the research are advised to contact the author for the final version of the publication, or visit the DOI to the publisher's website.

- The final author version and the galley proof are versions of the publication after peer review.

- The final published version features the final layout of the paper including the volume, issue and page numbers.

Link to publication

\footnotetext{
General rights rights.

- You may freely distribute the URL identifying the publication in the public portal. please follow below link for the End User Agreement:

www.umlib.nl/taverne-license

Take down policy

If you believe that this document breaches copyright please contact us at:

repository@maastrichtuniversity.nl

providing details and we will investigate your claim.
}

Copyright and moral rights for the publications made accessible in the public portal are retained by the authors and/or other copyright owners and it is a condition of accessing publications that users recognise and abide by the legal requirements associated with these

- Users may download and print one copy of any publication from the public portal for the purpose of private study or research.

- You may not further distribute the material or use it for any profit-making activity or commercial gain

If the publication is distributed under the terms of Article $25 \mathrm{fa}$ of the Dutch Copyright Act, indicated by the "Taverne" license above, 


\section{Does bipartite return- to-work policy work?}

An evaluation based on stakeholders' experiences in a Canadian healthcare setting 



\section{DOES BIPARTITE RETURN-TO-WORK POLICY WORK?}

An evaluation based on stakeholders' experiences in a Canadian healthcare setting 
colofon

Sources of financial support in the form of a research fellowship came from (former) Occupational Health \& Safety Agency for Healthcare (OHSAH) in British Columbia, Canada. Funding does not imply endorsement of the findings.

(C) Karin Maiwald, 2014

Cover design: Karin Maiwald

Printing: Datawyse bv

ISBN 978-94-6159-325-2 


\section{DOES BIPARTITE RETURN-TO-WORK POLICY WORK?}

An evaluation based on stakeholders' experiences in a Canadian healthcare setting

DISSERTATION

To obtain the degree of Doctor at Maastricht University, on the authority of the Rector Magnificus,

Prof. dr. L.L.G. Soete

in accordance with the decision of the Board of Deans, to be defended in public

on Wednesday 21 May 2014, at 14.00 hours

by

Karin Maiwald

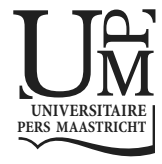




\section{Supervisor}

Prof. dr. F.J.N. Nijhuis

\section{Co-supervisors}

Dr. A.M. Meershoek

Dr. A.E. de Rijk

\section{Assessment Committee}

Prof. dr. IJ. Kant (Chairman)

Prof. dr. J.R. Anema, Vrije Universiteit Amsterdam, the Netherlands

Prof. dr. K. Horstman

Dr. I. Houkes

Dr. E. MacEachen, University of Toronto, Canada 


\section{Table of contents}

$\begin{array}{llr}\text { Chapter } 1 & \text { Introduction }\end{array}$

Chapter 2 Evaluation of a workplace disability prevention intervention 23

in Canada: Examining differing perceptions of stakeholders

Chapter 3 How policy on employee involvement in work reintegration can yield its opposite: Employee experiences in a Canadian setting

Chapter $4 \quad$ Policy on manager involvement in work re-integration:

Managers' experiences in a Canadian setting

Chapter 5 Policy on professional support in work re-integration:

Disability management staff and trade union representatives' experiences in a Canadian setting

Chapter $6 \quad$ General discussion

Summary

Samenvatting

A word of thanks

Curriculum vitae 155

List of publications 

Chapter 1

Introduction 



\section{The problem of work disability}

In industrial countries, the problem of work disability (WD) has received much attention in recent years [1-5] for many reasons. WD has become an economic problem as being shown by the slight rising trend over time in spending on disability and sickness programs (in \% of GDP) in several Organization for Economic Co-operation and Development (OECD) countries for the years 1990-2007 [6]. For example, in Australia, the trend in benefit spending is estimated to vary between 1.5 (in \% of GDP) in 2000 and 2.4 (in \% of GDP) in 2007 [6]. In Denmark, the spending is estimated to vary between 2.9 (in \% of GDP) and 3.1 (in \% of GDP) and in the United States these numbers vary between 1.5 (in \% of GDP) and 1.7 (in \% of GDP) for these same years [6]. In Canada, where this doctorate study took place, there has not been a recent rise in \% of GDP between 2000 and 2007 [6]. However, persons with disabilities are relying more than in Europe on benefits from workers' compensation schemes and private disability insurance benefits that are not included in spending on national (tax-based) social assistance payments [6, 7]. Work disability is also costly regarding productivity losses. In this respect, high numbers of the working-age population is involved in sickness absence and disability schemes. In Europe, the Netherlands has among the highest recipiency rates (at $8 \%$ of the working-age population) within the OECD area in 2007 [8]. In Canada, around $4.5 \%$ of the working-age population was depending on disability benefits in 2007 [7, 8]. In this country, the dependence on disability benefits was significantly below the OECD average (6\%) and lower than in most OECD countries [7]. Access to public disability schemes is relatively tight in Canada. This is partly mitigated by private disability benefits which play a more important role in Canada than in several other OECD countries [7].

In addition to focusing on the economic aspects, attention has also been drawn to the sociological aspect of work disability. Work disability recipiency seems to be concentrated among certain socio-demographic groups. Groups that are overrepresented in benefits are women; relatively peripheral working age-groups, chiefly younger and older people; those with manual occupation, particularly low and semi-skilled production jobs; and those with non-standard employment [8]. The same socio-economic groups are mentioned in North-America regarding WD [9]. Low income and poverty is a direct consequence $[7,8,10]$.

Exclusion from labour is also a regarded a serious threat for social cohesion. In a recent UK study [11] it was argued that "patterns of poverty and social exclusion blight entire communities and stunt the prospects of children and young people - the working age population of tomorrow" [p. 21]. Having a paid job is thus seen as the main path from 
social exclusion towards social inclusion [12] in the assumption that this improves health [11] and reduces poverty [13]. In welfare states there has been a shift from protection to activation in the approach to impairment of (work) function in recent years $[11,14,15]$. The ambition is thus to provide support to assist as many people as possible who have a disability to participate in the work process in a beneficial, integrative and sustainable way $[16,17]$.

An important aspect of reducing work disability is the availability of early interventions. The likelihood of permanent labour market exit rises with the duration of being away from the work process [7]. Particularly mental and psychological problems of individuals, chronic disorders in the ageing workforce, are seen as causing prolonged WD $[7,8]$. To prevent mild symptoms developing into more severe and permanent ones and to allow access to appropriate return to work (RTW) support when receiving a medical diagnosis is regarded as crucial.

The current research evaluated a specific work disability policy in a Canadian health care setting focusing on early intervention. Before explaining the policy under evaluation and our approach, first a short overview of the diverse national and organizational policies to reduce work disability will be given and next, the specific care of work disability in health care will be addressed.

\section{To approach work disability}

Many countries have developed legislation to reduce the length of the work disability, or in other words, the sickness absence ${ }^{1}$ duration. The legislative measures used to promote (early) work re-integration of workers with incapacities (the inability to work due to sickness or injury) include: tightening of disability criteria; financial incentives for RTW; adjusted work and support $[5,7,18]$. Tightening of disability criteria includes, for example, explicating the criteria of access to disability benefits [5] and shorter payment duration [7]. Financial incentives include compensation for employers in case of reduced productivity, higher compensation during early stages of work disability etcetera $[6,19]$. Adjusted work and support can be encouraged by sanctions. For example in the Netherlands, the employer might have to pay the wages of the absent worker for another (third) year if employer' RTW attempts are deemed incomplete [20]. In Canada, with regard to early work re-integration, financial incentives are provided for employers to prevent compensation cases and return workers back to work

\footnotetext{
${ }^{1}$ In Europe, work disability is often referred to as sickness absence. Even though the concepts are not entirely interchangeable, the legislative measures used to promote early work re-integration of workers with incapacities that are to guide work re-integration policy are similar.
} 
before full recovery of either their incapacities has taken place [21]. Other national measures are professional guidelines [e.g., 22, 23] as well as professional education [e.g., 24].

The current research focuses on the evaluation of a specific organizational policy aimed to reduce work disability. Organizations often offer a mix of approaches at various levels, -individual, organizational and a combination thereof-, to promote RTW in case of work disability $[25,26]$. Individual approaches mainly focus on prevention services, which are broad and can include, for example, safety programs and education, ergonomic services, health promotion, employee assistance programs and wellness services [27]. Organizational approaches mainly focus on promoting prevention and rehabilitation, which requires employers to commit to a supportive workplace climate, modified work, open and positive communication channels and the development and implementation of RTW policies including job accommodations, transitional employment, salary replacement elements etc. $[27,28]$. Demonstrated decreases in work disability duration suggest and some research underscores that mixed organizational policies, often referred to as disability management (DM), have some effect in reducing WD [29-33]. Still, many problems are identified and especially workers are at times disappointed in the type and amount of support they get $[26,34]$. One of the reasons for this failure might be that policies and RTW interventions seem not suitable adjusted to employers' and workers' needs and circumstances in practice [26, 35-39]. One of the responses to these bottlenecks is that employers and workers (representatives) are encouraged to get involved in policy making: the so-called bipartite policymaking approach. It is assumed that this leads to improved policies [40-42], however, to our knowledge, this has not been evaluated yet. The question is whether this approach functions for addressing WD, in other words does it help to develop a shared understanding of the problems underlying the bottlenecks in early return-to-work interventions? The return to work policy studied in this PhD thesis had been formulated with this bipartite approach. This thesis therefore investigates how and whether the result of this bipartite policy formulation combats the complexity of WD problems from the different perspectives of various stakeholders in a specific setting. A qualitative approach was chosen to be able to study the perspectives in-depth and in context. Before discussing this qualitative study more in depth, a description of our selected specific setting follows by addressing a few specific aspects of the Canadian healthcare workforce and work disability prevention and the policy under study. 


\section{The healthcare workforce}

The setting for this research is the healthcare sector. Its workforce faces a higher risk for WD compared to other industries [43-45]. Workers in the healthcare sector are potentially exposed to a wide range of health and safety hazards including: infectious, chemical and physical agents (allergies, exposures); ergonomic hazards associated with patient handling; psychological hazard (stress); workplace violence; and risks associated with changing organization of work (increased job complexity, increases in the number and acuity of chronic patients, cost containment and downsizing that alter the nature of work and the resources available to workers to do their work) [43-45].

In Canadian healthcare, the reported work-related musculoskeletal injuries have been as high as $60 \%$ and $72 \%$ for upper-body and lower-body symptoms respectively in workers [44]. These numbers and trends regarding incidence rate of sprains and strains involving days away from work in the healthcare sector are comparable to those in Europe [46-47] and the US [43]. Canadian healthcare workers report increasingly mental and psychological problems, which is in line with the international trend. Psychological distress in this particular workforce is associated with patient violence, aggression, high workload and other factors [44].

\section{Work disability prevention in Canada and the policy under study}

In Canada, policy making regarding WD in the public healthcare sector takes place at three main levels: federal Government, provincial Government and regional health organizations [48]. The federal Government is responsible to design and develop social security systems to maintain and regulate society [49]. Based on social security legislation, provincial Government and regional health organizations in British Columbia (BC) are authorized to develop provincial policy on WD in the healthcare sector [50]. In turn, each regional health organization, there are six health authorities in BC depending which year you check, is given authority to develop policies and procedures or programming to tackle the complexities of WD related issues in their own jurisdiction [50]. The studies in this thesis were performed in BC Healthcare.

For all BC residents, basic healthcare costs are covered on the basis of a public healthcare system [51]. In addition, employers are responsible for disability benefits for workers who experience work-related, industrial injuries and occupational diseases under federal Occupational Health \& Safety Regulations [52] and their respective provincial Workers Compensation Act [53]. If sickness absence is deemed to be not work- 
related or is the result of a motor-vehicle accident that is non-work related, there are various other insurance and benefits systems available. Social security arrangements in Canada are thus complex and not organized in a joint-up way [7].

With that in mind, in early 2000, return-to-work (RTW) policy was developed for the healthcare sector, taking an individual and organizational approach, in line with the international trend [25, 26]. Between 2003 and 2007, some evidence was found that bipartite policy making is effective in terms of measurable RTW outcomes targeted at reporting sick for work, claim duration, worker' satisfaction and cost savings [30-33, 54]. As it goes, RTW policy had been redesigned as part of on-going collective bargaining process for provincial collective agreements 2010-2012, whereby the bipartite arrangements were signed in January 2009 and put in place in April 2009 as a joint pilot program [55]. Recently, some initial evidence was found that bipartite policy making is effective in terms of measurable RTW outcomes targeted at reporting sick for work, claim duration and cost savings [55]. It is not clear yet whether the results can indeed be ascribed to the bipartite policy formulation and insight how bipartite policy formulation translates into practice is lacking.

In the specific BC Healthcare RTW policy under study, both the manager and individual workers are expected to participate in early intervention, wherein absent workers should reintegrate before full recovery of either their incapacities has taken place. An organizational structure to support both the manager and worker in early intervention includes a workplace-based disability management professional (DMP) (so called: case manager). These professionals are expected to contact the worker to request participation in RTW activities and ask for the worker's input in RTW planning (e.g., perceived limitations for work on either a straightforward plan for less than six weeks in duration or a complex plan for longer than six weeks). These professionals are also expected to ask for the manager's input in RTW planning (e.g. suggest adjustments on the plan). The DMP is thought to support the workers and employers (frontline managers) to complete their responsibilities in RTW and guide them through the various complex systems as well as focus on combining the different, may be even opposing perspectives of the workers and managers on the plan. Providing support and guidance plus focusing on getting the potential differing perspectives on the plan is supposed to get done in consultation with the local trade union representatives. The bipartite policy formulation in this setting thus draws a parallel between place-based disability management staff and trade union representatives' involvement when carrying out the policy in practice.

RTW programming is meant to include access to various support services (e.g., ergonomist, workplace rehabilitation advisors, -whom have a range of specialties to assess limitations the worker has to meet work demands). This is mostly done because 
the employer (frontline manager) has an obligation to make every reasonable effort to find a way to accommodate the worker (e.g., make a supernumerary ('extra') worker available upon RTW, carefully scrutinize their workplace for potential jobs into which the worker can be placed or, if equipment is required, investigate the cost of purchasing such equipment, provide access to internal human resources to help with the implementation of work -, job accommodations and further care.

The DMP must obtain consent of the workers' physician for re-integration at the workplace. They also must seek funding approval by insurers (e.g., workers compensation agencies, private disability benefits institutions) or by the employer (e.g., human resources) for needed support in RTW. External health and safety programming services may help with the implementation of work-, job accommodations and further care (as described above). Whether bipartite involvement in RTW policy formulation enhances practicability in terms of experienced effectiveness in a Canadian healthcare setting is not evaluated yet. That is what is evaluated in this thesis.

\section{Theoretical focus of this study}

In this thesis, a policy evaluation approach is taken. A basic distinction in the policy process that is often made is that between agenda setting, policy formulation, policy implementation and policy evaluation (see figure 1, based on Buse et al. [56]). Our research centers on the evaluation of the implementation of a specific policy as experienced by the various stakeholders. This contrasts with an effect evaluation that focuses on outcome parameters (e.g., duration of work disability).

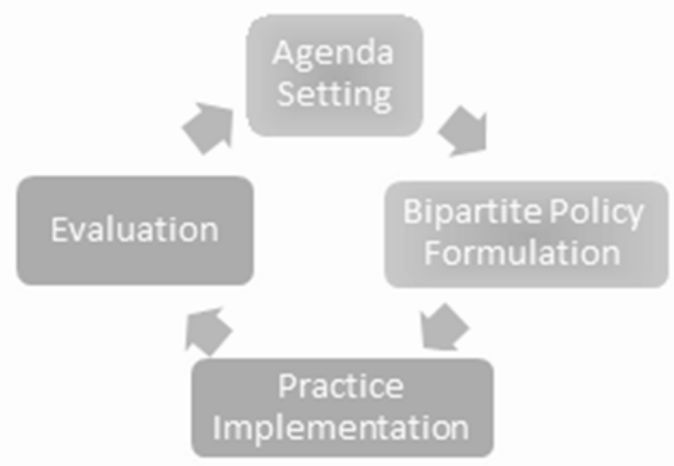

Figure 1. Diagram of the policy process (based on Buse et al. [56])

In BC Healthcare a bipartite policymaking approach is used and worker and employer representatives are involved in policy formulation to enhance practicability [50]. In 
general, it has been demonstrated that workers focus on their health, financial stability and happiness while employers focus on financial viability, workforce productivity and satisfaction, safety/security and their public image [57]. Explorative research in the context of $\mathrm{BC}$ Healthcare shows that, as in other contexts, both representative groups indeed have different, almost opposite interests. The worker representatives from the trade unions consider protection of workers' rights of the utmost importance. Their aim is to try to regulate and standardize the process as far as possible, as the explication of tasks and responsibilities of workers and employers can protect workers from arbitrariness and potential manipulation by employers [50]. The employer representatives from the health organization emphasize the importance of focusing on efficiency and practical solutions per regional health organization [50]. Thus, the basic distinction is that between defending workers' rights and the 'rights' (or rather effectiveness) of individual organizations. The BC healthcare RTW policy tried to combine these different aims.

The focus of the current study is to investigate how this policy, that is the result of a bipartite process, is experienced by the different stakeholders. Stakeholders we studied were 'designers' - those stakeholders who formulated the RTW policy (study 1), and 'deliverers' and 'receivers' - those stakeholders who implemented the RTW policy in practice (study 1-4).

To study how the policy is experienced, a social constructivist view on the policy process is taken, which starts with the assumption that policy often turns out differently and in unexpected ways in practice $[58,59]$. This is the case because policies consist of abstract rules that are based on broad assumptions of the situations they have to govern. In practice, stakeholders have to give meaning to these rules. They apply the abstract rules from the policy to concrete individual cases $[58,59]$. Rules do not determine their application but have to be interpreted and professionals have more or less discretionary space. This process of interpretation in practice is influenced by means of professional norms, social costumes, peer norms, moral beliefs and existing practices $[38,39,58-61]$. Local understandings or interpretations of rules by those involved in determining the best action also counts for transformations in policy. Discretionary space allows transformation of the policy. From a social constructivist point of view, this room is not a mistake of the rules as such but thought necessary to allow for including individual differences and contextual circumstances in decision-making processes to enhance fairness in social security processes [60]. Depending on the complexity of the situation that is governed by the rules, more or less discretionary space is needed to enable stakeholders to apply them. Thus, application of rules from a policy is a highly contextual and dynamic enterprise [58]. How the rules in the policy are 
given meaning in practice and how the discretionary space is experienced and handled, needs to be studied in the specific context of a specific policy.

Some research on the interpretation and transformation of rules regarding RTW has been done, which demonstrate the limited reach of policy in practice due to various reasons and which offer handles to improve policy and practice $[38,39]$.

\section{The research in this thesis}

Below the aims, research questions and methodology is explained.

\section{Aims and research questions}

The aim of this study was to investigate whether the BC Healthcare RTW policy is experienced as successful by the stakeholders. This was done by first getting more insight in the exact differences in perspectives of the stakeholders on the policy, including the designers. Second, detailed understanding of how the policy was experienced by receivers (workers) and deliverers (frontline managers, disability management staff and trade union representatives) was gained. Our research questions focused on how the stakeholders experience the RTW policy and these were addressed in four studies:

- What are the various stakeholders' appreciations of the BC Healthcare RTW policy? (study 1)

- How are the workers experiencing their new role in work reintegration trajectories and to what extent do they appreciate the policy? (study 2)

- How are the employers, that is the frontline managers or supervisors, experiencing their new role in work reintegration trajectories and to what extent do they appreciate the policy? (study 3)

- How are the occupational health professionals, that is the disability management staff and trade union representatives, experiencing their new role in work reintegration trajectories and to what extent do they appreciate the policy? (study 4)

\section{Methodology}

Qualitative research methods were selected because we considered this the best method, given that we intended to gain insight in stakeholders' experiences with implementation of RTW policy. We wanted to focus on the process of meaning making, and to get an in-depth understanding of their experiences.

To support data collection, (former) Occupational Health and Safety Agency for Healthcare (OHSAH-a provincially funded and bipartite-governed social services agency, in combination with university-affiliated researchers), BC, Canada was approached to collaborate in this doctorate study. In addition, two regional $\mathrm{BC}$ healthcare organiza- 
tions were contacted to participate in the studies, that were organized in two phases. In the first phase of this study we aimed to get a general overview of similarities and differences in perceptions of stakeholders on the bipartite agreed-upon RTW policy (chapter 2) at one small rural healthcare site (a geographical region in this province which holds small towns and has low population density, located outside the Lower Mainland). Because of the experienced short comings of the RTW policy in this small rural setting and since the BC Healthcare organizations varied in terms of role in RTW policymaking in this province, we then aimed to get detailed understanding of how the (reformed) bipartite agreed-upon RTW policy was experienced by stakeholders in another setting. In the second phase of this study (chapter 3-5), we thus selected a large considered provincial leading BC Healthcare organization and urban healthcare site (a geographical region called the Lower Mainland, which holds the main cities (e.g., Vancouver and surroundings) in this province and has high population density). Furthermore, three trade unions in BC healthcare agreed to facilitate this work. With local support of these various institutions, administrative materials on work disability and RTW were reviewed to gain understanding of local RTW policy-as intended.

The data collection methods we used in the studies, were individual semi-structured interviews with various stakeholders about RTW policy in practice.

In selecting participants for individual interviews, purposive and snowball sampling strategies were used to maximize variability of experiences, including negative experiences. Feedback loops were put in place to optimize recruitment and the interview questions.

Qualitative analyses of the collected data were completed to gain deep insight into stakeholders' perspectives [62-64]. In the first study, a somewhat different analysis was used compared to the other studies. In this study, also participant observations in provincial and local stakeholder meetings and notes of the discussions in the focus group meetings were included. By structuring data, identifying themes, initial coding and categorizing experiences and perceptions [65] we reconstructed stakeholders' ideas on work disability leading to sickness absence, on possible solutions to address it, and the effectiveness of current program services at this evaluation site in our analysis. In studies $2-4$, inspired by ethnographic approaches [66, 67], we reconstructed implementation of RTW policy, based on stakeholders' experiences, their actions and practical reasoning in our analyses. Firstly, by structuring data, identifying themes, initial coding and categorizing experiences and perceptions [65] we aimed to unravel the stakeholders' perspectives on bottlenecks and how these affected RTW. Secondly, we reconstructed patterns to interpret experiences and perception on challenges and opportunities [68]. Our interpretative analyses $[62,66,67]$ focused on the role of legis- 
lation, policy, organizational characteristics and the individual context on involvement in RTW planning. For this thesis, various review processes were put in place to ensure the accuracy of the descriptions, emerging themes, and revealed arguments (continues consideration of the data, comparing coding, comparing situations, relations and patterns of themes).

\section{Outline of the thesis}

In this thesis a bipartite agreed-upon RTW policy, that was implemented in BC Healthcare in Canada, is evaluated. The aim of bipartite involvement in RTW policy formulation is to include the workplace and worker perspectives in the assumption that this results in policies that are more workable in practice [40-42]. The aim of this study was to investigate whether the BC Healthcare RTW policy is experienced as successful by the stakeholders. We examined stakeholders' perspectives and investigated this from a social constructivist view. Chapter 2 presents a study on local stakeholders' (designers, deliverers, receivers) perspectives on RTW and the RTW practice in general (research question 1, study 1). Chapter 3 presents a study on how various workers (receivers) experienced RTW policy, in particular input in decision making processes in RTW planning (research question 2, study 2). Chapter 4 presents a study on how a number of frontline managers or supervisors (deliverers) experienced RTW policy, in particular input in decision making processes in RTW planning (research question 3, study 3). Chapter 5 presents a study on how different occupational health professionals, that is disability management staff and trade union representatives (deliverers), experienced RTW policy, in particular to bring varying worker and managers' perspectives forward; and on individual RTW plans (research question 4, study 4). In the general discussion, chapter 6 , an overview of the main findings will be provided and the results will be discussed. Furthermore, recommendations for future research will be offered. In addition, recommendations for practice will be provided. 


\section{References}

1. World Health Organization (WHO) (2011) World Report on Disability. http://www.who.int/disabilities/world_report/2011/en/index.html. Accessed Sep 302013.

2. World Health Assembly (WHA) (2005) Resolution 58.23. Disability, including prevention,

3. management and rehabilitation. http://www.who.int/disabilities/WHA5823_resolution_en.pdf. Accessed Sep 302013.

4. United Nations (UN) (2006) Convention on the Rights of Persons with Disabilities. http://www.un.org/disabilities/convention/conventionfull.shtml. Accessed Sep 302013.

5. WHA (2001). Resolution 54.21. International classification of functioning, disability and health. http://www.who.int/classifications/icf/wha-en.pdf. Accessed Sep 302013.

6. Kalisch DW, Aman T, Buchele LA. Social and Health Policies in OECD Countries: A Survey of Current Programmes and Recent Developments. Organization for Economic Co-Operation and Development (OECD). Labour Market and Social Policy Occasional Papers, No. 33, OECD Publishing. http://dx.doi.org/ 10.1787/720018345154; 2003.

7. OECD. Sickness, Disability and Work: Breaking the Barriers. A synthesis of findings across countries. OECD Publishing; 2010.

8. OECD. Sickness, Disability and Work: Breaking the Barriers. Canada : Opportunities for Collaboration. OECD Publishing; 2010.

9. OECD. Employment outlook. Chapter 4. Pathways onto (and off) Disability Benefits: Assessing the Role of Policy and Individual Circumstances. OECD Publishing; 2009.

10. Statistics Canada. http://www.statcan.gc.ca/pub/89-628-x/89-628-x2010015-eng.htm. Accessed Sep 302013.

11. National Institute for Health and Clinical Excellence. Managing long-term sickness

12. and incapacity for work. http://www.nice.org.uk/nicemedia/live/11779/43545/43545.pdf. Accessed Sep 302013.

13. Black DC. Working for a healthier tomorrow. Dame Carol Black's Review of the health of Britain's working age population. London. TSO; 2008.

14. Jagger C, Gillies C, Moscone F, Cambois E, Van O, Nusselder W, et al. Inequalities in healthy life years in the 25 countries of the European Union in 2005: a cross-national meta-regression analysis. Lancet. 2008;372:1224-31.

15. International Labour Organization (ILO). Code of Practice on managing disability in the workforce. Tripartite Meeting of Experts on the Management of Disability at the Workplace. ILO; 2001.

16. Gilbert N. The Enabling State. An Emerging Paradigm for Social Protection. Oslo: Fafo1999.

17. Vrooman C. Een succesvolle gedaantewisseling? De hervorming van de sociale zekerheid, 1985-2010. Tijdschrift voor Arbeidsvraagstukken [Magazine for Workissues]. 2010;26(4):358-77.

18. van der Veen R, Yerkes M, Achterberg P. The Transformation of Solidarity. Changing Risks and the Future of the Welfare State. Amsterdam; 2012.

19. Betzelt S, Bothfield S. Activation and Labour Market Reforms in Europe: Challenges to Social Citizenship-Introduction. Basingstoke, UK; 2011.

20. Europe 2010. http://ec.europa.eu/europe2020/index_en.htm. Accessed Sep 302013.

21. Høgelund J. In search of effective disability policies. Comparing the development and outcomes of Dutch and Danish disability policies. Amsterdam: Amsterdam University; 2002.

22. Uitvoeringsinstituut Werknemersverzekeringen (UWV). Ik heb een zieke werknemer. Wat nu? Informatie voor werkgevers over re-integratie tijdens de eerste twee jaar ziekte en de Ziektewet. UWV. [I have an ill employee. Now what? Information for employers about re-integration during the first two years of illness and the Illness law]. http://www.uwv.nl/Particulieren/ik_ben_ziek/ik_ben_bijna_ 2_jaar_ziek_en_kan_nog_werken/ik_ben_bijna_2_jaar_ziek/index.aspx. Accessed Sep 302013. 
23. MacEachen E, Lippel K, Saunders R, Kosny A, Mansfield L, Carrasco C, et al. Workers' compensation experience-rating rules and the danger to workers' safety in the temporary work agency sector. Policy Pract Health Saf. 2012;10(1):77-94.

24. Anema JR, Schellart AJ, Cassidy JD, Loisel P, Veerman TJ, van der Beek AJ. Can cross country differences in return-to-work after chronic occupational back pain be explained? An exploratory analysis on disability policies in a six country cohort study. J Occup Rehabil. 2009;9(4):419-26.

25. Berg M, Horstman K, Plass S, van Heusden M. Guidelines, professionals and the production of objectivity: standardisation and the professionalism of insurance medicine. Sociol Health IIIn. 2000;22(6):76591.

26. Hulshof $\mathrm{C}$, Frings-Dresen M. International $\mathrm{OH}$ systems. Part 2: occupational health delivery in the Netherlands. Occup Health Work.2010;6(5):19-23 (pg. 37).

27. Loisel P, Durand P, Berthelette D, Vezina N, Baril R, Gagnon D, et al.Disability Prevention: new paradigm for the management of occupational back pain. Disabil Manag Health Outcomes. 2001;9(7):351-60.

28. Anema JR, Steenstra IA, Urlings IJM, Bongers PM, de Vroome EMM, van Mechelen W. Participatory Ergonomics as a Return-to-Work Intervention: A Future Challenge? Am J Ind Med. 2003;44(3):273-81.

29. Westmorland M, Buys N. A comparison of disability management practices in Australian and Canadian workplaces. Work. 2004;23:31-41.

30. Williams R, Westmorland M. Perspectives on workplace disability management: A review of the literature. Work. 2002;19:87-93.

31. Anema J, Cuelenaere B, van $\operatorname{der}$ Beek A, al. e. The effectiveness of ergonomic interventions on returnto-work after low back pain; a prospective two year cohort study in six countries on low back pain patients sicklisted for 3-4 months. Occup Environ Med.2004;61:289-94.

32. Yassi A, Ostry A, Spiegel J, editors. Injury prevention and return to work: breaking down the two solitudes: Taylor \& Francis Books Ltd.; 2003.

33. Yassi A, Ostry A, Hatter B, De Boer $\mathrm{H}$. Joint health and safety committee education and the value of bipartite cooperation in the healthcare sector in British Columbia, Canada. Int J Occup Environ Health 2005;11:305-12.

34. Davis P, Badii M, Yassi A. Preventing disability from occupational musculoskeletal injuries in an urban, acute and tertiary care hospital: results from a prevention and early active return-to work safely program. J Occup Environ Med. 2004;46(12):1253-62.

35. Badii M, Keen D, Yu S, Yassi A. Evaluation of a comprehensive integrated workplace-based program to reduce occupational musculoskeletal injury and its associate morbidity in a large hospital. J Occup Environ Med.2006;48(11):1159-65.

36. MacEachen E, Clarke J, Franche R, Irvin E. Systematic review of the qualitative literature

37. on return to work after injury Scand J Work Environ Health.2006; 32(4):257-69.

38. Baril R, Clarke J, Friesen M, Stock S, Cole D, Group W-R. Management of return-to-work programs for workers with musculoskeletal disorders: a qualitative study in three Canadian provinces. Soc Sci Med. 2003;57:2101-14.

39. MacEachen E, Kosny A, Ferrier S. Unexpected barriers in return to work: Lessons learned from injured worker peer support groups. Work. 2007:155-64.

40. Eachen M, S F, A K, L C. A deliberation on 'hurt versus harm' logic in early-return-to-work policy. Journal Policy Pract Health Saf. 2007;5(2):41-62.

41. Meershoek A, Krumeich A, Vos R. Judging without criteria? Sickness certification in Dutch disability schemes. Sociol Health IIIn. 2007;29(4):497-514.

42. Meershoek A, Krumeich A. Multiculturalism and the Construction of Ethic Identities in Labour and Health Practices: Avoiding the Culturalistic Fallacy in Applied Research. Health Care Anal.2009 17:17397.

43. Franche $R$, Baril $R$, Shaw $W$, Nicholas $M$, Loisel P. Workplace-based return-to-work Interventions: optimizing the role of stakeholders in implementing and research. J Occup Rehabil.2005;15(4):525-42. 
44. Guzman J, Yassi A, Baril R, Loisel P. Decreasing occupational injury and disability: The convergence of systems theory, knowledge transfer and action research. Work.2008;30(3):229-39.

45. Van Oostrom S, Anema J, Terluin B, Venema A, De Vet H, Van Mechelen W. Development of a workplace intervention for sick-listed employees with stress-related mental disorders: Intervention Mapping as a useful tool. BMC Health Serv Res.2007;7:127.

46. National Institute for Occupational Health and Safety (NIOSH). http://www.cdc.gov/niosh/topics/healthcare/. Accessed Sep 202013.

47. Health Canada. Trends in Workplace Injuries, Illnesses, and Policies in Healthcare across Canada. Office of Nursing Policy. 2004. http://www.hc-sc.gc.ca/hcs-sss/alt_formats/hpb-dgps/pdf/pubs/2004-hwiipsmt/2004-hwi-ipsmt-eng.pdf. Accessed Sep 202013.

48. WHO. The world health report: working together for health. 2006. http://www.who.int/whr/2006/whr06_en.pdf. Accessed Sep 202013.

49. Alexopoulus E, Burdorf A, Kalokerrinou A. A comparative analysis on musculoskeletal disorders between Greek and Dutch nursing personnel. Int Arch Occup Environ Health.2006;79:82-8.

50. Bos E, Krol B, van der Star L, Groothoff J. Risk factors and musculoskeletal complaints in non-specialized nurses, IC nurses, operation room nurses, and X-ray technologists. Int Arch Occup Environ Health.2007;80:198-206.

51. Quality Worklife - Quality Healthcare Collaborative. Within Our Grasp: A Healthy Workplace Action Strategy for Success and Sustainability in Canada's Healthcare System. Canadian Council on Health Services Accreditation. 2007. http://www.qwqhc.ca/docs/2007QWQHCWithinOurGrasp.pdf. Accessed Sep 202013.

52. Service Canada. http://www.servicecanada.gc.ca/eng/home.shtml. Accessed Sep 302013.

53. Occupational Health \& Safety Agency for Healthcare. Bipartite policy to formulate policy on work disability and return-to-work programs in the healthcare sector in BC. A progress report. Maiwald $\mathrm{K}$, Meershoek AM, eds. Vancouver, Canada; Occupational Health \& Safety Agency for Healthcare; 2010.

54. Government of British Columbia, Canada. Ministry of Health. http://www.health.gov.bc.ca/msp/. Accessed Sep 202013.

55. ILO. Occupational safety and health country profile: Canada. http://www.ilo.org/safework/countries/americas/canada/lang--en/index.htm. Accessed Sep 2013.

56. WorkSafeBC. Occupational Health and Safety Regulation. http://www2.worksafebc.com/publications/ohsregulation/Introduction.asp. Accessed Sep 202013.

57. Ouellette V, Badii M, Lockhart K, Yassi A. Worker satisfaction with a workplace injury prevention and return-to-work program in a large Canadian hospital: the importance of an integrated approach. Work. 2007;28:175-81.

58. Canada Benefits. Get well sooner: How overhauling Vancouver Coastal Health Authority's disability management program saved \$ 2.5 million. Benefits Canada. 2012. http://www.benefitscanada.com/wp-content/uploads/2012/02/BC0212-Strategy.pdf. Accessed Sep 202013.

59. Buse K, Mays N, Walt G. The Health Policy Framework: Context, process and actors. Birkshire, England: Open University Press; 2005.

60. Young A, Wasiak R, Roessler R, McPherson K, Anema J, van Poppel M. Return-to-Work Outcomes Following Work Disability: Stakeholder Motivations, Interests and Concerns. J Occup Rehabil. 2005;15(4):543-56.

61. Stone DA. Policy paradox: the art of political decision making. Revised Edition ed. New York- London: W.W. Norton \& Company; 2002.

62. Lipsky M. Street-level Bureaucracy: Dilemmas of the Individual in Public Services. New York: Russel Sage Foundation; 1980.

63. Van der Veen R. De sociale grenzen van beleid: een onderzoek naar de uitvoering en effecten van sociaal beleid [The social boundaries of policy: a study into the implementation and effects of social policy]. Leiden: Stenfert Kroese; 1990. 
64. Van der Veen R. De transformatie van beleid [The transformation of policy] In: Witteveen WJ SH, Trappenburg MJ, editors. Het bereik van de wet [The reach of the law]. Zwolle: Tjeenk-Willink; 1992. p. 63-80.

65. Denzin NK, YS. L. Handbook of qualitative research. Thousand Oaks: Sage; 2005.

66. Polit DF, Beck CT. Nursing research: principles and methods. 7-th ed. Philadelphia, PA: Lippincott Williams \& Wilkins; 2004.

67. Stake R. Qualitative Case Studies. In: Denzin NK, Lincoln YS, editors. The Sage Handbook of Qualitative Research. 3-rd ed. 2005. p. 443-66 (p.51).

68. Corbin J, Strauss A. Basics of qualitative research: techniques and procedures for developing grounded theory. 3-rd ed. Thousand Oaks, CA: Sage publications; 2008.

69. Hammersley M, Atkinson P, London: Routledge. Ethnography: principles in practice. 3-rd. ed. London Routledge; 2007.

70. Tedlock B. The observation of participation and the emergence of public ethnography. In: Denzin NK LY, editor. Handbook of qualitative research. 3-rd. ed. Thousand Oaks, CA. 2005. p. 467-81.

71. Boeije H. Analysis in Qualitative Research. Los Angeles: Sage; 2010. 


\section{Chapter 2}

Evaluation of a Workplace Disability Prevention Intervention in Canada: Examining Differing Perceptions of Stakeholders

Karin Maiwald

Angelique E. de Rijk

Jaime Guzman

Eva Schonstein

Annalee Yassi

In: J Occup Rehabil. 2011;21(2):179-189. 


\section{Abstract}

Introduction: Workplace disability prevention is important, but stakeholders can differ in their appreciation of such interventions. We present a responsive evaluation of a workplace disability prevention intervention in a Canadian healthcare organization. Three groups of stakeholders were included: designers of the intervention, deliverers, and workers. The aim was to examine the appreciation of this intervention by analyzing the discrepancies with respect to what these various stakeholders see as the causes of work disability, what the intervention should aim at to address this problem, and to what extent the intervention works in practice.

Methods: A qualitative research method was used, including data-triangulation: (a) documentary materials; (b) semi-structured interviews with the deliverers and workers ( $n=14)$; (c) participatory observations of group meetings $(n=6)$; (d) member-checking meetings ( $n=3)$; (e) focusgroup meetings $(n=2)$. A grounded theory approach, including some ethnographic methodology, was used for the data-analysis. Results Stakeholders' perceptions of causes for work disability differ, as do preferred strategies for prevention. Designers proposed work-directed measures to change the workplace and work organizations, and individual-directed measures to change workers' behaviour. Deliverers targeted individual-directed measures, however, workers were mostly seeking work-directed measures. To assess how the intervention was working, designers sought a wide range of outcome measures. Deliverers focused on measurable outcomes targeted at reducing work time-loss. Workers perceived that this intervention offered short-term benefits yet fell short in ensuring sustainable return-to-work.

Conclusion: This study provides understanding of where discrepancies between stakeholders' perceptions about interventions come from. Our findings have implications for workplace disability prevention intervention development, implementation and evaluation criteria. 


\section{Introduction}

Work disability is a major problem in western industrialized countries, from the perspective of individual burden, public health, and economic costs. Long-term absence due to disability particularly contributes to these costs [1]. In Canada, as in many other countries, the largest numbers of days lost from work were recorded for full-time employees in health occupations in 2008 [2]. Illness and disability among healthcare workers in British Columbia (BC) costs an estimated one billion dollars annually [3].

Work disability prevention and return-to-work of workers who report sick is a complex phenomenon [4]. In the healthcare sector in BC, a workplace-based initiative called the 'Prevention and Early Active Return-to-work Safely' (PEARS) program was introduced in 2001. To meet the complexity, this intervention was designed by the Occupational Health and Safety Agency for Healthcare (OHSAH) in BC (a governmental agency with bipartite -employer and (labour) union representative- governance) in collaboration with affiliated researchers, and local employer and union representatives at a regional healthcare organization $[5,6]$. The reason for the bipartite involvement in designing this workplace-based intervention was that earlier studies [5-8] demonstrated the importance of an integrated workplace-based and work-focused approach, which is built around recognizing the importance of getting all the stakeholders involved in effective communication.

The intervention thus was designed to include primary prevention strategies to prevent work disability from occurring, as well as secondary and tertiary prevention strategies to reduce time-loss and to support return-to-work after a sickness absence. The focus of the PEARS program was work-related musculoskeletal disorders. The specific interventions involved individual and work- directed measures, and '20 principles' - a basic-framework or set of rules to guide the intervention in practice [9].

Quantitative evaluation of this intervention showed a reduction in work time-loss of registered nurses by $27-40 \%$ (depending on the comparison year), and reduced costs of claims by $27-44 \%[10,11]$. The basic framework of this intervention had been disseminated to other regional healthcare organizations province-wide. The PEARS site of this study had significantly lower average days lost per time-loss claim (30\% reduction) and had significantly lower average compensation costs per time-loss claim than non-PEARS sites (23\% reduction) $[12,13]$.

What is not known from the above evaluations is 'how' this work-place intervention is appreciated by the different stakeholders. In order to attune policy with local workplace needs, stakeholders' perceptions about program workings in workplace reality ought to be considered [13-19]. 


\section{Aim}

The aim of this article is to examine various stakeholders' appreciation of the intervention by analyzing the discrepancies between what these stakeholders see as the causes of work disability, what the intervention should aim at to address this problem, and to what extent the intervention works in practice.

Further, through collaboration with local stakeholders this inquiry aims to improve and refine program implementation, which may in turn improve its longevity [19-21]. Analysis of discrepancies between relevant stakeholders and unraveling tension between policy and practice can further improve intervention effectiveness [22].

\section{Theoretical Framework}

According to Guba \& Lincoln [19], how stakeholders judge the worth of an intervention largely depends on the degree to which this intervention aims to change what they see as the causes of the underlying problem that needs to be addressed. In social constructivist terms, the formulation of a problem is a social construction, reflecting how we make sense of patterns of difference between people [23]. Stakeholder' ideas on possible solutions to address a problem logically follow their ideas about underlying cause(s) [19].

The topic of our evaluation is an intervention for preventing work disability, often referred in the literature as sickness absence. Explanations of sickness absence have traditionally followed a 'reductionist' approach and medical model to treat 'disease or illness'; assuming that lay people, in this case healthcare workers who report sick from work, will respond to 'prescribed' treatments and life-style changes [24]. In recent scientific literature, the causes for sickness absence are attributed to (a) the individual worker; and/or (b) workplace/job-station; and/or (c) work organization. In relation to conceptualizing disability prevention, there seems to be a shift away from workers' personal characteristics (physical and psychosocial factors) towards the interaction between the worker and the workplace environment, compensation, and healthcare delivery system in addressing this societal problem [1, 25]. Even though, workplace interventions often focus their strategies on the individual workers' behaviour [26].

Literature suggests that those who design an intervention (planning) often do this with a different rationale or perspective than those who are impacted, that being the workers in the workplace [19]. Moreover, program deliverers, this being executers of the planning in the workplace, are charged with translating the policy into daily practice. Designers and deliverers might all have different norms and values than the workers who are most impacted by strategic policy on work disability [20, 21, 27].

In the intervention studied, employer and union representatives were expected to contribute to the design of the intervention, which was intended as the axis for a paradigm shift in the domain of work disability prevention [28]. Traditionally however, 
employer and union representatives do not regard each other as 'natural' partners in formulating policies, such as disability prevention interventions. Disability prevention might be regarded as a political arena where differences in perspectives of employer and union representatives exist in relation to perceived power differences.

Several authors argue that to ensure success of interventions, the interventions should reflect the diverse interests of societal stakeholders i.e. those of laypersons, administrators, clinicians and scholarly researchers [14-21, 25, 28, 29]. Building collaboration between various stakeholders, however, is often difficult, and action frequently breaks down [30]. This study intends to illuminate where and how stakeholders' differences in perspectives on disability prevention interventions originate and are perpetuated.

\section{Methods}

Qualitative research methods are shown to be useful when exploring stakeholders' perceptions [31]. Data for this study were collected between 2006 and 2008, in one regional health organization in $\mathrm{BC}$ that includes a regional hospital, a community hospital and a community health centre. Data triangulation was used to secure an indepth understanding of stakeholders' perceptions. This included five types of data collection: First, administrative and background documents, which included PEARS principles and guides, scientific articles on the intervention and internal evaluation reports on the PEARS program, were reviewed, by first author KM, to develop an understanding of the views and intent of the designers of the program.

Second, we conducted individual semi-structured interviews to ascertain the perspectives of deliverers executing and workers receiving services. Purposive and snowball sampling strategies were used to maximize variability of ideas and obtain information from the full range of stakeholders, including those with negative experiences. Interviews were taped and transcribed verbatim. To be included in this study, participants had to be adults over 18 years old and belong to one of the three above mentioned stakeholder groups.

Program deliverers $(n=10$; those who were responsible for executing policy on disability prevention, including implementation and evaluation) included: (a) bipartite committee members including employer and union representatives $(n=3)$, Occupational Health and Safety (OHS) director $(n=1)$ and staff $(n=3$; who performed the initial assessment of workers who reported sick from work, determined program eligibility, and coordinated return-to-work); (b) work-place based physiotherapists ( $n=3$; who provided physiotherapy services and return-to-work planning). 
The workers $(n=4)$ included registered nurse(s), licensed practical nurse(s) and lab technician(s). Types of injuries included work-related musculoskeletal disorders of the back, shoulder(s) and shoulder-neck, based on physician's medical diagnoses.

Participants in the interviews included 14 women, all between 30 and 60 years of age with a considerable range of working experience in the healthcare sector. All participants took part in the intervention between 2005 and 2008. Individual interviews lasted until saturation of information was reached.

Third, the principal researcher participated in local bipartite committee meetings $(n=3)$, and annual OHSAH-PEARS meetings $(n=3)$ that included designers, and province-wide program deliverers. She made notes of spoken discourse on justifications, explanations, motives of actions among and between stakeholder groups.

Fourth, notes of spoken discourse during within stakeholder groups i.e. workers only $(n=3)$ were made. Fifth, notes of spoken discourse during participatory observations of focus group meetings $(n=2)$ between stakeholder groups were made. (See Table I for all five types of data collection)

Table 1 All five types of data collection

\begin{tabular}{|c|c|c|c|c|}
\hline & \multicolumn{4}{|c|}{ Stakeholders involved in disability prevention at this workplace } \\
\hline & $\begin{array}{l}\text { Those who } \\
\text { designed the } \\
\text { intervention }\end{array}$ & $\begin{array}{l}\text { Those who delivered } \\
\text { the intervention }\end{array}$ & & $\begin{array}{l}\text { Those who } \\
\text { received the } \\
\text { intervention }\end{array}$ \\
\hline Data collection & $\begin{array}{l}\text { OHSAH } \\
\text { Employer and } \\
\text { employee } \\
\text { representatives }\end{array}$ & $\begin{array}{l}\text { Bipartite Committee } \\
\text { OHS director } \\
\text { and program staff } \\
\text { Front-line manager } \\
\text { and union representa- } \\
\text { tives }\end{array}$ & $\begin{array}{l}\text { Work place based } \\
\text { physiotherapists }\end{array}$ & Workers \\
\hline $\begin{array}{l}\text { Documentary mate- } \\
\text { rials }\end{array}$ & $\begin{array}{c}\text { Central PEARS } \\
\text { documents }\end{array}$ & Local PEARS documents & - & \\
\hline $\begin{array}{l}\text { Individual semi } \\
\text { structured inter- } \\
\text { views }\end{array}$ & - & $N=7$ & $N=3$ & $N=4$ \\
\hline Group meetings & $N=3$ & $N=3$ & & \\
\hline Member checking & - & $N=1$ & $N=1$ & $N=1$ \\
\hline $\begin{array}{l}\text { Focus group meet- } \\
\text { ings }\end{array}$ & & $N=2$ & & \\
\hline
\end{tabular}




\section{Data Analysis}

The administrative and background documents and the transcribed texts of the interviews were analyzed [19, 32]. The emerging themes were identified and categorized using an open coding system, deriving and developing concepts from the data. Peer review for checking of codes was carried out by researchers outside the setting of this study. Then, a constant comparison of the concepts, to assess the similarities and differences between stakeholders' perceptions, was conducted [33].

Next, separate within stakeholders group discussions were held (memberchecking) with the deliverers and the workers to present the preliminary findings, including obtaining feedback on the interpretation of the data to ensure accuracy and increase credibility of the analysis [34, 35]. These meetings were used to introduce differing perspectives (on causes, solutions and workings) to each stakeholder group. The meetings were followed by between stakeholder group meetings with the deliverers and workers combined to prioritize issues that needed to be addressed and to find shared solutions to improve the implementation of the local intervention. To facilitate a democratic-process for decision-making, the nominal-group technique was used to structure the meetings [36].

Finally, with ethnographic methodology $[33,37]$ we reconstructed patterns in similarities and differences in stakeholders' perceptions. Here, the stakeholders' perceptions were interpreted in terms of existing theories explaining sickness absence in scientific research; unraveling what sorts of differences in problem definitions regarding sickness absence are visible. Next, emerging patterns regarding perceptions on solutions and the perceived impact of this intervention were re-created. AY, original key designer of the PEARS program reviewed and discussed interpretation of document analysis to ensure accuracy. Thus, based on assembled evidence, we reconstructed stakeholders' ideas on work disability leading to sickness absence, on possible solutions to address it, and the effectiveness of current program services at this evaluation site in our analysis.

Computer-assisted qualitative data analysis (NVivo) was used to facilitate structuring and coding of data, and to explore relations [32-35, 37].

\section{Ethical Considerations}

Two research ethics boards approved this project. Participants were made aware they were free to refuse to participate. Written consent was obtained before the interviews took place. Participants were requested by the research study team to keep all group discussions confidential, but were aware that the researchers could not guarantee this. 


\section{Results}

We present stakeholders' perceptions on what, according to them: (1) are the causes of work disability (their problem definitions); (2) should the solutions be to address these problems;

and (3) to what extent this workplace intervention works in practice.

\section{Views on Problem Definitions}

Stakeholder groups defined the causes of work disability in similar ways however their emphasis differed. All stakeholders explained work disability as a lack of proper equipment usage, and/or individual behaviour such as skills in using equipment properly. Hereby, deliverers emphasized the attribution of work-related musculoskeletal disorders as a result of 'poor' health of the worker i.e. general fitness and an ageing workforce.

/.. . / we're aging, I think we've all got aging bodies and we all have probably been lifting things, stuff, for years. (Interview 2)

/.. / start out with older staff, older staff as we age, I don't necessarily think they're necessarily more prone to injury but they may, and this goes for all staff and not, so maybe more physically fit than others and being able to carry out the duties with their position, so certainly physical fitness has something to do with it. (Interview 3)

All stakeholder groups also defined the cause of work disability as a result of physical working conditions, improper job-station ergonomics and work-place organization such as work pressures. Hereby, workers emphasized the attribution of work-related musculoskeletal disorders as a result of a high turn-over rate of frontline managers and co-workers which impacted getting the necessary support to deal with work pressures on the floor and having a say in the health organization.

I guess we can go to our manager but I mean, I find that we're had 7 managers in 10 years /. . . / and we're rotating through all this new staff all the time, every 2 months or so we rotate through 4 staff, for different rotations right, so your always, like, okay; who am I working with? You don't get to know how they lift, you don't know, do you know what I mean. It's difficult/... / the thing is it's too hard on the floor to have all these new managers and then not being supported. (Interview 8) 
Designers and deliverers largely explained that returning to work could be predicted in specific time phases i.e. acute, sub-acute, or chronic phases after reporting sick. Designers and deliverers also both attributed return-to-work to workers' skills, to be influenced through individual-directed measures i.e. education, and exercises.

Deliverers moreover attributed return-to-work to workers' motivation, attitude and personality. In this view, return-to-work is to be influenced through individualdirected measures i.e. persuasion, demonstration, goal setting and re-assurance to change the worker.

Designers and deliverers agreed that these individual-directed measures were to be supported by work-directed measures i.e. job station modifications and workplace organization directed measures i.e. temporary exemption of duties and hours. One deliverer put it like this:

Two different kinds; the work site assessment basically starts head-to-toe, looking at awkward postures, what force, what equipment is in place, what are the risks, that's pretty much where it starts /... / And recommendations are made, you know here is plan $A$, here is plan $B$, plan $C$, because lots of times we can't just engineer the problem out, so it might be here is a 'retrofit way' to handle this in the interim, but you may need to consider renovating, because this is an issue and it will be an issue for all of your staff /. . . / but the assessments are not just about the physical environment, often times your assessment will take into administrative issues, so, if it was a so called work load. (Interview 11)

In contrast, workers perceived that return-to-work was largely dependent on their physical discomfort - that is the extent to which they can "make it through the day". To support their ability to "make it through the day", work-directed measures were needed, including front-line manager and co-workers support, and a reduction of work pressure on the entire floor. Moreover, according to workers, sustainable return-towork depended on permanent work-directed measures i.e. 'no-[patient] lift', staffing level and teamwork thus organizational policy changes.

\section{Views on Possible Solutions}

All stakeholders agreed on the importance of a safety work climate in the workplace. This was defined as a work climate that included cooperation and trust between management and unions to address work disability.

As part of this work climate model, the intervention was designed to have a strong primary prevention component, linked to the secondary prevention approach. Designers included primary prevention strategies (prior to reporting sick) including a work-site assessment, to be offered as a continuum by the health organization. Here, 
recommendations for individual and work-directed measures were to be given by a work-place based occupational health and safety program staff.

Designers emphasized next to a primary prevention focus, a two-pronged approach combining individual and work-directed organization of secondary prevention strategies to support return to work. To achieve this, designers proposed a step-wise approach with detailed ideas about specific steps: early contact with the worker reporting sick from work; a work site assessment, including work-place based occupational health and safety program staff, the front-line manager, the relevant union representative; and the option of workplace-based physiotherapy services. Most steps were to include individual and work-directed measures.

Deliverers agreed with this view in that they executed a two-pronged approach combining individual and work-directed organization of secondary prevention strategies to support return to work.

OHS program staff (part of deliverers) viewed that by making recommendations for work-directed measures for a worker returning to work to the frontline managers, they supported return to work. Deliverers viewed that as the front-line manager implemented work-directed measures for the returning worker, co-workers would also benefit from this measure. Here, deliverers linked their secondary prevention service with the primary prevention component of the intervention.

Workplace-based physiotherapists (part of deliverers) however focused solutions on individual-directed measures such as (medical) re-assurance, and emphasized to influence the workers' behaviour [read: decision] to return-to-work.

Interviewed workers reasoned that recommendations for work-directed measures coming out of a work site assessment would act as convincing information or evidence for the front-line manager to make changes to the workplace/job-station. One worker put it like this:

/... / needs a new [workplace] room as it is too confined and apparently, there is not enough money in the budget to make any improvements. How else do we know to be able to access a work-site assessment to help with the process of trying to convince the higher up? Or is this program not accessed for that reason? Maybe we are off topic? (Focus group meeting 1)

Workers viewed that that workplace- based physiotherapy services were to ameliorate their physical discomfort - in the short term to treat the musculoskeletal injury and offer professional advice - to ensure sustainable return to work in the long term. Workers appreciated receiving this workplace-based service without the involvement of (perceived as particularly unpleasant) insurance personnel i.e. from WorkSafeBC. 
All stakeholders agreed that early graduated return-to-work services were to ensure the worker would stay connected and participate at the workplace. Designers and deliverers both agreed return-to-work was also important to reduce costs and increase productivity.

We were paying a lot of these folks sick leave to stay at home and do nothing when we could be paying them to be at modified work. (Interview 10)

Designers and deliverers differed in the interpretation and meaning of bipartite involvement. Designers and some local bipartite committee members (part of deliverers) were in 'receive-mode' with the aim to obtain feedback and ideas from these stakeholders 'bottom-up' to improve the intervention' workings.

Well, I mean you can sent a piece of paper, but that will never get read, you can sent an e-mail, they get about a 100 a day, and there's all this nuances. I think and there is no opportunity to ask questions usually so I think a face to face is a way better route to go. I look at a lot more networking than a formal presentation. Letting them know what the possibilities are, allowing questions and answers, you don't get that with the other kinds of things, other stuff. (Interview 10)

However most bipartite committee members (part of deliverers) were in top-down transmit-mode', with the aim to find support for their activities among frontline managers and union representatives during bipartite meetings.

To summarize, stakeholders agreed on possible solutions to support return-to-work, however differed on their prioritization. It also included differing prioritizing individual and work-directed measures in relation to the return-to-work process, including implementation.

Views on Program (Component) Effectiveness

Designers, OHS bipartite committee members (part of the deliverers) valued monitoring the numbers of workers reporting sick from work. These stakeholders reasoned that as individual-directed and work-directed recommendations fall into place, these numbers will go down. However, deliverers got frustrated when the number of workers reporting sick did not really change over time. Moreover, deliverers started to doubt the value of these 'numbers'. Did perhaps the number of workplace related musculoskeletal disorders go up because the intervention included no charge physiotherapy services? Deliverers viewed that this workplace-based service served as an 
incentive to report musculoskeletal problems. They also viewed that these numbers didn't tell them 'how' to improve the intervention.

Organizing a work-site assessment that included frontline managers, union representatives and workers together proved difficult in practice. This was mostly due to busy work schedules, vast geographical distances, and a high-turnover rate of frontline managers; there was little time to built a working relationship with these important stakeholders. Nor did workers always want all these other stakeholders involved in, according to them, personal business [read: health issues]. Further, workers would have highly appreciated not having to report sick before getting a work-site assessment.

The workplace-based physiotherapists (part of deliverers), perceived that their services mostly targeted the individual worker. If workers returned to work, physiotherapists had reached their goal, that is, to effect workers' behaviour. If workers did not return to work, physiotherapists tended to brush this it off with "you can lead a horse to water, but you cannot get it to drink". These deliverers were not clear on their responsibilities to recommend work-directed measures. They perceived that implementation of recommendation largely depended on frontline managers' willingness to comply. As a consequence, these deliverers were frustrated that their services were only a small part of the return-to-work process.

/. . / we make recommendations; there is a paper trail that those recommendations have been made but depending on the individual manager and how valuable return to work and safety are to them I find sometimes I run into barriers there that people don't get accommodated as well as maybe they should. (Interview 5)

It's challenging because I have no power to change the work site. (Interview 13)

According to workers, work-directed measures, including support by their frontline managers and co-workers, and reduction of organizational work-pressures were not in line with their individual efforts to return-to-work, which was frustrating:

I didn't see paperwork, they push you out, you come to work, you are out on the floor, you are so busy, everybody sees you, they really want you, so I said 'well I can't do any lifting', I was bullied. They told us we could take micro breaks and stuff but the thing is you know, I mean when you're overworked at the floors and the floor is very heavy and there's limited amount of staff. I had lots of comments say 'well what are you doing here if you can't lift, if you can't work?' (Interview 9) 
Workers agreed that return-to-work was effective for staying connected to the work place, it had relevance towards the importance of work in their life, and to their feeling valued for their remaining skills:

You know I enjoy my job, I love my job as a [job position], working with people, to prevent, you know, getting depressed being at home, not able to be out. I mean I've got lots of friends here, my co- workers, we get along well, I mean that's a big one right there, to keep up my skills. (Interview 9)

Bipartite steering committee members (part of deliverers) differed in perceptions on the role and responsibilities of this committee and the meaning of bipartite collaboration to address disability prevention. Designers had used multi-disciplinary evidencebased practices, and various stakeholders' input, to develop, implement and evaluate this workplace intervention. However, local deliverers mostly used their own disciplinary training and experiential knowledge to interpret and implement the intervention.

Additionally, perceptions differed on the process to develop policy on disability prevention. Designers had planned a profound shift in authority-structures: to maintain a power balance between front-line manager and union representatives they had proposed a voting-procedure for shared decision-making. In practice, 'voting' never took place. Although front-line manager and union representatives were willing to influence this policy, they were unsure of their roles and responsibilities to achieve this.

I don't even know what my role is as a steering committee member. Am I supposed to be out there connecting with the [people they represent]. I have no clue. /. . . / Its like, am I supposed to be doing something here or you know, we, is this just a planning thing, or what is it? (Interview 6)

Difficulties around front-line manager and union representative involvement in the process to develop policy on disability prevention were accentuated when pilotfunding by OHSAH ended and financial costs of maintaining and reviewing this intervention were transferred back to the health organization. Front-line manager and union representatives themselves appeared resigned in the face of a 'traditional topdown' policy-making process: "that is just the way it is around here". (Group meeting 6)

Interviewed workers were not aware this workplace intervention was designed and delivered through front-line manager and union representative involvement. These interviewed workers reported difficulties they encountered in returning to work to their front-line manager, OHS program staff, and workplace based physiotherapists. 
Union representatives mentioned to reach some members however not all and report regional issues to their provincial union.

To summarize, deliverers' views about program effectiveness, including implementation differed from those of designers and workers.

\section{Discussion}

A Canadian work disability prevention intervention named PEARS was evaluated at one site. We examined the perceptions of three stakeholder groups on how they define the causes of work disability, what the intervention should aim at, and to what extent the intervention works in practice. Data were collected from various sources. Based on our data, we concluded that this intervention had been carefully designed with the participation of diverse stakeholders such as the employer and union representatives. A striking similarity among the stakeholder groups was their aspiration to approach work disability as something that can positively be affected by workplace-based interventions. Profound differences in views were however found between deliverers and designers, and between deliverers and workers on whether and how workplace-based interventions interact with the worker's disability. Whereas for designers the make-up and dimensions of the problem were mostly tied to the workplace and work organization, the deliverers mostly tied this to the individual worker. For workers, the make-up and dimensions of the problem were mostly tied to the workplace and work organization, including implementation. To workers the work organization did not only relate to addressing work demands when returning to work - in the short term, but moreover to the quality of work life, including support by frontline managers and co-workers, and organizational policy changes to ensure sustainable return to work - in the long term. Consequently, this differing focus for necessary change across stakeholder groups, and finding temporary versus permanent solutions, may impact the intervention itself and thus work disability.

Local deliverers and workers were frustrated that they were only a small part of the process to improve policy on work disability. Power struggles at the provincial and health organization level hampered bipartite steering of this intervention, including implementation. Moreover, it is not clear from this study if local union representatives represent rural healthcare workers at the provincial level.

\section{Differing Conceptions of Cause and Thus Solutions}

Deliverers had a predominant biomedical-psychological and administrative perspective on work disability. They mostly explained the problem in terms of risk factors, causes 
and phases at the individual level. From this perspective, return-to-work can be strictly planned and prescribed; stepwise early re-integration of workers who report sick from work is what is at stake - the goal is mostly to reduce costs, improve productivity and encourage work participation.

Workers, in contrast, mostly explained work disability in terms of the workplace and work organization. According to them, maintenance of their health is what is at stake, including a 'continuum' perspective to ensure this is achieved, more in line with the designers view. This was consistent with the results of studying the same intervention as implemented in a different health organization [38].

Interviewed workers felt that this intervention did not take measures to ensure sustainable return-to-work, including implementation. Consequently, workers got frustrated; they perceived being blamed for delaying a capricious process that was planned based on time-frames outside their control. Even though workers returned to work, they were less motivated to deal with employers' productivity demands.

Ståhl and colleagues [39] also found these profound differences in perspectives on work ability and named these a reductionist view versus a holistic view. However, these were held by different stakeholders than studied here (health professionals and Social Insurance Agency). Guzman and colleagues [40] found that the choice of priorities to address back-pain disability among researchers and occupational health stakeholders is primarily influenced by different views about disability and other components of personal experience.

\section{Program Effectiveness}

Designers and deliverers used formative and administrative criteria to evaluate if program services had been offered i.e. if a work-site assessment had taken place. However, despite the original design's calling for evaluation of whether recommendations for work-directed measures were indeed implemented at the organizational level, this did not take place - although this would have been highly appreciated by designers and the workers.

This is in line with Westmorland and Buys [41], who found that employees expressed concerns about employers who put employees back into work situations where they were at risk of re-injury. These authors reported that there was a lack of follow-up once the worker has returned to work.

Several authors argue that the outcome 'reported-injuries' should always be supplemented with measures more inclusive of recurrences of the injuries, and supplemented by other measurements i.e. impact on work-role functioning, quality of life $[42,43]$. Policy-makers and insurance companies are often tempted by guidelines and cost-effectiveness analyses as an ideal way to control work disability prevention interventions, and thus, to control the costs of health care [44]. 
This study found that stakeholders differed in ideas on the effectiveness of program services.

As a result of the varying dimensions of conceptualizing the underlying problem, and of the differing characteristics on the return-to-work process, their logic on what works to achieve disability prevention differed. OHS director and program staff (part of deliverers) focused on reducing time-loss and cost-benefit analysis - a management and administrative perspective. Workers focused on their health - a health perspective.

Earlier figures showed positive results for PEARS, but focused on reduced timeloss and costs at this health organization. The current study showed that, although intended otherwise by the designers, the intervention seems to have been delivered in a too narrow-scoped way which might reduce workers' motivation and their productivity. Our findings are in line with previous research [45] showing that different groups view success of interventions in significantly different ways.

\section{Bipartite View Versus Unilateral View}

Designers and deliverers also differed in ideas on bipartite collaboration to develop, implement and evaluate this intervention. Roles and responsibilities of these stakeholders were unclear, and agreements on monitoring and reviewing the bipartite process were not endorsed. These differences in perceptions of the meaning of bipartite collaboration/steering to develop policy on disability prevention at this evaluation site, lead to frustration between designers and deliverers. Ideas on bipartite policy formulation, execution, and evaluation of workplace-based interventions might even differ among the designers themselves.

\section{Implementation}

Differences between stakeholders seem inevitable and even indispensable. An earlier study [46] found that lay persons as well as professionals involved in health care decision-making recognized the importance of incorporating a diversity of expertise and opinion. This could be addressed by, among other things, paying attention to processes by which decisions are reached. As a result, participants will explore a wider range of possible solutions and reach decisions in the interest of everyone.

This study found that RTW coordinators and workplace-based physiotherapists (both deliverers) complained that they did not oversee the complexity of work disability. They were unsure about, and some were overwhelmed with, responsibilities for measures to be executed within this local intervention. Additionally, they had few means to actually implement workplace and/or work organization change besides forwarding information i.e. paper-trail, 'preaching', facilitate discussions between the worker and the workers' front-line manager. These difficulties can be regarded as the 
difficulty of interdisciplinary teams. Durand and colleagues [47] attributed implementation difficulties to the diversity of interventions and proposes to have agreements in place that are more precise in regard to the content of measures. Pransky and colleagues [48] attributed such difficulties to a lack of specific attributes by RTW coordinators and argued for specific training.

A second problem shown in this study was the limited focus on intervention at the individual level. Although both individual and work-directed measures were designed, most deliverers tended to individualize the focus of change. This was based on their disciplinary background; practical experiences (overseeing complexity, overwhelmed with responsibilities, means -or lack thereof) and finally, the underlying norms and beliefs that the problem to address is mostly behaviour related. Designers had proposed a continuum, an on-going, non-linear process, of seeking best solutions to address disability prevention through bipartite 'top and bottom' dialogue that included multidisciplinary collaboration with employer and union representatives. Stakeholders will always differ but can only compromise on solutions. However, this shift in authority requires time and money, and when pilot funding to this regional health organization stopped, this process stopped.

Finally, we found that in a multi-pluralistic health organization stakeholders may respond to policy differently. When the policy on bipartite collaboration/steering and policy on individual and organizational change fits local traditions- they may be easily internalized by the individuals and by the organization, whereas if they differ they may not [27]. The execution of policy is thus a rather capricious process in reality, which needs continuous attuning with (local) workplace reality [49].

\section{Methodology Discussion}

The findings of this study are limited to the local context. However, as our discussion shows, the findings match with the literature and have broader implications for workplace interventions. The small number of interviewees could be seen as a limitation. The study was designed to conduct interviews and focus groups with all three stakeholder groups. However, formal interviews, and focus groups were only conducted with the deliverers and workers. By recruiting participants through purposive and snowball sampling strategies, we addressed not getting a selection of dissatisfied interviewees only. Although it is not unusual in responsive evaluation to compare the perspectives of program deliverers and receivers with that in written policies [19], interview material would have added more depth. The use of data-triangulation improves the validity of the findings presented here, including observations of meetings in which designers participated, and verification with designer, co-author AY. 
The selection procedure of including three different stakeholder groups, and our dialectic and pluralistic approach support this study in getting an in-depth insight and understanding of workplace-based practical reality of workplace interventions.

\section{Conclusion}

Recognizing differing perspectives alone is not sufficient in the arena of work disability. In our view, improving our understanding of the background of stakeholders' logic and reasoning is a next step towards a more productive working relation and relationship between relevant stakeholder groups.

This study identified that deliverers' reasoning on the prevention of work disability and leading to sickness absence are not in agreement with the reasoning of workers. For deliverers, the focus is on productivity, encourage work participation and indeed saving money, which can be managed by a clear stepwise approach. For workers, their health is indeed at stake whereby prevention and sustainable return to work is a continuum process, including implementation. More specific, this includes implementation of workplace and work organization changes, which includes modifying work demands and improve social support- in the long term. In brief, what is at stake for workers to address work disability is organizational policy change. The latter is more in line with designers' intentions.

The existing discrepancies in perspectives of the stakeholders correspond to the natural differences. Even though the current study sheds new light on this, it also showed that these differences do not prevent many similarities to exist among the stakeholders on workplace-based intervention components to approach work disability. In the end, stakeholders can only compromise on common interventions for different reasons. Our findings show the consequences of these differences and compromises in regard to workplace disability prevention intervention development and implementation. This study also provides ideas to guide the design of evaluation research on work disability. We recommend including various measures for success at various levels and at varying time-lines, representing the differing stakeholder perspectives.

Furthermore, professional education and training on improving workplace-based intervention structures and procedures differs among the deliverers. These issues complicate agreement on appropriate strategies to address work disability at this health organization, including implementation.

Calls for employer and union representatives to cooperate in an approach to work disability and interventions at the workplace have an undeniable logic. However, the present study in the Canadian context suggests that constitution of a bipartite commit- 
tee is not a full guarantee for a productive analysis of this public health problem, nor for workplace-based interventions, including implementation in practice.

\section{Acknowledgements}

We are grateful to the participants of this study and Philip Mah, OHSAH and Karen Lockhart, University of British Columbia (UBC) for their kind assistance. Sources of financial support in the form of a research fellowship and project funding came from the Occupational Health \& Safety Agency for Healthcare (OHSAH), BC and a health organization, BC, Canada. Funding does not imply endorsement of the research findings. Annalee Yassi acknowledges the funding of the Canada Research Council to support her work in this project. Ilse Mesters, PhD, Department of Health Education \& Health Promotion, Prof. R.A. de Bie, PhD, Department of Epidemiology, and Anja Krumeich, PhD, Department of Health Ethics and Society, Care And Public Health Research Institute (CAPHRI), Maastricht University, Netherlands supported this study.

\section{Authors' contributions}

KM: study design, data gathering and analysis, and writing the manuscript; AdR: analysis and interpretation of data, and significant contribution to manuscript; JG: commenting on design, analysis and manuscript; ES: conception of evaluation study, and commenting on manuscript; AY: commenting on design, analysis and contribution to manuscript.

\section{Competing interests}

The authors declare that no competing interests or conflicting interests exist. 


\section{References}

1. van Oostrom SH, Driessen MT, de Vet HCW, Franche RL, Schonstein E, Loisel P, van Mechelen W, Anema JR. Workplace interventions of preventing work disability. Cochrane Database of Systematic Reviews. 2009, Issue 2.

2. Stats Canada, 2008. Available from: http://www.statcan.gc.ca/pub/71-211-x/2009000/part-partie1eng.htm.

3. Auditor General of British Columbia. 2004/2005 Report 2: In Sickness and in Health. Available from: http://www.llbc.leg.bc.ca/public/PubDocs/bcdocs/370018/Report2_in-sickness-and-health.pdf.

4. Loisel P, Buchbinder R, Hazard R, Keller R, Scheel I, van Tulder M, et al. Prevention of work disability due to musculoskeletal disorders: the challenge of implementing evidence. J Occup Rehabil. 2005; 15(4):507-524.

5. Yassi A, Curtis J, Miles-Tapping C, Vallentyne S. Prevention, early intervention and return to modified work program to decrease the incidence and severity of back injuries in nurses: The launching of a pilot program. Can J of Rehabil. 1991; 4(3A):25-26.

6. Cooper J, Tate R, Yassi A. Work hardening in an early return to work program for nurses with back injury. Work. 1997; 8:149-156.

7. Friesen M, Yassi A, Cooper J. Return-to-work: The importance of human interactions and organizational structures. Work. 2001;17:11-22.

8. Yassi A, Ostry A, and Spiegel JM. Injury prevention and return to work: breaking down the two solitudes. In: Sullivan T, Frank JW, editors. New views on preventing work-related disability. Taylor \& Francis Books Ltd. 2003; p.75-86.

9. Yassi A, Ostry AS, Hatter B, and De Boer HM. Joint health and safety committee education and the value of bipartite cooperation in the healthcare sector in British Columbia, Canada. Int J Occup Environ Health.2005; 11:305-312.

10. Davis PM, Badii M, Yassi A. Preventing disability from occupational musculoskeletal injuries in an urban, acute and tertiary care hospital: results from a prevention and early active return-to-work safely program. J Occup Environ Med. 2004; 46(12):1253- 1262.

11. Badii M, Keen D, Yu S, Yassi A. Evaluation of a comprehensive integrated workplace-based program to reduce occupational musculoskeletal injury and its associate morbidity in a large hospital. J Occup Environ Med. 2006; 48(11):1159-1165.

12. OHSAH-materials. In-house formal and informal documents on the PEARS program i.e. cost effectiveness of the PEARS program, Jan 12, 2006.

13. OHSAH-website. Available from: http://www.ohsah.bc.ca.

14. MacEachen E, Clarke J, Franche RL, Irvin E. Systematic review of the qualitative literature on return to work after injury. Scand J Work Environ Health. 2006; 32(4):257-269.

15. Frank J, Sinclear S. Preventing disability from work-related low-back pain. New evidence fives new hope- if we can get all the players onside. Can Med Assoc J. 1998; 158(12):1625-1631.

16. Guzman J, Yassi A, Baril R, Loisel P. Decreasing occupational injury and disability: the convergence of systems theory, knowledge transfer and action research. Work. 2008; 30(3):229-239.

17. Eakin J, MacEachen E. Health and the social relations of work: a study of the health-related experiences of employees in small workplaces. Sociol Health IIIn. 1998; 20:896-914.

18. Franche RL, Baril R, Shaw WS, Nicholas M, Loisel P. Workplace-based return-to-work Interventions: optimizing the role of stakeholders in implementing and research. J Occup Rehabil. 2005; 15(4):525542.

19. Guba EG, Lincoln YS. Fourth generation evaluation (1-st. ed.). Thousand Oaks, CA: Sage Publications,1989. 
20. Linnan LA, Sorensen G, Colditz G, Klar N, Emmons KM. Using theory to understand the multiple determinants of low participation on worksite health promotion programs. Health Educ Behav. 2001; 28(5):591-607.

21. Patton MQ. Utilization-focused evaluation: The new century text (3-rd ed.). Thousand Oaks, CA: Sage Publications, 1997.

22. Meershoek A, Horstman K, Plass S, Vos R. Wat regelen regels? (What do rules arrange?) In: Abma T, in 't Veld R, editors. Handboek beleidswetenschap. (Handbook of policy science) Boom, Amsterdam; 2001, p. $236-248$.

23. Clarke J, Cochrane A. The social construction of social problems. In Saraga E: Embodying the social: constructions of difference. London: Routledge, 1998.

24. Murray SA, Manktelow K, Clifford C. The interplay between social and cultural context and perceptions of cardiovascular disease. J Adv Nurs. 2000; 32(5):1224- 1233.

25. Loisel P, Durand M, Berthelette D, Vézina N, Baril R, Gagnon D, et al. Disability prevention: new paradigm for the management of occupational back pain. Disease Management and Health Outcomes. 2001; 9(7):351-360.

26. Cox T, Stavroula L, Ivanov I, Kortums E. Work, employment and mental health in Europe. Work Stress. 2004; 18(2):179-185.

27. Stone DA. Policy paradox: the art of political decision making (Revised Edition ed.). New York- London.: W.W. Norton \& Company, 2002.

28. Yassi A. Health promotion in the workplace - the merging of paradigms. Methods Inf Med. 2005; 44:278 - 284.

29. Baril R, Clarke J, Friesen MN, Stock S, Cole D, Work-Ready Group. Management of return-to-work programs for workers with musculoskeletal disorders: a qualitative study in three Canadian provinces. Soc Sci Med. 2003; 57:2101-2114.

30. de Rijk A, van Raak A, van der Made J. A new theoretical model for cooperation in public health settings: the RDIC model. Qualitative Health Research. 2007; 17 (8):1103-1116.

31. Schwandt TA. Three epistemological stances for qualitative inquiry: interpretivism, hermeneutics, and social constructivism. (2- nd ed.). Thousand Oaks, CA: Sage Publications, 2000.

32. Corbin J, Strauss A. Basics of qualitative research: techniques and procedures for developing grounded theory (3rd ed.). Thousand Oaks, CA: Sage publications, 2008.

33. Hammersley M, Atkinson P. Ethnography: principles in practice. London: Routledge, 1995.

34. Denzin, NK, Lincoln YS. Handbook of qualitative research. Thousand Oaks, CA: Sage Publications, 2000.

35. Polit DF, Beck CT. Nursing research: principles and methods (7-th ed.). Philadelphia, PA: Lippincott Williams \& Wilkins, 2004.

36. Delbecq A, Van de Ven A, Gustafson D. Group techniques for program planning: a guide to nominal group and delphi processes. Glenview, IL, 1975.

37. Tedlock B. Ethnography and ethnographic representation (2-nd ed.). In: Denzin NK, Lincoln YS, editors. Handbook of qualitative research. Thousand Oaks, CA: Sage Publications; 2000, p. 455-486.

38. Ouellette V, Badii M, Lockhart K, Yassi A. Worker satisfaction with a workplace injury prevention and return-to-work program in a large Canadian hospital: the importance of an integrated approach. Work. 2007; 10(1):44-52.

39. Ståhl C, Svensson T, Petersson G, Ekberg K. The work ability divide: holistic and reductionist approaches in Swedish interdisciplinary rehabilitation teams. J Occup Rehabil. 2009; 19(3):264-73.

40. Guzman J, Jones D, Cassidy JD, Furlan AD, Loisel P, Frank JW. Key factors in back disability prevention: what influences their relative prioritization? Spine. 2007; 32(9):E281-E289.

41. Westmorland MG, Buys N. A comparison of disability management in Australian and Canadian workplaces. Work. 2004; 23:31-41. 
42. Krause N, Frank JW, Dasinger LK, Sullivan TJ, Sinclear SJ. Determinants of duration of disability and return-to-work after work-related injury and illness: challenges for future research. Am J Ind Med. $2001 ; 40: 464-484$

43. Lorig K, Stewart A, Ritter P, Gonzalez V, Laurent D, Lynch J. Outcome measures for health education and other health care interventions (1-st ed.). Thousand Oaks, CA: Sage Publications, 1996.

44. LeDou J. Occupational medicine: the case for reform. Am J Prev Med. 2005; 28(4):396-402.

45. Melles T, Mclntosh G, Hall H. Provinder, payor, and patient outcome expectations. J Occup Rehabil. 1995; 5(2):57-69.

46. McKie J, Schrimpton B, Hurworth R, Bell C, Richardson, J. Who should be involved in health-case decision making? A qualitative study. Health Care Analysis. 2008;16(2):114-126.

47. Durand MJ, Vézina N, Loisel P, Baril R, Richard MC, Diallo B. Workplace interventions for workers with musculoskeletal disabilities: a descriptive review of content. J Occup Rehabil. 2007; 17(1):123-136.

48. Pransky G, Shaw WS, Loisel P, Hong QN, Désorcy B. Development and validation of competenties for return to work coordinators. J Occup Rehabil. 2010; 20(1):41-48.

49. Meershoek A, Krumeich A, Vos R. Judging without criteria? Sickness certification in Dutch disability schemes. Sociol Health IIIn. 2009; 29(4):497-514. 


\section{Chapter 3}

How policy on employee involvement in work reintegration can yield its opposite: Employee experiences in a Canadian setting

Karin Maiwald

Agnes M. Meershoek

Angelique E. de Rijk

Frans J.N. Nijhuis

In: Disabil Rehabil. 2013;35(7):527-537. 


\section{Abstract}

Purpose: Canada has a long tradition of involving employee representatives in developing work reintegration policies and expects this to positively affect employee involvement to improve work reintegration success. The purpose of this study was to examine employee involvement in reintegration in a Canadian province as experienced by employees.

Methods: Fourteen semi-structured interviews were held with employees in a healthcare organization. The interview topic list was based on a review of local reintegration policy documents and literature. Interviews were transcribed verbatim and analysed using ethnographic methodology.

Results: Employees do not feel in control of their reintegration trajectory. In the phase of reporting sickness absence, they wrestle with a lack of understanding on how to report in sick. In the phase of reintegration planning and coordination, they hesitate to get involved in the organization of reintegration. In the phase of reintegration plan execution, employees encounter unfulfilled expectations on interventions.

Conclusion: Employee involvement in the organization of reintegration makes them responsible for the development of reintegration trajectories. However, they consider themselves often incapable of completing this in practice. Moreover, employees experience that their contribution can boomerang on them. 


\section{Introduction}

There is widespread agreement that governments should encourage labour participation of people with disabilities [1-3]. Regional policies are believed to be more effective when the employee perspective is taken into account or employee representatives are involved in developing the (local) policy on disability management [4-6]. Work reintegration is supposed to have a better outcome if individual employees with disabilities are involved in selecting return-to-work activities [7-9]. Canada has a long tradition of involving employer and employee representatives in developing regional policies on disability management. Various scholars have however provided evidence that the provincial bipartite policies on work reintegration for employees with disabilities do not always work as expected in the local context either [10-12]. Unexpected effects of this policymaking approach were that employees and various involved institutional actors were troubled by (role) conflict, tension, frustration and power struggles in organizational processes to develop reintegration policy. The outcome is that competitive meanings and values regarding cooperative interactions with respect to labour participation can potentially exclude employees from enduring return-to-work and can ultimately affect employees' health, thereby bothering all parties. In the Netherlands, some evidence was found that the organizational approach of involving bipartite actors in processes to develop reintegration policy for employees with disabilities cannot avoid bottlenecks in practice [13]. For example, proposed bipartite solutions in reintegration activities could influence work modifications or accommodations but lacked binding authority to ensure implementation. Some scholars explain policy implementation difficulties in continually reforming work reintegration policy [14], its unintended consequences [15], and because of too many rules on forced collaboration [16, 17].

In a Canadian province in 2009 health employer association representatives and employee representatives re-formulated rules on work reintegration in a (public) health organization as part of the collective bargaining process between the social partners and provincial government. These reforms were built upon earlier local initiatives in such a way that employees who reported sick for work and local bipartite actors (front-line managers and respective trade union stewards) could provide input to align early work reintegration activities. According to provincial, health organizationemployer organization representative and trade-union representative policymakers, the employer-employee cooperation is supposed to be guided by local workreintegration experts or disability managers professionals (DMP) [18, 19]. The new policy strongly emphasizes expediting the reintegration of employees who report sick for work: they should reintegrate to work before full recovery of either their illness or injury has taken place which includes an invitation for employees to contribute in reintegration (ask for their ideas, suggestions they have) to optimize this process (see sec- 
tion below). Requiring employees with incapacities to contribute to the early reintegration plan offers this employee a new role in the work reintegration process.

To re-iterate, this local work place based intervention programming is designed and approved by employee and employer representatives. Although the assumption is that such bipartite involvement in policy development will improve its effectiveness, there is little evidence that this specific bipartite reintegration policy improves employee involvement in work reintegration and indeed is experienced as being effective by employees in terms of return-to-work.

Policies can always turn out differently and in unexpected ways in practice as they include general rules which allow for discretionary space for those delivering services. Thus an interpretation of the policy takes place $[20,21]$, influenced by social customs, peer norms, moral beliefs and existing practices [21]. To improve policies, knowledge about these influences is necessary, so policies can be better linked to local norms and values and ensure enduring implementation of policy [21]. One of the most important backgrounds of these influences is the differing perspectives of the various involved stakeholders. Guba and Lincoln [4] have therefore argued that policy evaluation should focus on these exact stakeholders' perspectives.

Studying the implementation of work reintegration policy in a Canadian setting that was developed together with the employee representatives is the focus of our study. This kind of research is important to gain more knowledge on how to positively affect work reintegration of employees after reporting sick for work. In the current study we take the focus of the 'receivers' of local work reintegration policy: the employees themselves [22-24]. Our research questions for this current study were:

1) How are Canadian employees experiencing their new role in work reintegration trajectories?

2) To what extent is policy on employee involvement in work reintegration deemed successful, according to the sick-listed employees?

\section{Compensation benefits and social insurance as regards re-integration}

In Canada, work-place based DM structures need to be embedded in the system of social security. There is however no uniform compensation benefits and social insurance system for people reporting sick for work. For one thing, employees' social securities in the public and private sector are determined differently and organized differently. In the public sector, securities are part of the collective bargaining structure e.g. short-term or long-term disability criteria and coverage. The outcome is that the levels of coverage vary by collective agreement. In the private sector, employee' securities are dependent on coverage the employer has chosen to purchase.

For this paper, we discuss arrangements for the public healthcare sector in one Canadian province. In this setting, compensation benefits and social insurance are orga- 
nized depending on the cause of sickness absence. It is not always easy to receive coverage and benefits and there are two main routes employees take. If sickness absence is work-related then all health services, including medical workplace accommodations and rehabilitation programming (related to the specific disability) and earnings replacement ( $90 \%$ of net pay) are covered through an umbrella provincial workers compensation system. Under the Workers Compensation Act and Occupational Health \& Safety Regulations, employers are responsible for short- and long term disability benefits for employees who experience work-related injury/illness, e.g. WorkSafeBC, an independent agency governed by a Board of directors appointed by government. Government regulations impose stringent parameters around what type of claim will be accepted, and the anticipated recovery time. If sickness absence is not-work related, employees access various insurance and benefits systems. For all employees, basic health care costs are covered, which means there is a public healthcare system in place which all provincial residents are entitled to (publicly funded medical insurance, run by the federal government department of human resources and social development). In addition, unionized regular employees have coverage for medical, dental and extended health benefits. (We note that casual or flex-workers do not). The provincial government however deregulated many paramedical health services several years ago, which means that there is no cost sharing for services such as physiotherapy, massage therapy, chiropractor, etcetera. The levels of coverage vary by collective agreement and entitlements for disability are coordinated through various (provincial, national based) employer-funded insurance agencies. In other words, if the employee does not have some kind of coverage for these services under their extended health benefit then they are responsible for the full cost. For earnings assistance, unionized regular employees will access an accrued sick leave bank. They may have to utilize their accumulated sick bank until such time as they have completed the waiting period for long term disability which is generally anywhere from 4 to 6 months. During that time, should the employee exhaust their accumulated sick, overtime, and vacation banks then, if they have worked sufficient hours, they can apply for government benefits through the employment insurance medical disability benefit program (around $70 \%$ of wages). A medical leave of absence claim may or may not be accepted by the insurance company. Then, unionized regular employees usually have long term disability coverage under their collective agreements. After undergoing the stipulated waiting period, they can apply for disability benefits, which may or may not be accepted by the insurance company. Premiums for these disability plans may be employee paid, employer paid, or may be cost-shared. If a claim is accepted then benefits may be paid while an employee is disabled from their own job during the first 1 to 2 years. During and after that timeframe, the employee must be able to prove ongoing disability from any gainful occupation or employment. If deemed employable, the long term disability benefit 
may simply end. In other words, the person is expected to return to work (own job or another job). If a person can no longer work they can apply for social assistance. This program provides individuals with access to employment search assistance and/or income assistance. Access to income assistance is determined by a review of income, assets, and defendants (the provincial programs are run by the provincial ministry of social development. They are funded by both provincial taxes and federal transfer payments to the province). There is also a federal disability income program called Canada Pension Plan Disability Benefits. The threshold for access to these benefits is very high in terms of required level of demonstrated disability.

If people report sick for work as a result of a motor-vehicle accident that is nonwork related, there is a government run auto insurance plan in place. Payments covered for injuries depend on the driver being 'at fault and injured' (accident benefits) or 'not at fault and injured' (may be able to claim a settlement payment). Rehabilitation services may be reimbursed by the insurance company upon resolution of the insurance claim. Meaning, the individual usually must pay those costs up front and most individuals involved in motor-vehicle accidents must get by on their own until such time as the claim settles. (The material presented here was taken from federal and provincial government and provincial insurance agencies' websites, and various provincial healthcare sector trade unions' websites and collective agreements. Information was completed by data provided by local healthcare sector trade union informants.)

Nevertheless, regardless which route an employee takes upon reporting sick for work, regular employment status is secured for about two years whereby benefits and coverage vary per cause of sickness absence and collective agreement.

In our research setting (one Canadian province; health-care sector), organizational structures to positively affect early work reintegration include a work-place based centralized intake system, where employees, management included are supposed to call an absence call line, using voice prompts to report sick for work and for claim status changes. According to policymakers, this automated reporting system aims to track and monitor sickness absence of the workforce and automatically notify the organization about individual employees' sickness absence. An internal-based DMP is then supposed to contact the employee and request their participation in work-place based disability management programming. Next, a reintegration plan is prepared, either a straight forward one (less than six weeks in duration) or a complex one (longer than six weeks). The DMP is supposed to check with, follow-up and contact the employee and other involved actors e.g. the physician, manager, union steward and insurer/compensation agency concerning progress, re-design and extensions of the reintegration plan. Disability management programming is supposed to include access to various other work-place based services e.g. ergonomist, workplace rehabilitation 
advisors to support transitional or gradual work reintegration. As part of the collective agreement a supernumerary worker can be made available upon reintegration ('extra worker'). Employee participation in work-place based disability management programming is voluntary in the first six weeks of sickness absence but mandatory thereafter and must include the consent of the employee's physician.

\section{Methods}

We found the support of a large regional health organization which provides general and specialized public healthcare services to a large portion of the provincial population to conduct this project. Public acute health care services are offered in their 13 hospitals across a vast geographical area whereby they also offer a number of other services including, primary care, community-based residential and home health care, mental health, addiction services, and public health. As per provincial collective agreements, this organization voluntarily created workplace-based reintegration intervention programming for its 22,000 employees. The three hospitals we selected are the largest, and considered leading hospitals for health service delivery. To find answers to our research questions, we selected qualitative research methods [25-27]; to obtain good insight on the experiences and perceptions of the employees, in-depth individual interviewing was selected as the best method of data gathering [25].

\section{Study sample}

Inclusion criteria were that the employee had participated or still was enrolled in reintegration intervention programming at this organization anytime between April 2009, when the 'new' policy on reintegration came into effect, and June 2010. Employees who only had reintegration experiences previous to April 2009 were excluded from this study.

To maximize variability in perspectives and to acknowledge the opportunity to obtain information from the full range of employees in this organization, purposive sampling $[28,29]$ strategies were used. Moreover, various recruitment strategies were used: a) dissemination of a one-page advertisement about this policy evaluation by DMPs to current and past users of work reintegration services; b) snowball sampling, where interviewees facilitated the recruitment of potential participants and sent introductory letters to others; c) announcements such as e-blast notifications by the organization' research institute to all employees and group-emails by trade union leadership for representatives to encourage its members to participate in the study. Recruitment strategies via anonymous email blasts by the work-place based research institute were more successful than recruitment by DMPs which included a one-page 
brief that was handed out during contact moments. This recruitment strategy has limitations, which we will discuss in the conclusion. The first round of interviews with 10 employees was held between September-December 2009. To reach the point of saturation another 4 additional interviews were held in May 2010. When an employee initiated contact to participate, he/she received a detailed four-page information sheet. Upon his/her agreement to participate, an interview was booked. Interviewees ranged in cause of sickness absence (as diagnosed by a physician), differed in age from 21-57, included both new and experienced employees, and held various occupations at three differing work sites (see Table 1 for a detailed summary of participant characteristics).

Table 1. Detailed summary of participant characteristics.

\begin{tabular}{|c|c|}
\hline Healthcare emplo & (ees) \\
\hline Cause of sickness & osed by physician) \\
\hline Medical disorde & \\
\hline Orthopaedica & Work-related \\
\hline & Not-work related \\
\hline & Motor vehicle accidents \\
\hline Systemic & \\
\hline Mental disorder & \\
\hline Age & 21- 57 years of age \\
\hline Length of service & 1.5 - 35 years of service \\
\hline Occupations & Nursing staff; Health sciences professionals; \\
\hline & Facility support staff; Management support staff \\
\hline Gender & \\
\hline Female & 13 \\
\hline Male & 1 \\
\hline Place of employm & \\
\hline Work site 1 & 955 beds \\
\hline Work site 2 & 268 beds \\
\hline Work site 3 & 191 beds \\
\hline
\end{tabular}

aThe type of health problem is categorized according to insurance coverage. Motor-vehicle accidents which are not work related fall under a different coverage than non-work related illness or injury.

\section{Ethical Considerations}

Besides obtaining the support from the organization itself, we obtained the support of the trade unions ( 3 - all of which had been part of the policymaking process) to conduct this study. Further, we received the approval of two local Research Ethics Boards from the University of British Columbia and the local (public) health organization. Interviewees were made aware that they were free to refuse to participate and were welcomed to ask questions and express concerns about the study any time before, 
during and after the interview. Informed consent forms to participate, to record the interview, and to review the findings were signed prior to each interview. Each interviewee was offered (hourly) wage replacement for the duration of the interview. Participants were given the option to receive the final study report.

\section{Interview procedure}

To prepare our topic list we reviewed administrative materials about local reintegration intervention programming, which we started collecting in April 2009 through various means, i.e. via DMP and the organization's intranet. Materials included formal documents and draft papers for example, local brochures for employees and managers, procedures, roles and responsibilities of DMP, referral process, purpose and principles, employee participation agreement forms, letter to the physician, process and policies on the disability management program, presentations, trade union letter of agreement. This review provided a basic understanding of what organizational and bipartite policymakers had developed and the provisions included in reintegration programming as planned. On the basis of this information, together with literature on work reintegration interventions and policy science, an interview topic list was developed, including questions such as: a) why the participant reported sick from work from their perspective, followed with questions about: b) what happened after that, c) what they considered as their tasks and responsibilities, d) who was involved, e) what happened at meeting(s), f) how and what did they talk about, g) how was the involvement experience for them, h) were there differences in ideas during contact moments, i) how were differences handled, j) how did that work or not work for them, et cetera. In addition, each interviewee was given the opportunity to speak freely and elaborate on topics they brought up on work reintegration in this setting. In this way, we finetuned our interview questions as data collection progressed. Both the first author, KM and the research assistant had previous research experience, qualitative data collection included. The individual face-to-face interviews were conducted in a private room, took between one to two hours, and were taped and transcribed verbatim. During the first round of interviews, the verbatim texts were reviewed to improve interviewing technique and interview questions.

\section{Analysis}

Following ethnographic methodologies, we completed qualitative analyses to gain deep insight into employees' perspectives [25-30]. In ethnography, detailed understanding of interviewees' experiences, actions and practical reasoning is gained. We focused our interpretative analyses on which aspects of the institutional arrangements, organization, and individual context of the reintegration trajectory facilitate employee involvement and which do not; and how that affected employee activities, 
according to the reintegrating employees themselves. So, the analysis of work reintegration experiences by employees resulted in an empirical description of the organizational context of their reintegration and the typical consequences. A review process was put in place to ensure the accuracy of the descriptions, emerging themes, and revealed arguments. After the first round of interviews, the first author, research assistant and a Canadian-based researcher performed the first-phase of the data-analysis (structuring data, initial coding). After the second round of interviews, the authors completed the data-analysis for this paper (continues consideration of the data, comparing coding, comparing situations, relations and patterns of themes, control). Member checking, to review preliminary study findings for the purpose of accuracy by interviewees, was completed after the first round of interviews.

\section{Results}

For clarity in the presentation of our results, we distinguished three main phases which more or less follow the chronology of reintegration processes. Roughly speaking, the reintegration process consists of three phases: reporting sickness absence, reintegration planning and coordination, and reintegration plan execution. In practice work reintegration is not clearly structured; the process is not simply onward and upwards and is rather capricious. Three themes emerged from our data analysis. We describe the most central experience-aspects or bottlenecks that dominate in these phases. The experience in practice however does not limit itself to the phase in which we describe it.

\section{Reporting sickness absence: a lack of understanding}

A key point to expedite reintegration is an absence call line which is a phone system that all employees, management included are required to call to report unplanned absences from work. This system is expected to centralize intake, notify the organization when an employee is off and if they qualify for the services designed to support them (claim status). This automated system will prompt the employee and ask a series of short questions about the expected absence. Once the system has recorded absence information of the employee, the live call is transferred to the manager and human resources, disability management included. The sickness absence claim needs supporting medical approval by a physician. Employees indicated that reporting sickness absence is done in different ways and denoted concerns about the procedures.

Despite the change in reporting policy, the first concern expressed by employees is that they felt unsure about how or where to report in sick in their workplace. There are 
employees who report in sick by emailing and/or phoning their supervisor and/or the manager.

"So I just emailed [the workplace] and let them know, but it was [motor-vehicle accident] related so I don't think work got involved at all because it wasn't employees' compensation or anything" [w4].

Employees reason that if reporting sick for work is non-work related the organization does not get involved in their care/work reintegration. In some situations employees were aware they could report in sick through the automated phone reporting system, yet they found that this system did not work well in terms of phone lines (frequently) being busy, inability to change their claim status, and not receiving a timely response after entering the prompt scheme.

Yeah, I think I was supposed to use the system and I was so frazzled that I didn't initially [use the system], but I did after (...) The [name] system is not a very good system (...) All the lines are busy. I don't bother [anymore]. I just call the unit. (w3)

Employees sometimes take the required action to try reporting in sick or change their status through the centralized reporting system, but they experience this system is not always available. In turn, they don't know what to do next and may go back to old reporting habits.

The second concern verbalized by employees was that they felt inept during medical consults. For starters, they understand, by virtue of working for a health organization, that medical professionals hold a position of authority. As a result, some employees felt intimidated when seeing a medical professional for the first time. Employees stated that during these consults they were asked how long they needed to be off and what they can do for work. Employees indicated that sometimes they do not know what is going on concerning their injury or illness and, or how long their recovery may take until they return to work.

There's no test so he [GP] would say to me, "Well, what do you think you can do?" and again with him, I don't know until I actually do it. At that time, I didn't know what I was capable of doing because I hadn't been at work for 5 months. (w1)

In this view, knowing what is best to choose in terms of predicting abilities and limitations and taking additional time off can be hard. 
So I went to my physician and she asked me what I wanted - which is crazy to me. So she had a form, she just said "I can give you a week to 10 days off or longer" essentially - I can't remember exactly what the numbers were and I had no idea. (...) Everyone was just like, "what do you want to do" and what I want to do is work or you know, live my life. And so that was difficult. (w2)

Medical practitioners are responsible for identifying the illness/injury and providing advice about relevant time off work to the employee and other involved actors. Employees expect these professional steps from these actors, yet then find out they are supposed to determine activities and set timelines themselves. Involvement in identifying the illness/injury and providing input about recovery and estimate timing for work reintegration is often difficult for employees. Employees' self-evaluations are used on medical reports and are sent to insurance or compensation agencies to approve the claim and grant services or eligibility for compensation.

The third concern brought forward is that employees felt ignorant about administrative paperwork they needed to complete. Employees felt that the various parties and differing people involved, i.e. family physicians, compensation and insurance agents, and healthcare professionals, provided them with equivocal information. There are employees who were only partly clear on the administrative paperwork which left them to wonder which party needed which kind of information.

One thing I found sort of unfortunate - I do find the wording of a lot of the documents rather difficult to understand. I'm not a complete idiot, however, I found the wording very difficult (...) I'd make an hour and a half appointment to go over some of the forms - and again, my doctor's not an idiot, and he just went, "this is like ridiculous". (w5)

Employees are unsure as to which information is the most relevant to them when filling out paperwork. What employees write down, through appraisal and guessing, goes to the insurance or compensation agencies and their workplace to meet their claim and to grant services. Completing paperwork is a tricky and time-consuming process.

In summary, self-reporting sick leave makes employees feel responsible for getting accurate information in place for organizing their work reintegration. If reporting sick for a non-work related illness/injury, employees do not assume the organization is involved in their care/work reintegration - different from when their illness/injury is seen as a work-related illness/injury. They understand that their claim to report in sick 
needs medical approval. However, they struggle because they lack understanding on their tasks and responsibilities, and what happens with what physicians write down during medical consultations and what they write down on insurance/compensations forms. This lack of understanding worries them because at the same time they are, as we will see in the next section, supposed to get involved in the organization of reintegration.

Reintegration planning and coordination: Hesitations to get involved

Key points to plan and coordinate reintegration is that the DMP, in consultation with the employee, is supposed to determine if the employee is suitable for enrolment in the program and to facilitate access to services and work reintegration within the employee's restrictions and limitations. The DMP is expected to hold a meeting with managers, staff, unions, and outside experts to develop a reintegration plan and monitor reintegration. The plan is supposed to receive medical accordance.

The intent is thus for a local DMP to seek input from the individual employee and the respective bipartite actors in the organization of reintegration. Employees appreciate the opportunity for such contact moments. These contacts can have different forms and employees pointed out concerns in practice.

The first concern indicated by employees is that they felt pressured when they received unexpected phone calls at home by the various involved actors from the different involved agencies/organizations after reporting sick for work. They appreciated the opportunity to set reintegration into motion but felt these multiple, sudden calls were awkward. Some employees stated that this left them feeling overwhelmed. For example, they may not have had their paperwork ready, or they did not recognize who was calling them and for what reason. This, in turn, left employees unprepared to reply to questions or to ask their own.

I said, you know, "it's not really a good time; I'm just going to an appointment." (...) Well, it wasn't tremendously clear the information I gave her, but I felt sort of pressured.(w5)

Employees experience an inability to oversee what their responsibilities are, and those of the other actors involved; yet feel they were given the greatest responsibility. As a consequence, they feel put under pressure to become involved. If someone supports the employee in getting a better overview, this is in fact highly appreciated. For example, sometimes front-line managers did a great job in terms of working out details on how to carry out a reintegration plan, casually checking in, and streamlining issues if needed. Other employees report that DMPs did a good job for them, for example, by 
improving the coordination of the planning with the frontline manager and/or coworkers. A trade union steward sometimes did a good job for them in terms of clarifying union linguistics and, or speeding up logistics on arrangements and referring them on to good contacts.

The second concern denoted by employees is that they felt insecure and fearful and alone during group meetings. In some situations, employees experienced that the other actors involved seemed to be familiar with one another yet they did not know who these people were or why they were present. This was tricky to them because their care plan or health records, which are private matters to them, were talked about publicly.

It was very uncomfortable for me because the meeting was about "me" (...) here I am feeling vulnerable, being talked about, being put on the spot (...) I didn't have any guidance and didn't really know what to expect because I had never been injured [before - at work]. (w2)

Some employees encountered an involved actor who did not acknowledge their presence, and felt that thoughtless comments about the employee were made. In line with this, some employees were uncomfortable with various actors taking differing positions, i.e. were too outspoken, aggressive, flirtatious or evasive. Employees indicated they did not want to come across as a difficult person and, thus, avoided asking questions, being frank and speaking openly.

I'm a little bit intimidated by asking those questions because I don't want to seem like a difficult person. I just kind of go along withwhat they say. (...) So that was what's the most upsetting part because it's almost like being in a court of law (w1).

Employees find it difficult to phrase problems and verbalize their point-of-view on work reintegration in group meetings. This is particularly hard if the various involved actors take different positions towards them and the meeting itself. Employees are hesitant about getting involved and feel they do not get a fair opportunity to be heard in group meetings.

Employees argued that over time they have improved insight on what they can and can not do for work. From this perspective, they were bothered that then, regardless of their and sometimes bipartite actor contributions, medical approval was required before modifications or accommodations can be made. In some situations, employees 
experienced that interpretational difficulties and nitpicking on word-differences of medical reports became the focus of the meeting. In a related way, employees found it hard that when they repeatedly came forward with issues or difficulties they were countered only with encouragements to try harder.

I would have the opportunity to address these [barriers] at the meeting (...) It just fell on deaf ears (...). They just disagreed with me and said that that has never happened and that wouldn't happen and that I'm well supported. And that's it and that's how it's been every step of the way. (w2)

Employees are expected to get ahead through sharing their experiences (contribution) yet can experience not being taken seriously.

Employees experienced on occasion that a trade union steward, who was involved as employee representatives - was not stepping forward as expected.

I feel like the union should have stepped in and said, "It's not okay to accommodate her in this way" (...) I was really taken aback because, I tried but I could not get anyone to fix it. (w8)

Employees are sometimes taken aback when expected support does not remain firm or is not persistent. They can get stuck and may not know where to turn. That getting some help is an important issue to them is also demonstrated by data showing the appreciation of "helpers".

Employees indicated that the introduction of an outside person with special know-how or expertise was helpful, especially if previous reintegration attempts failed. For this they pointed at long-term disability expert(s) or trade union relations personnel.

[Person] came in, and this was the first time anyone has ever done this, and immediately said: "I have to apologize if you're intimidated with all of these people on the table. I'm really sorry". (...) The [person] knew exactly how I was feeling and that just put me right at ease (...) so that was a wonderful [meeting], that's the best meeting we've had. (w1)

Employees find the introduction of an 'outsider' helpful if they can keep their reintegration afloat. 
The third concern employees indicated is that they were sometimes inconvenienced by follow-up contact moments. For example, there were employees who felt that work visits were poorly timed, which left them frazzled with having to organize duties before they could actually talk. In some situations, employees were put off if, instead of getting a chance to chat about their difficulties, they were called to account for completing un-listed tasks or hours. Employees stated they understand that they were to follow reintegration plans but pointed out they need to make appraisals and choices to deal with day-to-day circumstances, i.e. patient load, staffing levels, and how they feel in terms of not feeling very well on some days.

So I started working [more], but [DMP] was quite mad at me and said, "You can't do this. You have to learn to say no." So I talked with my manager and my co-employees and said, "I don't want to jeopardize my return to work". (w1)

When it needed to be altered, I found it - I was given information but it's not like I was given - the [DMP] wasn't pleased, you know? Or it would be challenging, or my progress was not what [DMP] wanted. (w3)

Employees find that unexpected work visits can frazzle them which can leave them with little room to have a serious discussion. Employees can experience that what they say or do was not appreciated or seen as a reasonable attempt on their behalf to make reintegration happen. Forcing the issue to stick with the strict planning does not help them to deal with struggles in practice: they need some flexibility.

When employees initiated action for follow-up themselves, such as when they were having difficulties, they sometimes received an extension and advice. However, they experienced little motivation by other involved actors to dive into the difficulties they encountered.

I just have this opinion of him [DMP] that his mind is set - that at the end of 8 weeks, I'm going to be cured, and that I'm going to be able to go back to my old job - and he's not really wavering from that (w1).

They get that the general mood or attitude is that what they say about obstacles is not explored.

Call if you've got a problem". So it came down to the last week, and I said "my [physical area] is really bad". [DMP] is like, "So you're waiting till the last week to tell me what's going on! (...) this is unacceptable, I'm sorry!" and I was like, "what 
am I supposed to do? It got worse in the last week!" (...) [DMP] basically said, "there's nothing more we can do for you (...) I'm closing your file". (w7)

Employees experience that when they take the required action to alert other involved actors, that reintegration turns out differently than expected, their practical difficulties are not explored. They encounter that they are reprimanded on failing to meet the expected outcome: a return to work in a specific 4-6 (8) week time frame. Then employees don't know what to do.

In sum, employees take part in the organization to develop work reintegration plans, which makes them feel responsible. However, employees hesitate on what and how their contributions actually influence decisions on work reintegration and return-towork. This is bothersome because organizational promises on intervention programming, which are supposed to support their reintegration, are being dealt with differently. This is explained in the next section.

\section{Reintegration plan execution: Unfulfilled expectations}

The DMP is supposed to maintain regular contact with the employee to offer support in performing work reintegration, services included. Cases are expected to be reviewed every thirty days by the union representative and DMP.

The first concern regarding the intervention that employees raised is that they felt failed in regards to the fitness intervention program component or vocational rehabilitation. For example, in some situations, employees found that exercise routines had little to do with the work duties they are supposed to return to.

They have no understanding what chronic pain is like. And yet they keep telling us it's in our mind. And some of the sessions were good but a lot of it was just a crock of shit (w13).

In other situations, employees experienced that the combination of continuing with their fitness routine while reintegrating was too much to keep up. Employees found on occasion that the assumption was made that after completing a $4-6$ (8) week fitness program, which at times was extended, they ought to be fit-for-duty. However, they indicated that this was not always the case. They blindly agreed to this option; yet if the work-reintegration attempt then failed, employees sometimes received the blame. 
The thing about this [fitness] program too is that once you're finished it, they say, "fine, you're ready to work full time" so they put you in and then they say, "okay get back." (w3)

Employees experience a lack of individual care and limited practical benefit when following a fitness or vocational rehab program. This may only become clear during or after its completion, thus, upon reintegration. They agree to this option with the expectation to get ahead; however they can understand that in practice this may not be the result. This is frustrating to them, especially when, in the end, they are being blamed. Yet those who deliver the intervention are not held accountable for their delivery of services.

The second concern employees indicated is that they had ambiguous feelings about the supernumerary option. Some employees indicated a lack of coordination occurring: sometimes the employee was the 'extra person' on the floor to meet workplace demands and sometimes there was an 'extra person' on the floor to meet the reintegration employee's job demands. This left the employee needing to sort out who does what components of the job position. In other situations, the employee needed that 'extra pair of hands'; yet the supernumerary or another co-worker was just too busy to help out. This was particularly tough when a co-worker called in sick and, in turn, the supernumerary was absorbed to meet daily staffing levels and workload. In some situations, employees feared re-injury for having to work with supernumeraries who had different job qualifications. There were employees who indicated that they felt disrupted within this option in terms of getting extra breaks and, or leaving the floor while everyone else was busy.

Cause our ward is busy (...) you just get sucked into so many things, like "oh, can you do this, or "oh, can you do that?" and sometimes I say, "No, like I really have to do my own work and I need to get out of here" but I just feel bad. (w4)

Employees are dependent on varying inter-organizational arrangements, and the willingness, availability and qualifications of colleagues to benefit from the supernumerary option. The option can cause additional work and moreover, emotional burden; if this option fails they have nowhere to go.

The third concern employees stated in this phase is that they felt disillusioned about finding work that fits their work abilities. For example, there were employees who worked reduced hours at their regular job versus (other, new) transitional work as promised, which left them to wonder: what is so new about that? In some situations, 
employees were indeed offered alternate work, yet this was in another department and, or outside their usual shift hours. This does not always make sense to them and may not work in practice because of uneasiness working with unknown co-workers or other commitments such as family responsibilities. In a related way, finding permanent modification or accommodation work to meet their revised abilities was a long and arduous process, leading employees to ask themselves if they would ever be able to make reintegration happen.

Nobody has ever explained my options and, I have been worried sick for a year now (...) Every single day I was so worried because nobody was telling me. (w1)

Making my return-to-work plan was not accommodating me; it was accommodating the workplace (...) What sort of pressure is that going to put on the employee?. (w14)

Employees with a temporary or permanent limitation get no guarantees and may have to wait for a long time to reintegrate to the workplace. They become conscious of this and come to realize they may not get anywhere with their experienced difficulties (as described in the previous theme).

Intervention programming which promises to support reintegration raises expectations. However, the solution's timing is important. Employees have committed to proposed programming, yet are restless because they can encounter additional demands, more work and emotional pressures. Furthermore, they run into a lack of accountability on the relevance of interventions or a measure of the quality to in fact return-towork. In the end, employees do not feel in control of their reintegration trajectory.

\section{Discussion}

In a Canadian province, new policy was developed to encourage employee involvement in work reintegration. The current study examined how this employee involvement in work reintegration is experienced by the sick-listed employees themselves. We asked ourselves how these employees experienced their new role in work reintegration trajectories and to what extent this policy on employee involvement in work reintegration was deemed successful, according to the reintegrating employees. In order to answer these questions, we conducted 14 interviews with health care workers who had been off work because of sickness in a Canadian setting. 
To resume our analysis, it appears that employees are often uncertain about local procedures and daily routines on reporting in sick for work and planning RTW, which makes them insecure. Invitation for more employee involvement in decision making is recurrently a frightening experience in frequently intimidating circumstances. In turn, employees often hesitate to get involved and experience being (put) under pressure.

Next, the experiences reported in this study demonstrate that even though the employees are given responsibility in RTW, substantive discussions and concrete agreements regarding interventions or services to support the individual employee are not maintained.

Finally, based on practical insights it seems that when employees encounter that their expectations on interventions are not fulfilled, they feel they are being backed in a corner. On the other hand, employees appreciate those stakeholders involved in their care who offer social support and take responsibility to make concrete changes in order to keep the reintegration trajectory afloat.

\section{Discussion of the results}

Several implications for practice and further research can be made. As a consequence of the inflexibility of set agreements, there is little room for the employee's side and therefore options to better coordinate the process and support the employee are missed. It is critical to recognize the importance of feeling believed and taken seriously regarding disorders and work capacity for successful work reintegration [31]. In a similar vein, calls to assess individual levels of empowerment in people with long-term disability are being made [32]. In a related way, some scholars have demonstrated the importance for caregivers to respond in such a way to patients i.e. reintegrating employees' so competence can be raised, and to help them in making sense of their situation and in decision-making [33]. Empowering approaches may encourage employees to consider that they are capable to become involved in influencing processes for work participation and career options. Settings out procedures that are inflexible in practice do however not recognize that employee involvement in work reintegration trajectories can develop over time [32]. Being ill in particular when having a disease with an unpredictable course limits capacities [34]. Even though the assumption is made by policymakers that giving the employee responsibility in organizing work reintegration can improve return-to-work outcomes, our data demonstrate that employees consider themselves incapable in completing this.

According to the new policy, the DMP has a central role in organizing and supporting employee involvement in work reintegration. However, the employees do not experience this is indeed happening. Difficulties on the DMP to have a central role in a multi-actor arena in care are also reported in other studies [35-42]. More research on the DMP perspective is necessary. 
The incentives by the system (compensation/insurance/organization) for management strategies appear to affect the health of employees in different ways and, in turn, can exclude employees from work reintegration [43- 45]. Some other scholars provided evidence that less strict compensation policies to be eligible for long-term (partial) benefits, contributed to sustainable return to work; the rationale of these policies is that less disagreement between claimants, employers and insurers creates a safe and secure workplace environment for return-to-work without risk of losing benefits [46]. Above all, it has been demonstrated that the institutional arrangements and local interpretations can be hindering factors in terms of options for approaching disability $[21,47,48]$. Employee representatives could point out that organizational structures itself may need correction to deliver quality and/or optimize employee involvement. Employee representatives should steer the development and adjustment of measures to ensure that the various employees with differential needs are met (flexibility of set agreements). They also ought to take steps to observe that employees' contributions are taken into account to realize individual work opportunities (concrete action based on employee' contribution; attunement and/or integration of the new role of the employee to organize work reintegration in the existing organizational structures). On top of that, measures to improve chances and/or create options are needed to improve the contribution of the employee to organize work reintegration activities (empowerment strategies; DMP support). How policymakers position the various involved health care professionals in care and intervention programming delivery practices (controlling and/or judgment role; guiding strategies) to improve work reintegration successes needs further exploration.

\section{Study limitations and strengths}

The findings of this study on employee involvement in work reintegration are specific to the local context. The number of interviewees involved in this study may be seen as a limitation. We cannot guarantee that bias in case selection did not take place because the respondents were self-selected. Yet, our methods ensured the selection of a diverse range of employees from different workplaces within this research setting and we were able to reach saturation. In addition, in policy-making processes it is important to also consider negative cases and to address unexpected negative consequences or bottlenecks that policies simply have in practice. Furthermore, the methods selected support this study's in-depth insight and our understanding of the practical reality of policy and intervention programming at this organization. By using both a theoretical framework to design this study and analyze the data, and employing peer review and member-checking processes we are confident in the trustworthiness of our findings. For these various reasons, the content of the conclusion might raise the awareness of policy-makers that changing the policy on employee involvement in work 
reintegration alone is not a guarantee for success when the system to organize work reintegration does not sway. In other words, this study shows that the necessary conditions under which employees are able to exert influence (knowledge, opportunities options and capacities) in finding solutions for problems in reintegration need to be considered.

\section{Conclusions}

Although promising, our study shows that employee involvement policy does not automatically result in better re-integration practice and the employees' contributions might boomerang on them. Employee involvement in the organization of reintegration makes employees responsible for the development of work reintegration activities; however they consider themselves incapable of completing this. The inability to complete responsibilities can be understood as inflexibility of the formalized agreements. Assessment is agreed-upon and then committed to papers. Notably, it is not that employees are not able to think along or decide on their reintegration trajectory. Rather they are expected to do so at times when they cannot oversee their illness and/or recovery trajectory $[35,49-51]$.

This study has demonstrated that the specific policy on employee involvement in organizing work reintegration is in fact a dynamic organizational principle that is influenced by contextual factors. To guide these dynamics more measures are needed to support implementation in the entire organizational structure of work reintegration. Also, local workplace based intervention programming and implementation needs to be adapted regarding timing of interventions and planning. Start of the involvement in rehabilitation for work should fit with what is feasible for an individual employee and there should be acknowledgement that employees can often not exert influence over the development of their illness. Finally, in the implementation DMP support needs to be guaranteed.

\section{Implications for rehabilitation}

- It is not that employees are not able to think along or decide on their reintegration trajectory but rather they are expected to do so at times when they cannot oversee their illness and/or recovery trajectory.

- Settings out reintegration procedures that are inflexible in practice do not recognize that employee involvement in work reintegration trajectories can develop over time. 
- The disability management professional has a central role in organizing and supporting employee involvement in work reintegration, however, the employees do not experience this is indeed happening.

\section{Acknowledgements}

We are grateful to the participants of this study and Noushin Khushrushahi, former Occupational Health \& Safety Agency for Healthcare (OHSAH), BC, Canada, for her assistance. The authors kindly acknowledge Dr. Jaime Guzman, M.D., MSc, FRCPC and Renée-Louise France, PhD, both former OHSAH, BC, who supervised this study in Canada. This author acknowledges her training at the Work Disability Prevention Canadian Institute for Health Research (CIHR) Strategic Training program, University of Sherbrooke, Montreal/University of Toronto, Dalla Lana School of Public Health, Toronto, Canada to support her work.

\section{Declaration of interest}

This work was financially supported by former OHSAH, BC, Canada through a Research Fellowship for Karin Maiwald. 


\section{References}

1. Fifty-Eighth World Health Assembly Resolution. WHA58. Disability, including prevention, management and rehabilitation. Electronic citation. http://www.who.int/nmh/a5817/en/index.html. Last accessed: June 2010.

2. Europa Commission Communication. Equal Opportunities for people with disabilities. Electronic citation. http://ec.europa.eu/social/main.jsp?catld=430\&langld=en. Last accessed: June 2010.

3. United Nations Enable: Rights and Dignity of Persons with Disability. Electronic citation. http://www.un.org/disabilities/. Last accessed: June 2010.

4. Guba EG, Lincoln YS. Fourth generation evaluation. Thousand Oaks, California: Sage; 1989.

5. Williams RN, Westmorland M. Perspectives on workplace disability management: A review of the literature. Work 2002; 19: 87-93.

6. Frank J, Sinclear S. Preventing disability from work-related low-back pain. New evidence fives new hope - if we can get all the players onside. Can Med Assoc J 1998; 158: 1625-1631.

7. Loisel P, Durand P, Abenheim L, Gosselin L, Simard R, Turcotte J, et al. Management of occupational back pain: The Sherbrooke model. Results of a pilot and feasibility study. J Occup Environ Med 1994; 51: 597-602.

8. Yassi A. Health promotion in the workplace - the merging of paradigms. Methods Inf Med 2005; 44:278 -284 .

9. Loisel P, Durand P, Berthelette D, Vezina N, Baril R, Gagnon D, et al. Disability Prevention: new paradigm for the management of occupational back pain. Disabil Manag Health Outcomes 2001; 9: 351360 .

10. Baril R, Clarke J, Friesen MN, Stock S, Cole D, \& Group WR. Management of return-to-work programs for workers with musculoskeletal disorders: a qualitative study in three Canadian provinces. Social Science \& Medicine 2003; 57: 2101-2114.

11. MacEachen E, Kosny A, Ferrier S. Unexpected barriers in return to work: lessons learned from Ontario injured worker peer support group. Work 2007; 29: 155-164.

12. Maiwald K, De Rijk AE, Guzman J, Schonstein E, Yassi A. Evaluation of a Workplace Disability Prevention Intervention in Canada: Examining Differing Perceptions of Stakeholders. J Occup Rehabil 2011; 21:179.

13. Anema JR, Steenstra IA, Urlings I JM., Bongers PM, de Vroome EMM, van Mechelen W. Participatory Ergonomics as a Return-to-Work Intervention: A Future Challenge? Am J of Indus Med 2003; 44: 273281.

14. van Raak A, de Rijk AE, Morsa J. Applying new institutional theory: the case of collaboration to promote work resumption after sickness absence. Work Employment Society 2005; 19: 141-151.

15. Meershoek A, Horstman K, Plass S, Vos R. Wat regelen regels? De rol van wetgeving bij de bevordering van reintegratie van zieke werknemers. (What do rules arrange? The role of legislation to promote reintegration of sick employees). In T Abma \& R in 't Veld (Eds.), Handboek Beleidswetenschap. Perspectieven, thema's, praktijkvoorbeelden (Handbook Policy Science. Perspectives, themes and examples of practice). Amsterdam: Boom; 2001.

16. Meershoek A, Plass S, Horstman K, Vos R. Zicht op reïntegratie. Een onderzoek naar de uitvoering van de poortwachtersfunctie (Sight on Reintegration; A study on the execution of the WVP Act). Zoetermeer: College van toezicht sociale verzekeringen; 2000.

17. Meershoek A, Krumeich A, Vos R. Judging without criteria? Sickness certification in Dutch disability schemes. Sociol Health Illness 2007; 29: 497-514.

18. Davis PM, Badii M, Yassi A. Preventing disability from occupational musculoskeletal injuries in an urban, acute and tertiary care hospital: results from a prevention and early active return-to-work safely program. J Occup Environ Med 2004; 46: 1253-1262. 
19. Ouellette V, Badii M, Lockhart K, Yassi A. Worker satisfaction with a workplace injury prevention and return-to-work program in a large Canadian hospital: the importance of an integrated approach. Work 2007; 28: 175-181.

20. Lipsky M. Street-level Bureaucracy: Dilemmas of the Individual in Public Services. New York: Russel Sage Foundation; 1980.

21. Stone DA. Policy paradox: the art of political decision making. New York- London.: W.W. Norton \& Company; 2002.

22. Polit DF, Beck CT. Nursing research: principles and methods. Philadelphia, PA: Lippincott Williams \& Wilkins; 2004.

23. Denzin NK, Lincoln YS. Handbook of qualitative research. Thousand Oaks: Sage; 1994.

24. Denzin NK, Lincoln YS. Handbook of qualitative research. Thousand Oaks: Sage; 2005.

25. Hammersley M, Atkinson P. Ethnography: principles in practice. London Routledge; 2007.

26. Tedlock B. The observation of participation and the emergence of public ethnography. In NK Denzin \& YS Lincoln (Ed.), Handbook of qualitative research. (3-rd. ed., pp. 467-481.). Thousand Oaks, CA; 2005.

27. Bouije H. Analyseren in kwalitatief onderzoek: Denken en doen (Analysis in qualitative research: Thinking and doing). The Hague: Boom onderwijs; 2008.

28. Stake R. Qualitative Case Studies. In NK Denzin \& YS Lincoln, The Sage Handbook of Qualitative Research (3-rd ed., pp. 443-466 (p.451); 2005.

29. Boeije H. Analysis in Qualitative Research. Sage; 2010.

30. Corbin J, Strauss A. Basics of qualitative research: techniques and procedures for developing grounded theory. Thousand Oaks, CA: Sage; 2008.

31. Östlund GM, Borg KE, Wide P, Hensing GK, Alexanderson KA. Clients' perceptions of contact with professionals within healthcare and social insurance offices. Scand J Public Health 2003; 31:275-282.

32. Samoocha D, De Koning J, Zaeyena T, De Vet HC, Bruinvels DJ, Nijhuis F, et al. Empowerment of people with a long-term work disability: development of the 'VrijBaan' questionnaire. Disabil Rehabil 2011; 33:734-742.

33. Benaroyo L, Widdershoven G. Competence in mental health care: a hermeneutic perspective. Health Care Anal 2004; 12: 295-306: discussion 265-272.

34. Hal L van, Meershoek A, Nijhuis F, Horstman K. 'The 'empowered client' in vocational rehabilitation: the excluding impact of inclusive strategies'. Health Care Analysis (published online: 14 July 2011). Available at: http://www.springerlink.com.ezproxy.ub.unimaas.nl/content/74q8657532711u14/

35. Horstman K, de Vries GH, Haveman O. Gezondheidspolitiek in een risicocultuur; burgerschap in het tijdperk van de voorspellende geneeskunde. (No. Studie 38). (Health care politics in a risk-culture: citizenship in an era of predictive medicine). Den Haag: Rathenau Instituut; 1999.

36. Pransky G, Shaw WS, Loisel P, Hong QN, Désorcy B. Development and Validation of Competencies for Return to Work Coordinators. J Occup Rehabil 2010; 20: 41-48.

37. Shaw WS, Hong QN, Pransky G, Loisel PA. Literature Review Describing the Role of Return-to-Work Coordinators in Trial Programs and Interventions Designed to Prevent Workplace Disability. J Occup Rehabil 2008; 18: 2-15.

38. Gardner BT, Pransky G, Shaw WS, Hong QN, Loisel P. Researcher perspectives on competencies of return-to-work coordinators. Disabil Rehabil 2010; 32: 72-78.

39. James C, Southgate E, Kable A, Rivett DA, Guest M, Bohatko-Naismith J. The Return-To-Work Coordinator Role: Qualitative Insights for Nursing. J Occup Rehabil 2011; 21: 220-227.

40. van Gunsteren HR. Theory of Citizenship: Organizing Plurality in Contemporary Democracies: Westview Pr; 1998.

41. De Rijk AE, Van Raak AJA, van der Made JA. New Theoretical Model for Cooperation in Public Health Settings: The RDIC Model. Qualitative Health Research 2007; 17:1103-1106.

42. Benschop R, Horstman K, Vos R. Voice Beyond Choice: Hesitant Voice in Public Debates About Genetics in Health Care. Health Care Anal 2003; 11:141-150. 
43. LeDou J. Occupational medicine: the case for reform. Am J Prev Med 2005; 28: 396-402.

44. Lippel K. Therapeutic and anti-therapeutic consequences of workers' compensation. Int J Law Psychiatry 1999; 22:521-546.

45. Cox R, Lippel K. Falling through the legal tracks: the pitfalls of using workers' compensation data as indicators of work-related injuries and illnesses. Policy and Practice in Health and Safety 2008; 6:31-49.

46. Anema JR, Schellart AJ, Cassidy JD, Loisel P, Veerman TJ, van der Beek AJ. Can cross country differences in return-to-work after chronic occupational back pain be explained? An exploratory analysis on disability policies in a six country cohort study. J Occup Rehabil 2009; 19:419-426.

47. Stone DA. The Disabled State. Philadelphia: Temple University Press; 1984.

48. Saraga E. Embodying the social: constructions of difference. Milton Keynes: Routlidge, London and New York and The Open University; 1998.

49. Tarasuk V, Eakin JM. The Problem of Legitimacy in the Experience of Work-Related Back Injury. Qualitative Health Research 1995; 5:204-221.

50. Roberts - Yates $C$. The concerns and issues of injured workers in relation to claims/injury management and rehabilitation: the need for a new operational framework. Disabil Rehabil 2003; 25:898-907.

51. MacEachen E, Kosny A, Ferrier S, Chambers L. The 'toxic dose' of system problems: Why some injured workers don't return to work as expected. J Occup Rehabil 2010; 20:349-366. 


\section{Chapter 4}

Policy on manager involvement in work re-integration:

Managers' experiences in a Canadian setting

Karin Maiwald

Agnes M. Meershoek

Angelique E. de Rijk

Frans J.N. Nijhuis

In: Work: A Journal of Prevention, Assessment \& Rehabilitation [EPub, ahead of print, Sept 4 2013]. 


\section{Abstract}

Background: In Canada and other countries, sickness absence among workers is a significant concern. Local return-to-work policies developed by both management and workers' representatives are preferred to tackle the problem.

Objective: This article examines how managers perceive this local bipartite agreed upon return-to-work policy, wherein a social constructivist view on the policy process is taken.

Methods: In-depth interviews were held with 10 managers on their experiences with execution of this policy in a Canadian healthcare organization. Interviews were transcribed verbatim and qualitative analyses were completed to gain deep insight into the managers' perspectives.

Results: Results show that the managers viewed themselves as a linchpin between the workplace and the worker. They did not feel heard by the other stakeholders, wrestled with worker's limitations, struggled getting plans adjusted and became overextended to meet return-to-work objectives.

Conclusions: The study shows that the managers felt unable to meet the responsibilities the policy demanded and got less involved in the return-to-work process than this policy intended. RTW policy needs to balance on the one hand, flexibility to safeguard active involvement of managers and, on the other hand, strictness regarding taking responsibility by stakeholders, particularly the health care and re-integration professionals. 


\section{Introduction}

In Canada, as well as in other societies, sickness absence is a significant concern and challenge [see e.g. 1-3]. In particular the health care workforce faces the risk of illness [4]. Therefore policymakers from various countries have agreed to find solutions [see e.g. 5].

Several policies and interventions for return to work (RTW) have been tried in Canada. They are often referred to as disability management (DM), that is "a process in the workplace designed to facilitate the employment of persons with a disability through a coordinated effort and taking into account individual needs, work environment, enterprise needs and legal responsibilities" [5, page 3]. Westmorland and Buys identified key DM principles from the literature namely: integrated prevention and remediation; corporate leadership; joint union and management collaboration; timely return to work and employee involvement [6]. New policies were developed to support early RTW of workers with incapacities (the inability to work due to sickness or injury). These particular strategies do, however, not always have the expected results from the perspectives of re-integrating workers with incapacities in Canada [6-11]. Workers' disappointment with early RTW policy is also found in other countries [12].

To improve effectiveness of RTW, collaboration was sought with both management and worker organization representatives when developing RTW policy in Canada: the so called bipartite policy-making approach. At the provincial level, this bipartite policy process has even been institutionalized $[13,14]$. In this setting, provincial Occupational Health and Safety (OHS) regulations and legislation define DM intervention programming per industrial sector. Taking the bipartite perspectives into account is firmly believed to an effective remedy to reduce sickness absence [15] due to reduction of bottlenecks in the planning, implementation and management of RTW programming $[16,17]$. Involvement of bipartite stakeholders to formulate the RTW policy in British Columbia (BC), Canada for the healthcare sector seemed, however, not to prevent practical bottlenecks when implementing the policy according to the diverse stakeholders [10]. These findings raise the question what the reasons are for stakeholders' difficulties in the execution of RTW policy and that is the focus of our research.

In 2009, RTW policy in BC, Canada for the healthcare sector was reformed as part of the collective bargaining process between the provincial government and healthcare management- and trade union representatives. Local bipartite stakeholders (human resource executive and management, senior executive, trade union representatives) also provided input in policymaking process. This new bipartite agreed upon RTW policy was built upon earlier provincial, sector-specific initiatives [18]. 
The finding of our earlier study on the workers' perspectives on the reformed RTW policy in practice showed that the policies and procedures made workers with incapacities responsible for the design of RTW plans. At the same time, however, reintegrating workers considered themselves incapable to answer this responsibility, within which they were offered too little flexibility regarding involvement and interventions in RTW planning to meet their needs [11].

Our current study focuses on the managers' perspectives on RTW policy in practice. The scarce literature that takes a manager perspective on RTW policies and procedures illustrate this particular stakeholder group struggles with not knowing how to respond to the worker with health problems [19], finds it difficult that re-integrating workers may not be qualified to meet certain functions in terms of limitations and productivity demands [20], and worries about increased costs and fear legal liability [21]. The scarce studies also show that RTW decisions and outcomes are affected by managers' behaviour $[22,23]$.

To study how RTW policy works from the managers' perspectives in the BC healthcare practice, a social constructivist view on the policy process [24] is taken. Policy often turns out differently and in unexpected ways in practice and can have normative implications [24]. This happens because policies and procedures that have to govern daily practice include general rules that are based on general assumptions of the situations in that same practice. Therewith rules and policies permit discretionary space for those stakeholders who deliver the services and have to apply rules and policies on individual situations [24, 25].

Discretionary space, on the one hand, allows for including individual differences and contextual circumstances in decision-making in the execution of rules and policies in practice. Thus discretionary space is thought to enhance fairness in process. On the other hand, as the rules and policies itself do not predict how the discretionary space is used in practice, this space also counts for transformations in rules and policy intentions in practice. In applying abstract rules and policies to concrete individual cases, rules have to be interpreted. This process of interpretation-in practice is influenced by professional norms, social costumes, peer norms, moral beliefs and existing practices which may transform the meaning of the rules and policy-as intended [24-29]. Research of Meershoek et al. [26, 27], for instance, showed how administrative procedures can have counter-productive effects in practice in the Dutch setting of work reintegration. They concluded that, in practice, the duty for the employers to work on reintegration of workers who reported ill became an empty letter, due to formal procedures and control mechanisms.

The application of rules and policies is thus a highly contextual enterprise, and therefore implementation process in practice often has consequences that cannot be predicted by the policy itself [24]. Insight in and understanding of the environmental 
and workplace context in which the rules and policy have to function can help to formulate rules and policy that are better adapted to this local context, within which the risk of unintended consequences can be reduced.

In our research into Canadian RTW rules and policy execution, we therefore investigate how RTW policy functions in practice in the BC healthcare sector. How do local stakeholders interpret and apply the new RTW policy, which is intended to add to what is already arranged by social security legislation in Canada and how do these stakeholders handle the discretionary space? Insight in these practices will answer the question whether bipartite stakeholder involvement in the RTW policy development phase in policy process indeed guarantees that policies and procedures are adjusted to the dynamics of daily re-integration practice. In this article we focus on the perspective of the managers of workers who had reported ill and were re-integrating in their own or in accommodated jobs.

\section{The policy studied}

The RTW policy in this setting contains the following aspects. Generally, both the managers and individual workers are expected to participate in coordinating the organization of early RTW activities and development, wherein absent workers should reintegrate before full recovery of either their incapacities has taken place. Organizational structures to positively affect RTW include a workplace-based disability management professional (DMP) (so called: case manager) who is supposed to contact the worker to request their participation in RTW programming and ask for the workers input in RTW planning (e.g. either a straightforward plan for less than six weeks in duration or a complex plan for longer than six weeks). The DMP is further supposed to check with, follow-up and contact the manager and other stakeholders (e.g. the physician, a trade union steward and insurer/compensation agent) to aide and steer decision-making during re-integration. RTW programming is supposed to include access to various support services (e.g. ergonomist, workplace rehabilitation advisors). A supernumerary ('extra') worker can be made available upon RTW as well as access to internal human resources (e.g. help with the implementation of work -, job accommodations and further care). Participation in RTW programming is voluntary in the first six weeks of sickness absence but mandatory thereafter and must include the consent of the worker's physician. External health and safety programming services may also help with the implementation of work-, job accommodations and further care (as described below).

\section{Social security in Canada}

As said, in Canada, as in many other countries, RTW policy only adds to what is already arranged by social security legislation. In the BC healthcare sector, management is responsible for disability benefits for workers who experience work-related inju- 
ry/illness under the Workers Compensation Act and OHS regulations. If sickness absence is deemed not work-related or is result of a motor-vehicle accident that is nonwork related, there are various other insurance and benefits systems available. For all workers, basic health care costs are covered on the basis of a public healthcare system.

Employment status for regular staff is secured for about two years during which management needs to relate to the Compensation Act and OHS regulations. Benefits and coverage for workers vary per cause of sickness absence and collective agreement. The management has an obligation to make every reasonable effort to find a way to accommodate the worker (e.g. must carefully scrutinize their workplace for potential jobs into which the worker can be placed or, if equipment is required, investigate the cost of purchasing such equipment).

\section{Aim and research questions}

The aim of this article is to gain deep insight in managers' perspectives on reformed bipartite-agreed RTW policies and procedures in practice. The experiences with and perceptions on the reformed bipartite-agreed RTW policy is part of our study how RTW policy works in practice to, in turn, find out how bipartite involvement in policy process in the $\mathrm{BC}$ healthcare sector functions. The research questions are:

1) How do the managers experience their new role in organizing RTW trajectories for absent workers described in the bipartite-agreed upon RTW policy?

2) To what extent is the bipartite agreed upon RTW policy to give local managers more responsibility perceived as successful by the managers?

3) How are contributions by the DMPs to steer and guide collaboration in the relation management-worker in RTW experienced and perceived by the managers?

\section{Methods}

This study took place in the largest and considered leading health organization in BC, Canada which provides general and specialized public healthcare services to a large portion of the provincial population. Public acute health care services are offered in their 13 hospitals across a vast geographical area whereby they also offer a number of other services including, primary care, community-based residential and home health care, mental health, addiction services and public health. As per provincial collective agreements, this organization created workplace-based RTW policy for its 22,000 workers. To find answers to our research questions, qualitative research methods were selected [30-32] and to obtain good insight on the experiences and perceptions of the management, in-depth individual interviewing was selected as the best method of data gathering [31]. The first author performed the data collection and had the main 
role in data analysis. All authors had experience with qualitative data collection and analysis. Besides the involvement of the other authors, two staff members of the Occupational Health and Safety Agency for Healthcare (OHSAH) of BC supervised the data-collection. OHSAH had been involved in the development and evaluation of the workplace-based RTW policy. The first author and supervisors did have professional work relationships with the participating BC health care organization. None of the authors or supervisors had professional or private relationships with the interviewees.

\section{Study sample}

Managers were defined as the clinical managers and direct supervisors. Inclusion criteria were that they had or still were involved in re-integration of staff with work incapacities anytime between April 2009, when the 'new' RTW policy came into effect, and June 2010. Managers who only had experiences with re-integrating workers previous to April 2009 were excluded from this study. Purposive sampling with various recruitment strategies were used to maximize variability in perspectives and to acknowledge the opportunity to obtain information from the full range of local managers for intensive study [30, 33]. The first round of interviews with eight managers was held between September and December 2009 and the second round with two managers was held in May 2010. When a manager initiated contact to participate, he/she received a detailed four-page information sheet and upon agreement to participate an interview was booked. Interviewees ranged in management-level, differed in age from 35-60, included both new and experienced managers, and managed various size department, delivered differing health care services at multiple work sites (see Table 1 for a description of participant characteristics).

\section{Ethical Considerations}

For this study, support was obtained from the organization itself and various trade unions (three - all of which had been part of the policy process) to conduct this study. Further, we received the approval of two local Research Ethics Boards from the University of $\mathrm{BC}$ and the health organization. Interviewees were made aware they were free to refuse to participate and were welcomed to ask questions and express concerns about the study any time. Informed consent forms to participate, record the interview, and review the findings were signed prior to each interview. Participants were given the option to receive the final report.

\section{Interview procedure}

The topic list was based on administrative materials about the local RTW policy formal documents and draft papers (e.g. brochures, procedures on DM that were collected via DMPs and the organization's intranet), RTW literature and from policy science. The 
topic list included the following topics: on imposing rules and responsibilities, monitoring and reviewing, decision making, controversy and conflict, influence and authority structures in RTW. To increase validity, interviewees were invited to address these topics by means of various real worker cases they brought up themselves during the interviews. They were also given the opportunity to elaborate on topics they brought up on RTW in this setting. Interview questions were fine-tuned as data collection progressed. The individual face-to-face interviews were conducted in managers' office, took from $40 \mathrm{~min}$ to two $\mathrm{h}$, and were taped and transcribed verbatim.

\section{Analysis}

Following ethnographic methodologies, qualitative analyses were completed to gain deep insight into stakeholders' perspectives [34, 35], within which detailed understanding of interviewees' experiences, actions and practical reasoning was gained [31, 32]. By identifying, coding and categorizing experiences and perceptions [36] (with pen and paper and word processor) and, then, pattern-seeking to interpret experienced challenges and opportunities [30] we were able to unravel how practical bottlenecks affected RTW. Our interpretative analyses [31, 32, 34] focused on the role of policy, legislation, organization characteristics and the individual context on involvement; and how that affected RTW activities, from managers' perspectives. The analysis of RTW policy as experienced and perceived by these stakeholders resulted in an empirical description of organizational process in RTW and the typical consequences in practice. A review process was put in place to ensure the accuracy of the descriptions, emerging themes, and revealed arguments between the authors. After the first round of interviews, the first and second author performed the first-phase of the data-analysis (structuring data, initial coding). After the second round of interviews, the interpretations and patterns were discussed stepwise during the process of analysis among all authors. Member checking, to review preliminary study findings for the purpose of accuracy by interviewees, was not done in this study. 
Table 1 Detailed summary of participant characteristics

\begin{tabular}{|c|c|c|}
\hline \multicolumn{3}{|c|}{ Clinical managers and supervisors (10 interviewees) } \\
\hline \multirow{6}{*}{$\begin{array}{l}\text { Participants supervise(d) workers } \\
\text { with cause of sickness absence of } \\
\text { (as diagnosed by physician) }\end{array}$} & \multicolumn{2}{|l|}{ Medical disorder } \\
\hline & \multirow[t]{3}{*}{ Orthopaedic* } & Work-related \\
\hline & & Not-work related \\
\hline & & Motor vehicle accidents \\
\hline & Systemic & \\
\hline & \multicolumn{2}{|l|}{ Mental disorder } \\
\hline Positions & \multicolumn{2}{|c|}{$\begin{array}{l}\text { Regional Supervisor; Team Director; Team Leader; Clinical Supervisor; } \\
\text { Regional Practice Lead; Charge Nurse; Supervisor }\end{array}$} \\
\hline Gender & 8 Female & 2 Male \\
\hline Health care services & \multicolumn{2}{|c|}{ Hospital; Community Health Centre; Clinic; Residential Care } \\
\hline
\end{tabular}

* The type of health problem is categorized according to insurance coverage. Motor-vehicle accidents which are not work related fall under a different coverage than non-work related illness or injury.

\section{Results}

On the basis of the experiences and perceptions of the managers, we identified three main phases regarding their involvement in RTW: (1) return-to-work plan design; (2) execution of the return-to-work plan; and (3) final re-integration strategy. In practice, re-integration is not clearly structured; the RTW process is not simply onward and upward and is ever-developing. We describe the most central experience-aspects or bottlenecks that succinctly dominate in these phases. However, the experiences do not limit itself to the phase in which we describe it.

Developing a return-to-work plan: feeling unheard

The procedure calls for a DMP to determine safe work options for the re-integrating worker. A group meeting is supposed to be held with the manager, worker, union steward, and possible other stakeholders to review and finalize details of the plan. The managers argued that involvement is difficult and they identified concerns in practice. RTW plans need medical accordance and approval by the insurance/compensation agency.

The managers' first concern was that RTW policies and procedures were unclear to them. In some situations the managers felt unaware of where to find this information.

'How does it work? Who is responsible for what? That would be nice to have, an outline, kind of how this process works and for the employee to be able to say: Okay, at this point I should be here, and this is who I would contact if I had any concerns.' 
Besides difficulties experienced in finding information on policies and procedures, the second concern the managers indicated was that an expected routine in organizing reintegration was not happening. According to the managers, not getting regular updates around workers' progress, an anticipated re-integration date and readiness for work was confusing.

'It was all very confusing (...) you know, getting information and making sure the person's ready.'

Besides challenges perceived in getting information on worker's progress and confusion around organizing re-integration, the third concern the managers pointed out were the developments of the RTW plans itself. As explained above, the managers were interested in finding out whether the worker was ready for work. This was mostly because their experience told them that over- or underestimations of work abilities by workers themselves, including pressure and coercion by insurers and trade union stewards do take place. Keeping the right to privacy in mind, the managers stated it was nevertheless difficult that the assessment on work abilities was kept silent, that ways on how the assessments on limitations and hours came about was not made clear and that they were given no guidelines or direction on what they could or could not say to make suggestions to adjust the plan (e.g. during contact moments).

'I wanted to make it work and I didn't want to have unnecessary conflict ( . . ) I was in a position of sort of receiving information from them around how things would go.'

In similar vein, the managers' experienced that selected support services on the plan did not work on their specific department, nor were aligned with specialized job responsibilities.

'They said: "Well, she can come back supernumerary." And I said, "What do you mean, supernumerary? I'm three positions down. So there's no way you can come and be somebody's shadow here. It doesn't work like that".'

In realizing a plan, the managers expect better insight in worker's expected progress and a better understanding of worker's abilities. Yet they do not receive this. On the contrary, the managers are left to feel dubious about how assessments and selected services come about and if the individual worker can meet the complexities of work. They feel they cannot contribute their practical insights to improve the plan before 
finalizing it. As a result of not including the workplace perspectives, the RTW plan does not materialize well in practice as will be addressed next.

Return-to-work plan execution: getting frustrated

The managers saw themselves as having a key-role in the interface between the worker and the workplace:

'I think that the manager has a really key role in helping the employee see what's happening in the workplace. I think that's the extent of it. We have to help them and that we're interested in having them back to work but not having them back to work if they're not able. ( . . ) if they're not able [to complete work], then it becomes a risk issue for themselves and a risk issue for care.'

From this perspective, the first concern regarding the RTW plan was that re-integrating workers did not always function as well as expected, according to the managers. They felt that the worker was sometimes not motivated for work ('work ethic') and/or did not meet what they perceived as agreed upon tasks, duties and hours. The managers mentioned they discussed unforeseen, subtle factors with the worker. However, they experienced it was sometimes hard to know how to approach this worker's situation (see also previous theme on what they could or could not say, or ask).

'When we first started this, it was like, "Don't try to take on too much." And that's the other problem is that the person feels like you're telling them, they'd better take on more, which makes them less productive. You know, so it's hard to know how to approach them.'

The managers experience difficulties when re-integration plans are not working out as expected. They find it sometimes difficult how to best address practical difficulties.

The second concern the managers pointed out was that difficulties in RTW could, in their view, create unwanted tension at the workplace (e.g. the worker reported sick again). They stated that (repeated) sickness absence and limited work ability puts more responsibility and pressure on co-workers. The managers perceived this could result in turn and over time in tension, resentment and mistreatment among other staff members: 
'So sometimes there is that resentment. I know that goes on. Now whether that's verbal, or you just sort of hear it through the grape vine, "don't bring her in my area; she's really of no help to me" or "he can't help". So it's the chronic ones that I think are probably mistreated, maybe because they're misunderstood.'

The managers obtain better insight into practical difficulties in re-integration efforts, and experience tension on the floor if RTW plans do not work as expected.

The third concern the managers pointed out were unfilled expectations on monitoring by 'experts'. According to them, reviewing progress and, in turn, their expectation to address practical difficulties with 'experts' early on was not happening:

'I didn't know enough about Return To Work (. . . ). I emailed the advisor, just with my questions and it took a long time to get any response. That was the most frustrating for me, that time kept passing and I wasn't getting any kind of response! ( . . . ) It would be nice to be able to go back to the Return To Work advisor and say,

"This is what I'm noticing, is there any[thing we can do]?".'.

There are managers who argued that upon making contact with 'experts' to voice practical concerns they were countered with 'must' arguments to follow organizational routines and procedures on RTW versus reconsidering the appropriateness of plans:

'Return To Works are always set up Monday to Friday because that's when they say the most support is in the hospital, but it's also the busiest. (. . ) But [a] Return to Work is not allowed to work in the evening and they're not allowed to work on a weekend. So you're putting them in at the busiest time!'

Other managers mentioned that being countered with arguments to 'follow the rules', upon raising worker's difficulties to complete workload and the person functioning on the floor was not improving does nothing to solve re-integration problems, which they expected:

I've tried talking to the unions [that the worker could not meet work demands] but I guess because it's in the Collective Agreement that's what we have to do, that's what we have to do.'

The managers experience that measures for evaluating practical problems and integrating the workplace perspective in RTW process are unclear to them. They find that careful handling by 'experts' of daily difficulties is not taking place. This is upsetting to 
the managers, especially in perceived (poor) combination with 'experts' counters to follow the rules. Workers oftentimes return to their own job or accommodated job before details on work (in-) capacities are worked out as we will see in the next section.

\section{Final return-to-work strategy: getting overextended}

In the final phase, formal assessment on RTW or integration to own job or accommodated job is completed. Workers are no longer designated for RTW programming or 'extra' support services and are expected to complete duties and tasks in line with the job responsibilities.

The first concern the managers highlighted was that workers' capacity to meet the complexities of work remained unpredictable and unexpected limitations could still become clearer upon formalized re-integration. For example, there are managers who stated getting concerned when other staff (silently, discretely) pointed out that the reintegrated worker to his/her own job or accommodated job was making errors in patient care:

'He is needing to be directed much more than he did prior to going off on his illness. He is missing treatments and medications and, you know, those small mistakes that I don't believe he ever made prior to being off.'

The managers mentioned tenseness at the department rising (also see previous theme on tension) as re-integrated workers were on occasion assigned duties/tasks which other staff considered 'promotion opportunities':

'There are people who have worked within that department for over 20 years. All of a sudden someone comes in, kind of what they perceive as through the back door (. . . ) and you're kind of feeling . . frustrated.'

The managers thus experience that unexpected, subtle worker' incapacities around healthcare service delivery and inconsiderate job accommodations raises tension on the work floor.

The second concern the managers pointed out was the lack of follow-up care to deal with such unforeseen practical difficulties in relation to the re-integrated worker and the workplace: 
'Once they go on their own nobody is following them up. I mean, I am and their coworkers are, but we don't have any way of returning that. Maybe they are not interested in how they do once they go back on their own; I don't know.'

In more detail, there are managers who highlighted that the human resources department (which they have to deal with and includes DMPs) and external agents did not recognize their calls, e-mails, consultations hence workplace arguments that workers were having unexpected, new incapacities in meeting (fluctuating, increasing) job demands. They argued that 'experts' encouraged a 'keep going' approach and in doing so failed to acknowledge they might set re-integration up to fail:

'They didn't understand the disabilities we were talking about (. . ) The people in terms of [name organization] were useless, absolutely non helpful.'

The managers experience there is a lack of follow-up in care to ensure workers with incapacities meet job complexities. They find a lack of accountability of support services in terms of recognizing experienced difficulties, help problem solve and offer possible solutions. In the end, the managers find that the worker's limitations might not be acknowledged by the worker themselves (e.g. in light of financial worries the worker may have to report ill again, or worries to lose their job) and may neither be recognized, explored nor considered by (health, re-integration) professionals.

The managers respond in different ways to these practical bottlenecks. In some situations, managers left it up to the worker to report in sick again (see previous themes), whereas other managers attempted to work out details. The managers acknowledged getting a better understanding what was going on from worker's perspective was important and could require a shift in working relations (e.g. for the worker to start sharing personal/private difficulties, for the individual and team to cooperate - a give-andtake approach), which did not always occur. They pointed out to realize that sometimes the re-integrated worker really needed to see a physician for a better diagnosis and, in turn, better targeted treatment and support at work. For this realization to mature, the managers mentioned successful interactions with knowledge allies they had (e.g. College of Nurses, physicians). Building this bridge between external health professionals and the workplace, however, was a lot of effort:

'I had to do a lot of work around articulating what we were seeing and whether that made any sense for him and gave him stuff to take to his physician. (...)

What worked well was finally to help both this employee and his physician realize 
that by continuing to put him in the workplace he was going to lose any prospective (. . .) which in my mind was completely unfair.'

The managers experience that improving work relations can, in turn, enhance articulation of re-integration difficulties. This, in turn again, can support decision-making in organizing individual re-integration relative to operational work processes. The managers find it unacceptable that failure to get a good diagnosis for accurate treatment and to coordinate work demands and support can potentially result in workers losing their job or professional license.

Nevertheless, the managers pointed out that worker's incapacity could sometimes permanently hamper work flow and ultimately organizational objectives. They sometimes simply could not solve nor stretch themselves any further, according to them. For this the managers pointed to the system/organization and their responsibility for better organizing RTW policy:

'My concern actually is, is how the system is put in place (...) I think there should be some more consideration about what we do and how they can help us operationally, make it work. I don't feel that. It's as simple as that.'

The managers experience that despite their willingness to meet the expectation to reintegrate workers with incapacities, the formal RTW policies and procedures do not comply with the work they have to do. They find that if they improve their understanding of health issues that affect the worker' capacity they can, in turn make efforts in adjusting the specific strategies the worker employs to meet work demands. But which cause worker health problems (e.g. being too altruistic or "can do" approach which can result in problems relating to what are called issues in psychosocial functioning) they cannot change. The managers then feel wronged and overextended having to sort-out RTW difficulties and issues (e.g. work stress, when work demands exceed the worker's ability to cope or control on their own).

\section{Discussion}

In a leading healthcare organization in BC, Canada, RTW policy was reformed in which (early) re-integration of workers with incapacities as well the management' participation and the inclusion of the workplace perspectives in RTW process was encouraged. The study examined how, in practice, policy execution of this bipartite agreed upon organizational RTW policy was experienced by the management. We conducted 10 
interviews with clinical managers and direct supervisors who were each involved in several RTW trajectories of various re-integrating workers.

The management took steps to meet the organizational objective of re-integrating workers with incapacities. However, they experienced their organization and other involved institutions not keeping the bipartite agreement that encourages managers' participation and inclusion of the workplace perspectives in RTW process. Consequently, the management found it unacceptable that poorly implemented RTW policy can put the delivery of healthcare services at stake and can exclude workers with incapacities from participating in the workforce. Moreover, managers felt oftentimes blamed as the ones at fault. This study is one of few studies with a management perspective on RTW policy [6, 37-39]. Though some studies on workers' perspectives on RTW policy suggest that management oftentimes does not want to support workers with incapacities in re-integration $[37,38]$, our study illuminates the management' trials to do just that.

RTW policy gives managers the responsibility to ensure the plan is attuned to the worker's limitations relative to the job responsibilities. Asking for manager's input is in line with the obligation to find a way to accommodate the worker and is supposed to ensure plans fit the practical experiences of managers. In practice, however, at the moments when decisions on a plan have to be made, managers do not have a clear picture of worker's limitations. The management thus has to offer adapted work places without knowing what to adapt. At the same moment, as RTW plans are formal decisions, the management is bound to the proposals they make on the plan. In addition, RTW policy demands that the management implements this RTW plan and supports this re-integration. It is managers' responsibility to notify the workplace and organize the selected strategies. Yet, due to uncertainties in the assessment of limitations during the design of the plan, the management finds often that unexpected worker's limitations occur during re-integration. Furthermore, managers encounter that reintegration trajectories are time and again unpredictable and non-linear. The management gets that unpredictability of illness process are not taken into account within the plans and they do not get help or facilitation to deal with the various limitations and differing dilemmas that happen. The mistaken assessments of re-integration result in costs and efforts shouldered by the management. RTW policy also gives the management responsibility for workers who completed RTW programming. The 'idea' is for workers to be recovered after four-six weeks of support services, albeit extensions can be requested. In practice, however, the managers find unexpected limitations and various dilemmas remain to be an issue for which, again, they are not facilitated. They can sometimes work these difficulties out but it stretches managers and in some cases 
they simply do not succeed in getting or keeping adaptations in place. Managers are forced to deal with costs and effort to figure out unresolved value disputes on implications of illness and guidance for re-integration.

When compared to the findings of an earlier study on workers' experiences with and perceptions on the same RTW policy [11] striking similarities were found. These authors demonstrated with empirical research how policies for involvement, in this Canadian setting of work re-integration, were not as effective as intended, and excluding consequences of these policies. They concluded that, in practice, the procedures did not result in better RTW practice due to timing of involvement, recognition of practical insights and support services or lack of it.

\section{The discretionary space}

The social constructivist view on the policy process assumes a natural gap to exist between policy and policy execution, which allows for discretionary space. The findings of Maiwald et al., [11] among workers and the current study among managers demonstrate that the misconception on the extent to which RTW can be planned in advance is the major bottleneck. In bipartite agreed upon RTW policy the importance of both worker' and manager' involvement in re-integration is acknowledged, and both stakeholders' perspectives have to be included on the plan. The first assumption in this RTW policy is that at the moment the plans have to be defined, which is before RTW itself starts, both stakeholders can provide information relevant for this re-integration. Although medical advisors demand workers' input, the advisors cannot predict what the limitations and possibilities of the worker are and how they will develop, resulting in plans based on inadequately defined limitations. While managers are asked for input on plans that appear inadequate, they cannot suggest appropriate adjustments or make adjustments on the plan. A second assumption in this RTW policy is that 'sitting around the table with all the stakeholders' is the best process to guarantee that deeprooted differing interests of managers and workers are brought forward on the plan and are reckoned with during re-integration. However, these (re-) negotiations are far more difficult than assumed. Workers are uncomfortable in meetings and managers find that, despite seeing themselves as having a key-role, they cannot get practical difficulties addressed. Both workers and managers find that internal health and reintegration professionals and external compensation agents do not help to problem solve nor facilitate.

This study demonstrates that inflexibility and inability of arrangements for RTW are counterproductive for managers to meet re-integration objectives, in combination with other organizational demands. This same inflexibility and inability of arrange- 
ments for RTW affected the workers' chances to succeed in the work abilities they theoretically had and their real work participation [11].

This study thus shows clear tension between bipartite-agreed upon RTW policy and policy execution, and the discretionary space becoming an organizational sub-level battleground. Insight in how the discretionary space is interpreted is relevant because it demonstrates the nucleus of this tension in this organizational context, and further draws attention to unintended consequences of these bipartite policies in this setting.

The finding of Maiwald et al., [11] and the current study demonstrates the same policy paradox [24]. The policy intention is more responsibility to be given to the management and workers and better support by health and re-integration professionals. However, both the managers and workers experience the inability to complete responsibilities and run into practices of (social) exclusion in consultation processes. The findings of both studies therefore support the tentative conclusion that bipartite involvement in RTW policy process does not guarantee that policies and procedures are better adjusted to processes in practice. More research is needed regarding what input these bipartite representatives have and how they interpret and translate managers and workers interests into policy to meet the complexity of work re-integration.

\section{Limitations}

The number of interviewees involved in this study may be seen as a limitation. Bias in case selection could not be avoided as the respondents were self-selected. Our methods ensured the selection of a diverse range of managers and data collection was performed in two stages, yet, saturation might not have been reached on the practice of work re-integration in the entire $\mathrm{BC}$ healthcare sector in Canada. Using both a theoretical framework to design this study and analyse the data supports trustworthiness of findings and gained insight into various mechanisms which hamper implementation of reformed RTW policy.

\section{Implications for practice and further research}

Several implications of the study for practice and recommendations for further research can be made. The results of this study demonstrate that illness processes are capricious and RTW trajectories are dynamic and therefore re-integration planning requires continued adaptations. To address this, the management indeed seemed to need a more central role during re-integration, which is in line with conclusions from other research $[22,23]$. Nonetheless, on-going modification of plans based on practical insights must be guaranteed. For example, in the Netherlands there is room for adjustments and RTW plans should be allowed flexibility in which try-out opportunities and room (timing for involvement and choosing another intervention) must be based on gained insights in the various stakeholders' perspectives $[26,40]$. 
Another vital point for practice improvement is that health and re-integration professionals are supposed to support the new role of the management during reintegration [41]. Nonetheless, the management does not experience this service is happening in practice. Research shows challenges and opportunities regarding the supporting role of health care and re-integration professionals [6, 22, 42, 43], also from the perspective of costs being made by management [39]. Soklaridis and colleagues demonstrated in a Canadian setting that management felt the relevance of making medical costs but also experienced them as a financial burden on the management [39].

While the findings of this study on RTW policy are specific to the local context, there are lessons to be learned for other settings. First, RTW policy implementation is linked to the social security legislation regarding RTW. The current positive attitudes of managers towards RTW might be rooted in the extensive RTW legislation in Canada. Lack of management involvement is found in settings with dearth of legislation, such as in Belgium [44]. Second, the implementation of a new policy in the health care sector needs to be understood in the light of its structural characteristics [45]. The present positive views and behaviours of managers towards seeking alternative ideas on guidance in re-integration might be because they embrace changing professional and work/organizational structures in this sector.

\section{Conclusions}

Management representatives' involvement in RTW policy process does not reduce bottlenecks in re-integration programming and thus does not secure implementation of agreed upon policy. Our current study shows that on the one hand, more flexibility in practice is needed to allow for active participation of managers. On the other hand, strictness is needed regarding taking responsibility by stakeholders, particularly the health care and re-integration professionals. The findings did not contradict that found in a study among workers who were re-integrating into work in the same setting, but rather appeared to parallel these. Bipartite representation in the RTW policy process and how representatives exert their authority to formulate rules and policies needs further study.

\section{Acknowledgements}

We are grateful to the participants of this study. The authors kindly acknowledge Dr. Jaime Guzman, M.D., MSc, FRCPC and Renée-Louise Franche, PhD, both former 
OHSAH, BC, who supervised data-collection in Canada. This work was financially supported by former OHSAH, BC, Canada through a Research Fellowship for Karin Maiwald. She further acknowledges the Work Disability Prevention Canadian Institute for Health Research (CIHR) Strategic Training program, University of Sherbrooke, Montreal/University of Toronto, Dalla Lana School of Public Health, Toronto, Canada. 


\section{References}

1. Statistics Canada (2010) Topics of interest on labour and income. Work absences at: http://www.statcan.gc.ca/pub/75-001-x/topics-sujets/topics-sujets-eng.htm, Last accessed on December 3, 2012.

2. Kalisch DW, Aman T and Buchele LA (1998) Social and Health Policies in OECD Countries: A Survey of Current Programmes and Recent Developments. OECD Labour Market and Social Policy Occasional Papers 33. OECD Publishing at: http://dx.doi.org/10.1787/720018345154

3. OECD (Organization for Economic Co-operation and Development) (2003) Transforming disability into ability. Policies to promote work and income security for the disabled. Paris: OECD.

4. WHO (World Health Organization). (2006) The World Health Report 2006 - working together for health at: http://www.who.int/whr/2006/en/index.html, Last accessed on December 3, 2012.

5. ILO (International Labour Organization) (2001) Code of Practice on managing disability in the workforce at: http://www.ilo.org/public/english/standards/relm/gb/docs/gb282/pdf/tmemdw-2.pdf, Last accessed on December 3, 2012.

6. Westmorland MG and Buys N (2004) A comparison of disability management practices in Australian and Canadian workplaces. WORK 23, 31-41.

7. MacEachen E, Kosny A and Ferrier S (2007a) Unexpected barriers in return to work: lessons learned from Ontario injured worker peer support group. WORK 29(2), 155-64.

8. MacEachen E, Ferrier S, Kosny A and Chambers L (2007b) A deliberation on "hurt versus harm" logic in early return to work policy. Policy and Practice in Health and Safety 5(2), 41-62.

9. MacEachen E, Kosny A, Ferrier S and Chambers L (2010) The 'toxic dose' of system problems: Why some injured workers don't return to work as expected. J Occup Rehabil 20(2), 349-66.

10. Maiwald K, De Rijk A, Guzman J, Schonstein E and Yassi A (2011) Evaluation of a workplace disability prevention intervention in Canada: examining differing perceptions of stakeholders. J Occup Rehabil 21(2), 179-89.

11. Maiwald K, Meershoek A, De Rijk AE and Nijhuis FJN (2013). How policy on employee-involvement in work reintegration can yield its opposite: employee experiences in a Canadian setting. Disabil Rehabil 35(7), 527-537.

12. Tjulin A, MacEachen E and Ekberg K (2011) Exploring the meaning of early contact in return-to-work from workplace actors' perspective. Disabil Rehabil 33(2), 237-145.

13. WSBC (WorkSafeBC). (2012) Workers Compensation Act at: http://www.worksafebc.com/about_us/governance/default.asp, Last accessed on December 3, 2012.

14. WSIB (Workplace Safety and Insurance Board). (2010) Annual Report 2010 at: http://www.wsibontario.ca/PDF/OnlineAR_E_2010.pdf, Last accessed on December 3, 2012.

15. Franche RL, Baril R, Shaw WS, Nicholas M and Loisel P (2005) Workplace-based return-to-work Interventions: optimizing the role of stakeholders in implementing and research. J Occup Rehabil 15 (4), 525-42.

16. Guzman J, Yassi A, Baril R and Loisel P (2008) Decreasing occupational injury and disability: The convergence of systems theory, knowledge transfer and action research. WORK 30 (3), 229-39.

17. Van Oostrom S, Anema JR, Terluin B, Venema A, De Vet HC and Van Mechelen, W (2007) Development of a workplace intervention for sick-listed employees with stress-related mental disorders: Intervention Mapping as a useful tool. BMC Health Services Research (7), 127.

18. Ouellette $V$, Badii M, Lockhart $K$ and Yassi $A$ (2007) Worker satisfaction with a workplace injury prevention and return-to-work program in a large Canadian hospital: the importance of an integrated approach. WORK 28(2), 175-81.

19. Van Petersen A, Vonk M and Bouwmeester M (2004) Onbekend maakt onbemind: attitude onderzoek naar de positie van arbeidsgehandicapten op de arbeidsmarkt. [Unknown makes unloved: Attitude research into the position of work disabled people into the jobmarket]. Research voor beleid [Research 
for policy], Leiden at: http://www.ohcbv.nl/hulppagina/documenten/Onbekend\%20maakt\%20onbemind.pdf, Last accessed December 03, 2012.

20. CWP (Commissie het Werkend Perspective) (2007). Bouwen op vertrouwen [Committee the Working Perspective. Build on trust]. CWP, Den Haag.

21. Kaye SH, Jans LH and Jones EC (2011) Why Don't Employers Hire and Retain Workers. J Occup Rehabil 21, 526-36.

22. Nieuwenhuijsen K, Verbeek JHAM, De Boer AGEM, Blonk RWB, Van Dijk FJH (2004) Supervisory behavior as a predictor of return to work in employee absent from work due mental health problems. J Occup Environ Med 61(10), 817-23.

23. Munir F, Yarker J, Hicks B and Donaldson-Feilder E (2012) Returning Employees Back to Work: Developing a Measure for Supervisors to Support Return to Work (SSRW). J Occup Rehab 22, 196-208.

24. Stone DA (2002) Policy paradox: the art of political decision making, Norton \& Company, New YorkLondon.

25. Lipsky M (1980) Street-level Bureaucracy: Dilemmas of the Individual in Public Services, Russell Sage Foundation, New York.

26. Meershoek A, Krumeich A and Vos R (2007) Judging without criteria? Sickness certification in Dutch disability schemes. Sociol Health Illness 29(4), 497-514.

27. Meershoek A and Krumeich A (2009) Multiculturalism and the Construction of Ethic Identities in Labour and Health Practices: Avoiding the Culturalistic Fallacy in Applied Research. Health Care Analysis 17, 173-97.

28. Van der Veen RJ (1990) De sociale grenzen van beleid: een onderzoek naar de uitvoering en effecten van sociaal beleid [The social boundaries of policy: a study into the implementation and effects of social policy], Stenfert Kroese, Leiden.

29. Van der Veen RJ (1992) De transformatie van beleid [The transformation of policy] in Het bereik van de wet [The reach of the law], eds. Witteveen WJ, Stout HD, Trappenburg MJ, Tjeenk-Willink, Zwolle, 6380.

30. Boeije H (2010) Analysis in Qualitative Research, Sage, Los Angeles.

31. Hammersley M and Atkinson P (2007) Ethnography: principles in practice, Routledge, London.

32. Tedlock B (2005) The observation of participation and the emergence of public Ethnography in Handbook of qualitative research, eds. Denzin NK and Lincoln, Sage, Thousand Oaks, 467-81.

33. Stake R (2005) Qualitative Case Studies in Handbook of Qualitative Research, eds. Denzin NK and Lincoln YS, Sage Publications, Thousand Oaks, 443-66.

34. Denzin NK and Lincoln YS (2005) Handbook of qualitative research, Sage, Thousand Oaks.

35. Polit, DF and Beck, CT (2004) Nursing research: principles and methods, Lippincott Williams \& Wilkins, Philadelphia PA.

36. Corbin J and Strauss A (2008) Basics of qualitative research: techniques and procedures for developing grounded theory, Sage, Thousand Oaks.

37. Feuerstein M, Luff GM, Harrington CB and Olsen CH (2007) Patterns of workplace disputes in cancer survivors: a population study of ADA claims. J Cancer Survivor 1, 85-192.

38. MacEachen E, et al. (2012), The 'Ability' Paradigm in Vocational Rehabilitation: Challenges in an Ontario Injured Worker Retraining Program. J Occup Rehabil 22, 105-17.

39. Soklaridis S, Cassidy JD, van der Velde G, Tompa E and Hogg-Johnson S (2012) The economic cost of return to work: An employer's perspective. WORK 43, 255-262.

40. Anema JR, Schellart AJ, Cassidy JD, Loisel P, Veerman TJ and Van der Beek AJ (2009) Can cross country differences in return-to-work after chronic occupational back pain be explained? An exploratory analysis on disability policies in a six country cohort study. J Occup Rehabil 9(4), 419-26.

41. Pransky G, Shaw WS, Loisel P, Hong QN and Désorcy B (2010) Development and Validation of Competencies for Return to Work Coordinators. J Occup Rehabil 20(1), 41-48. 
42. Hoefsmit N, Houkes I and Nijhuis FJN (2012) Intervention Characteristics that Facilitate Return to Work after Sickness Absence: A Systematic Literature Review. J Occup Rehabil 22, 462-477.

43. Eikenaar T, Van Groenestijn M-H, De Rijk A and Meershoek A (2012). Goed bespiegeld, beter begeleid! De rol van grondhoudingen in re-integratiebegeleiding en de vertaling ervan in het reflectie-instrument 'MIRROR'. [Good reflection, better support! Frames of references in reintegration support and translation into the reflection instrument 'MIRROR'], Maastricht University Press, Océ Business Services, Maastricht.

44. Tiedtke C, Donceel P, Knops L, Désiron H, Dierckx De Casterlé B and De Rijk A (2012) Supporting Returnto-Work in the Face of Legislation: Stakeholders' Experiences with Return-to-Work After Breast Cancer in Belgium. J Occup Rehabil 22 (2), 241-251.

45. Hirschkorn KA and Bourgealt, IL (2008) Structural constraints and opportunities for CAM use and referral by physicians, nurses and midwifes. Health 12(2), 193-213. 



\section{Chapter 5}

Policy on professional support in work re-integration:

Disability management staff and trade union representatives' experiences in a Canadian setting

Karin Maiwald

Agnes Meershoek

Angelique E. de Rijk

Frans J.N. Nijhuis

Submitted 


\section{Abstract}

Background: In Canada and other countries, sickness absence among workers is a significant concern. Return-to-work policies developed by both employer and worker' representatives are preferred to tackle the problem.

Objective: We examined how bipartite agreed-upon return-to-work policy works from the occupational health professionals' perspectives in a healthcare organization in Canada. This is the perspective of disability management staff and trade union representatives who are given responsibility to implement RTW policy.

Methods: In-depth interviews were held with 9 professionals on their experiences with execution of return-to-work policy. Interviews were transcribed verbatim and qualitative, social constructivist, analysis was completed.

Results: The professionals experienced four main problems: 1) timing and content of physician' medical advice cannot be trusted as a basis for plans; 2) legal status of the plans and thus needing workers' consent and managers' approval can create tension, conflict and delays; 3 ) limited input and thus little fruitful inference in meetings; and yet 4 ) the professionals can be called to account for plans.

Conclusions: Bipartite representation in return-to-work policy process does not entirely delete bottlenecks in executing RTW policy. More room is needed allowing the professionals to get and keep quality RTW plans in place. Additionally, enhanced professionalism is needed to complete the RTW mandate given. 


\section{Introduction}

In Canada, as well as in other societies, sickness absence ${ }^{2}$ is a significant concern and challenge [1-3]. The health care workforce faces a higher risk for sickness absence [4]. Policymakers from various countries have been working for years and agreed upon a code to guide employers to adopt a positive strategy in managing disability-related issues in the workplace [5]. Return to work policies and procedures were developed to support early work re-integration of workers with disabilities (the inability to work due to illness while in employment) in Canada. These particular strategies to enhance participation in the workforce do not always yield the results expected from re-integrating workers' perspectives though [6-9]. In other countries, also workers' disappointment with early return-to-work (RTW) policy has been demonstrated [10].

In Canada - where the current study took place-, federal social security arrangements, provincial Occupational Health and Safety (OHS) regulations, Workers Compensation Act and collective agreements define disability management (DM) programming (also referred to as return to work programs) per industrial sector. To improve effectiveness of RTW policy, collaboration was sought with both employer and worker representatives: the so called bipartite policy-making approach. This approach has largely been institutionalized in Canada [11-12].

Bipartite involvement in RTW policy process is firmly believed to be an effective remedy to reduce sickness absence [13] as it is assumed that including employer and worker perspectives in policy will align policy to the complex practical settings and make it more workable [14-17]. But bipartite agreed-upon RTW policy in British Columbia (BC), Canada for the health care sector, as is the case with policy in general, seemed no guarantee that the policy is implemented as intended by the policy-makers $[9,16]$. In this study, we investigated the implementation through the eyes of the occupational health professionals.

In 2009, DM for the BC health care sector in Canada was reformed as part of the collective bargaining process between the provincial government, employer- and worker (trade union) representatives. Further, place-based stakeholders (e.g. human resources executives, disability management staff and trade union representatives) provided input in this policy process.

The finding of our earlier studies on the workers' and frontline managers' perspectives on this bipartite agreed-upon BC Healthcare RTW policy showed that the policies and procedures made these stakeholders indeed responsible in RTW processes. On the other hand, the workers and frontline managers considered themselves

\footnotetext{
${ }^{2}$ In Europe, work disability is often referred to as sickness absence. Even though the concepts are not entirely interchangeable, the legislative measures used to promote early work re-integration of workers with incapacities that are to guide work re-integration policy are similar.
} 
incapable to answer this responsibility because they were offered too little flexibility regarding involvement and interventions in RTW planning to meet their needs [18, 19]. Furthermore, these stakeholders did not feel supported by occupational health professionals in RTW reference.

Our current study focuses on the occupational health professionals perspectives' on this (same) RTW policy. This refers to the perspectives of those stakeholders who are given responsibility to deliver programming that addresses the needs of those workers considered able to return to work. They are disability management (DM) staff who report to the organization as well as trade union representatives who report to the respective union. The trade union representatives are included in this study as 'policy executers' because in Canada they are involved in supporting the worker during RTW by optimizing treatment and services, handling of compensation claims in consultation with the workers etc. [16]. The literature that takes a professionals' perspective on RTW policy illustrate the struggle of these stakeholders with their role in the RTW processes. For example, some scholars demonstrate problems around dependence and funding resources concerning that occupational health professionals experienced difficulties getting and keeping needed support in place [20-22]. Other scholars show problems around professional development in that professionals' body of knowledge and skills and interpretations (of rules, cause of ill-health) largely vary [23, 24]. In a recent study by Pranzky et al. [25] it was argued that other stakeholders are, in turn, not sure what they can expect from 'occupational health professionals' to deal with individual (and social) problems.

For the current study on occupational health professionals' perspective, a social constructivist view on the policy process is taken, which starts with the assumption that policy often turns out differently and in unexpected ways in practice [26]. The theory explains that this occurs because policies that have to govern everyday practice include abstract rules that are based on broad assumptions of the situations in that same practice. In doing so, policy permits discretionary space for those stakeholders who deliver the services and have to apply rules from the policy on individual situations [26, 27]. Discretionary space is in fact not a mistake of the policy but necessary to allow for including individual differences and contextual circumstances in decisionmaking in the execution of policy in practice. Thus discretionary space is thought to enhance fairness in processes. However, as this space also counts for transformations in policy in practice, the policy itself does not predict how the discretionary space is used in practice. In applying the abstract rules from the policy to concrete individual cases, rules and policy have to be interpreted. This process of interpretation-in practice is influenced by means of professional norms, social costumes, peer norms, moral beliefs and existing practices which may transform the meaning of the rules and policyas intended [26-31]. To really understand how this transformation of policy takes place 
in executing the policy, empirical research is needed. Meershoek et al. [28, 29], for instance, demonstrated with empirical research how administrative procedures can have counterproductive effects in the Dutch setting of work re-integration. These authors concluded that, in practice, the duty for the employers to work on re-integration of workers who reported ill became an empty letter, due to formal procedures and control mechanisms. The execution of policies is thus a highly contextual enterprise [26]. In this article we investigate how the RTW policy transforms when executed in practice.

\section{The RTW policy studied}

The BC Healthcare RTW policy under study contains the following aspects. Absent workers should re-integrate before full recovery of either their incapacities has taken place. They are expected to participate in place-based RTW programming, which is voluntary in the first six weeks of sickness absence but mandatory thereafter. The employer has an obligation to make every reasonable effort to find a way to accommodate the worker (e.g. must carefully scrutinize their workplace for potential jobs into which the worker can be placed or, if equipment is required, investigate the cost of purchasing such equipment). The place-based professionals are expected to support the frontline managers and workers to complete their responsibilities in RTW and guide them through the various complex systems. More precise, a disability management professional (DMP) (so called: case manager, RTW advisor) is expected to ask for worker's input (e.g., perceived limitations for work on either a straightforward plan for less than six weeks in duration or a complex plan for longer than six weeks) as well frontline managers' input in RTW planning (e.g. suggest adjustments on the plan). Next, this DM staff member is supposed to combine the differing perspectives on the plan in RTW in consulting with a trade union representative in order to meet judicial arrangements (e.g., workers' rights, collective agreements) in RTW process. The DMP may invite colleagues/other DM staff, whom have a range of specialties to assess limitations the worker has to meet work demands. For example, they may ask a placebased rehabilitation advisor (with differing training background as physiotherapists, kinesiologists, etc.) to assess the worker and recommend treatment and services on a plan (e.g., first offer external-based 'fitness' programming before RTW in the workplace, suggest place-based support services such as a 'supernumerary' (an extra worker) and duration). Last but not least, the DM staff must include the consent of the worker's physician for re-integration at the workplace and seek funding approval by financial institutions (e.g. insurance/compensation agencies, employer) for needed support in RTW. Stakeholders were informed about the RTW policy in several ways: an organization-wide press release; several presentations to various management levels of the organization and to different (smaller) work sites; a training session for all occu- 
pational health professionals (DM staff and trade union representatives); participation in redefining policies and procedures (DM staff and trade union representatives).

\section{Social security in Canada}

In Canada, as in many other countries, RTW policy only adds to what is already arranged by social security legislation. In the $\mathrm{BC}$ healthcare sector, the employer is responsible for disability benefits for workers who experience work-related injury/illness under the Compensation Act and OHS regulations. If sickness absence is deemed not work-related or is a result of a motor-vehicle accident that is non-work related, there are various other insurance and benefits systems. Employment status for regular staff is secured for about two years. Benefits cease to be paid when a worker fails to provide satisfactory evidence of medical disability during the benefit period. For all workers, basic health care costs are covered on the basis of a public healthcare system. The employer pays the full cost of coverage of this public benefit for regular (working) staff. Extended benefits and coverage for workers vary per cause of sickness absence and differ per collective agreement.

\section{Aim and research questions}

The aim of this article is to gain deep insight in the occupational health professionals' (DM staff and trade union representatives) experiences in the execution of RTW policy in a Canadian healthcare setting. How do these stakeholders interpret and apply the reformed bipartite agreed-upon RTW policy? Insight in and understanding of the work context in which the regulations and policy have to function can help to formulate regulations and policy that are better adjusted to the dynamics of daily re-integration practice in this work context, and reduce unintended consequences.

The research questions are:

1) How do the occupational health professionals interpret their new roles to advice and facilitate RTW planning?

2) What are the occupational health professionals' experiences with executing the RTW policy?

\section{Methods}

This study took place in the largest and considered leading health organization in BC, Canada which provides general and specialized public healthcare services to a large portion of the provincial population. Public acute health care services are offered in their 13 hospitals across a vast geographical area whereby they also offer a number of other services including, primary care, community-based residential and home health care, mental health, addiction services and public health. As per collective agreements, 
this organization created place-based RTW policy for its 22,000 workers. To find answers to our research questions, qualitative research methods were selected [32-34] and to obtain good insight on the experiences with and perceptions of the occupational health professionals on the RTW policy, in-depth individual interviewing was selected as the best method of data gathering [33]. The first author performed the data collection and had the lead role in data analysis. Besides the involvement of the other authors, two staff members of the Occupational Health and Safety Agency for Healthcare (OHSAH) of BC supervised the data-collection in Canada.

\section{Study sample}

The inclusion criterion was: the occupational health professional had or still was involved in re-integration of workers with work incapacities anytime between April 2009, when the RTW policy came into effect, and June 2010. Professionals who only had experiences with re-integrating workers previous to April 2009 were excluded from this study. Purposive sampling with various recruitment strategies were used to maximize variability in perspectives and to acknowledge the opportunity to obtain information from the full range of place-based professionals for intensive study $[32,35]$. Interviews with (different) professionals were held between September and December 2009 and two more professionals were interviewed in May 2010 to deepen our gained insights. When a professional initiated contact to participate, he/she received a detailed four-page information sheet and upon agreement to participate an interview was booked. Interviewees ranged in representative status and authority level, differed in age from 35-55, included both new and experienced professionals, managed various caseloads and delivered differing support services at multiple work sites (see Table 1 for a description of participant characteristics).

\section{Ethical Considerations}

For this study, support was obtained from the organization itself and various trade unions (three - all of which had been part of the policy process) to conduct this study. Further, we received the approval of two local Research Ethics Boards from the University of $\mathrm{BC}$ and the healthcare organization. Interviewees were made aware they were free to refuse to participate and were welcomed to ask questions and express concerns about the study any time. Informed consent forms to participate, record the interview, and review the findings were signed prior to each interview. Participants were given the option to receive the final report.

\section{Interview procedure}

The topic list was based on administrative materials about the RTW policy formal documents and draft papers (e.g., brochures, procedures on DM that were collected via 
DM staff and the organization' intranet), RTW literature and from policy science. The topic list included the following topics: on imposing rules and responsibilities, monitoring and reviewing, decision making, controversy and conflict, influence and authority structures in RTW. To increase validity, interviewees were invited to address these topics by means of various real worker cases they brought up themselves during the interviews. They were also given the opportunity to elaborate on topics they brought up on RTW in this setting. Interview questions were fine-tuned as data collection progressed. The individual face-to-face interviews were conducted in private offices, took from $1 \mathrm{~h} 30 \mathrm{~min}$ to two $\mathrm{h}$, and were taped and transcribed verbatim.

Table 1 Detailed summary of participant characteristics

\begin{tabular}{|c|c|c|}
\hline \multicolumn{3}{|c|}{ Re-integration professionals and trade union representatives (9 interviewees) } \\
\hline \multirow{6}{*}{$\begin{array}{l}\text { Participants supported re- } \\
\text { integration of workers with cause } \\
\text { of sickness absence of } \\
\text { (as diagnosed by physician) }\end{array}$} & \multicolumn{2}{|l|}{ Medical disorder } \\
\hline & \multirow[t]{3}{*}{\begin{tabular}{l|l} 
& Orthopaedic*
\end{tabular}} & Work-related \\
\hline & & Not-work related \\
\hline & & Motor vehicle accidents \\
\hline & Systemic & \\
\hline & \multicolumn{2}{|l|}{ Mental disorder } \\
\hline Representative status** & Report to the organization & $\begin{array}{l}\text { Report to the union and the organi- } \\
\text { zation }\end{array}$ \\
\hline Authority levels** & $\begin{array}{l}\text { Disability management profes- } \\
\text { sionals; } \\
\text { Workplace rehabilitation } \\
\text { advisors }\end{array}$ & $\begin{array}{l}\text { Union stewards; } \\
\text { Union leaders } \\
\text { (of three different trade unions) }\end{array}$ \\
\hline Gender & 6 Female & 3 Male \\
\hline Age & \multicolumn{2}{|l|}{ Differed in age from 35-55 } \\
\hline
\end{tabular}

\section{Analysis}

Qualitative analyses were completed to gain deep insight into stakeholders' perspectives [36, 37], within which detailed understanding of interviewees' experiences, actions and practical reasoning was gained $[33,34]$. By identifying, coding and categorizing experiences and perceptions [38] and, then, pattern-seeking to interpret experienced challenges and opportunities [32] we were able to unravel how practical bottlenecks affected RTW from stakeholders' perspectives. Our interpretative analyses [33, $34,36]$ focused how professionals see the role of policy, legislation, organization characteristics and the individual context plays in RTW activities. The analysis of RTW policy as experienced and perceived by these stakeholders resulted in an empirical description of decision making processes in RTW and experienced bottlenecks. A review process was put in place to ensure the accuracy of the descriptions, emerging themes, and 
revealed arguments between the authors. Firstly, the first and second author performed the first-phase of the data-analysis (structuring data, initial coding). Secondly, the interpretations and patterns were discussed during the process of analysis among all authors. Member checking, to review preliminary study findings for the purpose of accuracy by interviewees, was not done in this study.

\section{Findings}

On the basis of the experiences and perceptions of the professionals, we identified four main phases regarding decision making processes in RTW processes, which we called: (1) Assessing for RTW plan; (2) Facilitating for RTW plan; (3) Execution of RTW plan; (4) Re-negotiation for RTW plan. In practice, re-integration is not clearly structured; these four decision-making phases are not simply onward and upward but are 'on-going'. We describe four domains of experience-aspects or bottlenecks that dominate in these phases according to the professionals. The bottlenecks are not limited to the phases in relation to which we describe them. We start the description of professionals' perspectives with a short factual summary of what the policy says about this phase, to allow the reader to place the findings in context.

\section{Assessing for RTW plan: Difficult start}

The RTW policy dictates RTW planning to start as soon as the worker reports sick for work. In this phase, DM staff need to focus on assessments to prepare advice for a RTW plan. The professionals have to adequately define worker's limitations (and how they will develop) to know where to adapt the workplace to or, have a supernumerary option on the plan (for regular staff - as part of the collective agreement).

Assessing for a RTW plan is experienced as a rather doubtful process. The professionals mentioned three concerns. The professionals' first concern was that preparing a worker's file/dossier was more difficult than they thought. They experienced that requests to prepare a RTW plan and start programming came from different directions and that the next steps were unpredictable.

'That comes from a family physician or a specialist or it could be from WorkSafe BC or it could be from our Long Term Disability carrier, it could be anything; ( . . ) I review basically any benefits, because again, who is funding it?' [P9]

Besides difficulties experienced in preparing workers' files, the professionals' second concern was that medical advice could not be trusted as a basis for a RTW plan. The 
professionals experienced that due to workers' financial pressures (e.g. no or exhausted sick bank, that is a system of sick leave credits according to a formula of hours paid per month of service, which can be utilized in the event of sick leave deemed non-work related) the worker was sent back to work by the physician, despite not having recovered enough from their illness/injury to meet the demands of any job, be it their former job or another one.

'They have no income coming in so they need to get back doing something. Yeah, that's the main reason why they would come back earlier than they should.' [P3]

Medical advice could also not be trusted, because the professionals felt that this was not professional as the fit notes often changed within a worker's re-integration process and physicians relied too heavily on what workers told them they could do for work.

'I had a case where a doctor wrote six different notes. Can work, can't work, can work, can't work (. . .) it's not going to be successful (. . .) They are looking at their stingy reasons why the person wants to return to work. "I need funds. I'm bored".' [P4]

Medical advice (including notes from community health - and vocational rehabilitation professionals) could also not be trusted because worker's limitations were inadequately defined in relation to worker's actual job requirements.

'A doctor may say: "Don't lift more than 5 pounds." So where have they got that 5 pounds from? (... ) And if you really want to get sticky, is that in a day, or in every hour?' [P1]

Moreover, given medical advice on work limitations did not line up with the demands on the floor according to the professionals.

'And is the doctor aware of the fact that when he's making these limitations, well, really in the Return To Work that means that they can't do their job. So really, that takes - that would require either an accommodation, a temporary accommodation or whatever.' [P2]

Professionals explained they needed (more) time for assessments to define limitations and needed support on a RTW plan because of the difficulties they had to collect information to prepare a file and unreliability of medical judgments. The professionals handled these problems in different ways. Some DMPs reported that at times they 
went back to the involved stakeholders, including referring/treating physicians to clarify a worker's situation.

'If it doesn't match, what is the area of concern? (...) We need to have the medical because I have employees that will push themselves too much, right, and we have to show due diligence on our [employer] part.' [P9]

In other cases, the professionals mentioned that by getting a supernumerary (extra) worker in place potential problems in re-integration would likely be minimized.

'Ninety-five percent of our Return To Works the employees are supernumerary ( . . . ) So in most cases the Return To Works are feasible because they have that ability to step away and they're attached to a person, right?' [P9]

In sum, the professionals experienced that despite their willingness to meet the expectation to define worker's abilities for a RTW plan, this effort might not go well because file and medical advice conditions do not orient themselves to the protocol. The professionals find that if they could improve their understanding of health issues that potentially affect the worker's capacity, they could get the workload accurate. Now, they tended to emphasize sending the worker back to work with a supernumerary.

\section{Facilitating for RTW plan: Tough interactions}

Prior to entry into RTW programming, the professionals are expected to hold a group meeting to give workers and frontline managers a chance to modify the (draft) RTW plan, after which the plan needs to be confirmed in writing.

Facilitating for a RTW plan is experienced as a rather unpredictable process and the professionals mentioned three concerns. The professionals' first concern was that health-related issues and re-integration needs could not be discussed in an open manner due to privacy rules (professional health act, collective agreement). To meet confidentiality demands, they narrowed the meeting on work limitations in terms of reduced (physical) tasks and hours on the plan.

'They won't talk about what the actual medical condition is. So they'll only talk about restrictions, what a person can and can't do, what they can lift, how long they can stand, how long they walk, how long they can sit, based on the medical [advice].' [P4]

From this perspective, the professionals' second concern was that the thinking along approach to planning was difficult to carry out. Some professionals experienced that 
tension and conflicts between for example frontline managers and trade union representatives as well as among professionals occurred during meetings to formalize plans. One DM staff member explained that this way:

'The client's just sitting there going, "What's going on here?" Like they were happy with the way it [the plan] was drawn up in the first place and suddenly this back and forth is going on. They're just sitting there taking it all in, going "Uh, should I be here for this?".' [P3]

In similar vein, other professionals explained tension and conflict occurred during meetings because they experienced that frontline managers disputed the medical recommendations that were given for timelines on the plan.

'A lot of times the doctor will say, "I think it should be six weeks." The employer thinks every doctor says it should be six weeks so they're going to say two weeks, right? Because it's supernumerary, right? So there is a cost to the employer (...) I'm generally successful in getting them to agree whether it should be, generally it falls around the four week mark, like I say. Most Return To Works in my experience are four weeks.' [P4]

The thinking along approach for the plan was further difficult because this approach was not felt to be the best for all medical conditions. More precisely, due to (varied) unpredictable conflicts and tensions between frontline managers and union representatives, some professionals felt it was better to discuss the situation of the workers with diagnosed mental health problems and re-integration plans in separate stages - as to not upset the worker.

'Mental health and/or addiction issue (. . ) there's got to be some sensitivity there; I want to make sure that we're all on the same page before we meet with an employee with that type of a condition.' [P9]

Another difficulty that hampered the thinking along approach for the plan was the delays caused by organizing the required place-based meetings. The professionals felt that delays or lagging RTW was not in line with early re-integration objectives (using up sick time bank, or lack of it; productivity demands). 
I would try my best, because I don't want employees being off sick or on paid sick if they can return back to work [... ] but setting up meetings can be a bit of a challenge with everyone's schedules [... ] that's probably one of the most timeconsuming aspects.' [P6]

Professionals explained that they need (more) space for finalizing plans by difficulties they have to bring perspectives together (privacy rules, case specificity) and unpredictability how meetings will go (tension and conflict between the stakeholders, administrative delays). Depending on the perceived cause, the professionals chose different ways to handle the problem. For example, there are professionals who felt that going ahead before formalizing the plan can keep re-integration from lagging.

'And so I'll outline the gradual Return To Work, I'll send it in an email to the union, I'll send it in an email to the manager. I won't start a gradual Return To Work if I don't hear back from the manager because it's their employee; it's their department. I want to make sure they are aware. But if I don't hear back from the union, because they're out of the office or no one's getting back to me, I won't delay the gradual Return To Work because I feel like, "We can meet next week".'[P6]

Some professionals felt that taking a careful line to formalize the plan can be a more successful approach.

'If you don't have everybody in agreement it's going to skew sideways (. . ) It has to be an agreed-to plan that is bipartite, tripartite, whatever you want to call the process now. It is a collaborative approach (. . . ) especially somebody that's been off for an extended period of time, seeing that the supports are in place (. . ) it's a huge piece.' [P9]

In sum, the professionals experienced that despite their commitment to facilitate meetings for formalizing a RTW plan, this process is hampered because open discussions and the think along approach cannot always be realized in practice. They limited the discussion on limitations and hours, and in doing so, they focused on getting the plan approved (and obtain workers' consent to participate). Having a discussion on timelines is felt important because the frontline manager/employer has to organize the support services (and thus needs to approve the plan). To limit the discussion on worker's limitations is felt necessary because the frontline manager has to accommodate the worker or to prove undue hardship. 
Execution of RTW plan: Stubbornness of the reality

The professionals are expected to monitor the execution of the RTW plan and progress. They are supposed to signal if problems occur and to use their (professional, practical) insights to respond appropriately.

Execution of a RTW plan is experienced as a rather bumpy process and the professionals mentioned two concerns. The professionals' main concern was that the plan was not working as planned. There are professionals who experienced (i.e. during a work visit) that the worker could not meet the work demands outlined in the RTW plan. They felt it was important to try to get a sense of how the worker was doing (at work, outside work) but expressed feeling unsure how to interpret what the workers said regarding the extent to which they were able to meet job demands.

'You still base it on a lot of subjectivity in respect of what the person's saying, right? (...) really you're relying on the employee to give you details of how they're doing.' [P1]

Regarding the interpretation of what workers themselves tell about meeting the job demands, some professionals reacted by contacting the worker to alert them they need to stick to the plan (i.e. by means of education, encouragements). If that did not work they responded by recommending to change the plan (i.e. extension, delay RTW, try getting another service through the family physician).

'I'll just follow them through the Return To Work and ask them if they're having any difficulties with anything. I might observe them while they're doing some of their activities to see if there's anything I can give them support with or show them a safer way, or maybe a more efficient way of doing something [ . . ] maybe give them more time [...] If it takes a lot longer than that then maybe they're not ready. Maybe they should stay off a little bit longer. But unfortunately that's not up for me to say; it's up for the doctor to say.' [P3]

This reaction is based in their idea that workers have tendencies to be hesitant (due to various reasons), do too much (due to differing causes) and/or have other thing going on they do not know about (due to different views).

Plans were furthermore not working because the worker's manager did not implement the plan according to the professionals. For example, they heard from the worker that the frontline manager did not follow-through with an agreed-upon services i.e. the supernumerary option was not in place. 
'Yeah, they [the worker] mainly say that supernumerary or the plan looks great on paper, but in practicality it doesn't happen.' [P1]

Regarding the experience that workers say that frontline managers do not implement the plan, some professionals reacted by contacting this manager.

'You're just giving advice (... ) It's mainly to make them aware that this person is an extra on their ward (...) They're an extra, the union doesn't want the person being taken advantage of, right? They're very tricky in that you're not telling the supervisor what to do. Right? You're just giving advice (. . . ) So it's mainly want of a reminder.' [P1]

This reaction is based in their idea that managers have many organizational responsibilities and do not understand illness processes. Moreover, the professionals' reaction is based in rooted hierarchical structures to address the managers.

Plans were also not working because a worker and frontline manager did not get along to follow-through on the plan. For example, they experienced hearing from colleagues about work-relations complications.

'Okay, I know that this relationship that someone's had with, let's say their manager or their unit or whatever it is hasn't been the best scenario so you can almost see it coming (...) we're dealing with people who interact. You know, we're not robots, right!' [P8]

Regarding difficulties in the frontline manager-worker relationship, some professionals reacted by giving, what one person named, a 'mother' spiel to try to get the worker and manager talking again. [We note that not all professionals perceived having authority to approach managers and workers this way].

'I give what I call my 'mother' spiel ( . . ) So it's sitting down and actually outlining again the requirements (...) My role is to get them talking again, right, between the two of them so that they understand what the role is.' [P9]

This reaction is based in rooted approaches to manage RTW difficulties. As well, this reaction is based in their idea that a frontline manager and worker just sometimes do not get along and do not progress together to meet RTW objectives (due to interpersonality issues) but must meet set forth requirements. 
Regarding plans not working for differing reasons, professionals explained they needed clearer channels to face these difficulties.

'There's not a formalized process to go back and to visit this scenario and say, "Well, in this scenario, the accountability lies in the system . . ." It's not really that clear, I guess; it's probably a little grayer than that (. . . ) Those things aren't always made completely clear to me. I don't get all those conversations (... ) They're our co-workers, right, so we know a little bit about them, so we can kind of sense what's happened and kind of get a scenario.' [P8]

In sum, the professionals experienced that despite their willingness to meet the expectation of executing the RTW plan, this can be complicated because workers and frontline managers do not connect to the plan and difficulties in worker-manager relationships are experienced. They found that if they get a better understanding of worker's limitations to meet workload they can recommend changing the plan but sticking to the plan is imperative. To focus on sticking to plans is felt important because the worker has to show medical evidence of illness to change the plan and the employer has a duty to accommodate the worker (or to prove undue hardship). The professionals realized they perceived practical problems differently but felt clarifying them did not really happen (for making the judgment or choice how to adequately answer this).

Re-negotiation for RTW plan: Be left empty handed and having little control

According to the policy, the professionals are given time to gain insight in workers and workplace' perspectives and integrate these ideas in RTW planning. It is the professionals' responsibility to re-negotiate the distribution of responsibility and support demands, including to obtain advice (internal, external) if they are not satisfied with decision making processes in RTW processes.

Re-negotiation for a RTW plan is experienced as a rather potholed process and the professionals mentioned two concerns. The professionals' main concerns were that improving certain situations and finding solutions if a plan continued to fail was more difficult than expected. Some trade union representatives experienced too much leeway for frontline managers to implement the plan e.g. around the supernumerary option. What is more, the trade union representatives felt they were not really in the position to speak to a manager about implementing the plan. 
'So there's a barrier to come back because the advisor [DM staff] isn't pushing the manager to help set things up (... ) Because it's not me as the union steward. I have to agree to the process is of due diligence (.. ) but I'm not the one that's going to facilitate that.' [P8]

On approaching the frontline manager to improve the situation, DM staff experienced however no flexibility to find out worker's real work abilities due to protective union rules. More precisely, DM staff perceived that to keep, again and again, a supernumerary on the plan did not help to find out actual worker' abilities.

'Now the problem with than come is the union, who says that the person cannot have their own patient, right? You can't assign them a patient. Somebody has to be over them. That's fine, but the main thing is you need to give them a patient to see how they are doing.' [P1]

In similar vein, some union representatives perceived not enough progress was made to fit the work better to the individual worker by the DM staff. They felt that due the large size of the organization this should be handled better.

'Their level of undue hardship [name organization] is much higher - if they can't facilitate someone exactly here but they could facilitate them over here or over there, or they could do some modifications to things that would allow for that person to come back, right? And that's what they're expected to do.' [P8]

On attempts to fit the work better to the individual worker, DM staff oftentimes experienced that the frontline manager countered them that there was no (accommodated, alternate) work available the worker could do. Generally, DM staff felt little support by the executive management and union-leadership to meet this RTW demand.

'They [managers] didn't want to have union problems on their doorstep so a lot of them were very nervous about it, they didn't see the point in it (. . ) I don't have any authority, okay, so I'm going to go and I'm going to preach to a manager that they should be doing transitional work. Because I told them so? Maybe it should come from higher up.' [P3]

The professionals handled these difficulties with not being able to enhance the plan in different ways. The first way was by calling another team meeting. According to the professionals, this could be done by any of the professionals and can work well to enhance the plan. 
'Sometimes it's by us, to say we really need to talk about this plan. I think that was one scenario; and the other one was just the advisor recognizing that we really needed to readdress a bunch of the issues again, and so brought everybody back to the table. I think that was good.' [P8]

Other good experiences to handle difficulties was by contacting senior professionals for suggestions, advice and help. Generally, the reaction to contact 'authorities' was felt as a fine line: the professionals perceived asking for higher-level support could be viewed as a 'push' within RTW planning teams, which could negatively affect team/workplace relations in turn.

'And we don't really want to bring [Labour Relations] into the picture because she plays hardball, right? (. . . ) it's a fine line. Like how much you push for certain things to facilitate that and how you try to keep a good working relationship with the people you are dealing with.' [P8]

In accordance with the (senior-level) professionals' experiences of the situation, they interpreted difficulties in different ways and thus responses to enhance the RTW plan varied. For example, a trade union representative (leader) perceived that a way to try to improve the situation was by arguing with a manager (e.g., because they oftentimes do not understand illness processes, they said).

'Oh, you don't want a diabetic on your floor?" "That's different!". I said: "Oh, is it? ( ... ) So every time they say the words 'drug addict' I say 'diabetic' and then I finally get them [the frontline manager] along, and they say, "Okay. We'll take her back.' [P5]

Another positive way to improve RTW planning was, according to senior-level professionals, to attempt the frontline manager and worker to work out troubles by coaching. For example, a trade union representative (leader) said they sometimes knew about the workplace/manager' dilemmas to meet organizational demands and they perceived the worker was really trying hard to stay at work.

'Rather than get involved from a union perspective (. . .) we sent him directly to the manager, and [with coaching] said [cannot cope with workload demands, can you prioritize for me?]. The manager's response to that was (...) "you're saying the same thing as the two previous people. I'm going to try to get a budget for [extra staff]".' [P4] 
Nevertheless, all professionals experienced that at any point in time efforts to improve plans had to stop because insurance/compensation agencies' coverage for benefits ended (due to disproving medical evidence of illness or prove undue hardship). They felt they could neither oversee funding nor predict how funding would be organized.

'If it's not a WorkSafe BC claim and it's someone who's had an illness or an injury outside of work, then there's not as much money around to support a long Return To Work so the shorter the better. So it all depends on the circumstances as well.' [P3]

In sum, the professionals experienced that despite their willingness to meet the expectation of re-negotiation for a RTW plan, this advancement could be problematic because genuine dialogue about gained insights around particular difficulties did not come off the ground. As the professionals could not reflect on and analyze perceived problems in RTW processes, the professionals felt empty handed and asked for an extra meeting or help from senior-level professionals who had more power in the organization. They found that if they gained insights in worker's and frontline manager's perspectives on the plan (regarding work stress, when they observed the worker's ability to cope or control work demands; hearing/understanding the manager' dilemmas) they are better able to bring the perspectives together and then RTW planning is more effective. The professionals experienced that despite their efforts to combine the perspectives on the plan (i.e. demanding more effort, offer support to relate to each other's account), impossibilities to come to agreement and sudden funding stops occurred. The professionals then feel having no control in decision-making in RTW yet can be called to account concerning RTW process (and outcomes).

\section{Discussion}

In a leading healthcare organization in BC, Canada, bodies of worker and manager representatives were involved in RTW policy process. The bipartite agreed-upon RTW policy included (early) re-integration of workers with incapacities as well as inclusion of the workplace' and worker' perspectives in RTW planning. The study examined how the execution of this specific RTW policy was experienced by the occupational health professionals, that is, the disability management (DM) staff who report to the organization, and the trade union representatives (in Canada they are involved in actual worker support) who report to their respective union and also to the organization. A social-constructivist perspective was taken on the policy execution by these professionals, aiming to highlight the processes of giving meaning to the policy in its actual 
work context. We conducted 9 interviews with the professionals who were each involved in the RTW process of various re-integrating workers at different workplaces. We then analyzed how the professionals interpreted the policy and what problems they experienced in executing the RTW policy in practice.

The professionals took steps to meet the organizational objective to encourage participation of both the frontline manager and worker in RTW planning and combine these stakeholders' perspectives on the RTW plan. Our study illuminates in detail that the professionals experienced four main problems: 1) timing and content of physician' medical advice cannot be trusted as a basis for RTW plans; 2 ) legal status of the plans and thus needing workers' consent and frontline managers approval can create tension, conflict between the various stakeholders and administrative delays; 3) limited input and thus little fruitful inference in meetings; and yet 4) the professionals can be called to account for RTW plans (in spite of being empty handed and having little control). Given the persistent importance placed on collaboration among stakeholders to the effective management of work disability [16, 17, 39, 40], we demonstrate that according to the professionals the bipartite agreed-upon RTW policy only partially supports RTW, and the policy does not withstand the many problems arising in practice. The new directions can even be counterproductive to achieve this mandate.

\section{The discrepancy between policy and concrete situations in context}

According to the social constructivist view on the policy process discrepancies between policy and concrete situations exist. This is because policy consists of 'general or abstract rules' that are based on assumptions of the practical situation which do not always reflect the actual situation. In this paper we identified several assumptions in RTW policy that create difficulties for professionals to execute the policy in practice and we have discussed how the stakeholders deal with those tensions and how that impacts RTW process.

In bipartite agreed-upon RTW policy the importance of both worker and frontline manager involvement in RTW planning is acknowledged, and both these stakeholders' perspectives have to be included on the RTW plan. This feat is supposed to get done with the help and insights of trained occupational health professionals. A first assumption in this RTW policy is that at the moment the plans have to be defined, medical advisors (physicians) can provide information relevant for planning this re-integration. In addition, it is presumed that the professionals have collected medical, social and financial information in the context of this individual situation. Although medical and occupational health professionals demand workers and managers' input, these professionals ultimately cannot predict what the limitations and possibilities of the workers will be and how they will develop. This results in plans based on inadequately defined work limitations. A second assumption in this RTW policy is that 'joint meetings' are 
the best approach to guarantee that deep-rooted differing interests of frontline managers and workers are brought forward in discussions. In addition, it is presumed the professionals can eventually bring the differing perspectives together on the plan in the work context (and social security system). Nonetheless, meetings are far more vexing than presumed. Even though the professionals get together they experience they cannot facilitate the dialogue that is necessary to overcome differing appreciations of a worker's progression to meet the work demands. They cannot resolve the distribution of responsibility and support demands and moreover, they feel that they cannot break established structures.

The disability management staff and trade union representatives thus experienced bottlenecks in implementing the RTW policy. This group perceived that more flexibility was needed to allow for getting and keeping quality plans in place regarding capricious RTW process, including unpredictable recovery and unforeseen health issues. This was because disability management staff and trade union representatives felt they could not truly fulfill their function to get the perspectives on the RTW plan. Further, patient confidentiality made it, according to the professionals, impossible to discuss individual worker's health-related issues and limitations (medical proof of as well as perceived) to meet work demands with other stakeholders; trade union stewards who were supposed to advice on the workplace and OHS Regulations/collective agreements did not feel comfortable to point managers in the right direction; disability management staff who were expected to get the perspectives on the plan did not feel supported to come with possible solutions that could thwart workers' right for protection as well as chance funding/earning arrangements. Because influences by contemporaneous privacy rules, social hierarchy structures and judicial arrangements were too fickle, this group of deliverers did not feel well-equipped, actually, stifled to complete the RTW mandate given and combine this with the other organizational objectives. For all these reasons, this study demonstrates a paradox in the execution of the RTW policy by professionals: inflexibility and inability of arrangements for RTW in the policy affect the professionals' chances in achieving the RTW objectives in sequence with the specific characteristics of this work context.

The current findings are in line with earlier studies in the same setting among workers [18] and frontline managers [19]. These stakeholders perceived a lack of flexibility regarding timing and involvement. This was because both the workers and managers experienced that the RTW process was unpredictable and their expectations that the occupational health professionals (and their employer, agencies) will support them to coordinate RTW in deliberation with them stayed unfulfilled. For example, in RTW planning, both the workers and frontline managers found it troublesome that RTW 
plans could not be modified on the basis of practical ideas and experiences. They felt that details were not worked out. To follow-up on the agreed-upon RTW plan, both groups found it bothersome that when RTW did not work as expected - for example when diverse, sudden and unexpected changes in a worker's capacities occurred neither disability management staff nor trade union representatives took concrete action. Time and again, both the workers and frontline managers encountered that services (administrators) tended to be unresponsive to support them in RTW and they then felt unsubstantiated to complete their responsibilities in RTW in combination with the demand to meet other organizational objectives. The findings of these studies therefore support our conclusion that the professionals (DM staff and trade union representatives) and frontline managers and workers can ultimately do nothing but function suboptimal in RTW. We purport that the policy makers' assumptions are inadequate: they assume predictability of RTW process, and are far too optimistic about the idea that if you just involve everyone in RTW planning than everything in the work context will turn out fine. In turn, the discretionary space is left too small in places and becomes a muffled space when it comes to bringing the differing perspectives forward and on the RTW plan. Therefore, stakeholder representation in the policy formulation phase will not lead per definition to a policy that better fits practice.

\section{Limitations}

The number of interviewees involved in one setting may be seen as a limitation. Bias in case selection could not be avoided as the respondents were self-selected. Yet our methods ensured the selection of a highly diverse range of occupational health professionals (which in Canada includes both DM staff and trade union representatives) and this purposive sample served our specific need to examine how RTW policy functions from these stakeholders' perspectives. This study is one of few who examine (differing) professionals' perspectives on RTW policy. In addition, the interviewees also reported good experiences (e.g., calling an extra team meeting sometimes helped to get all noses in one direction, coaching between the worker and frontline manager sometimes helped to enhance planning) and are thus not a selective subsample of those with only negative experiences. Although saturation might not have been reached on the practice of RTW planning in the entire BC healthcare sector in Canada, the interviews still show relevant bottlenecks in RTW-policy. Using both a theoretical framework to design this study and analyze the data supports trustworthiness of findings and gained detailed insight into various mechanisms which hamper implementation of the RTW policy and how that creates troubles (that do not seem insoluble though). Thus, this study contributes to fill the knowledge gap on the professionals' perspectives on RTW policy and that can, in turn, support policy developments in Canada. 


\section{Implications and recommendations}

Several implications of the findings of the study for practice and recommendations for further research can be made. The results of this study clearly demonstrate friction between a bipartite agreed-upon RTW policy and policy execution. To address this, occupational health professionals (DM staff and trade union representatives) in the practical setting really need more flexibility on arrangements to allow for adjustment of individual plans, which is in line with conclusions from research in the Swedish context [40]. Also, continual adjustment and attuning of the plan must be made possible in terms of financial support in the work context in case of work disability [41].

Another vital point for practice improvement is that professional strategies are supposed to fill the gap between policy and individual circumstances [30]. As Westmorland et al. [42] repeated, everyone agrees that professionals at various levels can advise on work adjustments in a way that these fit workers' limitations. In practice, however, involvement and professional measures in a RTW process is anything but a straightforward drill. Supporting RTW is a social process, in which emotions, uncertainties, differing perspectives and various interests play a role. Professionals in our study struggle with this social dimension of RTW-support. They don't seem to be very well equipped to coach such dialogue. For starters, the rules from the policy don't leave enough room, but, what is more, it can be questioned whether professionals are educated enough to coach a deliberative process of this kind. This social dimension in RTW, requiring more expertise from professionals than they actually have, is also indicated as a key point in conclusions from research in the Dutch context [43]. Thus, how professionals are trained and educated for improving RTW guidance in complex practices and how the implementation of these professional strategies is sealed in work contexts seems a direction for in-depth study [25, 43-47].

While the findings of this study on RTW policy are specific to this local context, there are lessons to be learned for other settings. In the first place, RTW policy implementation is linked to the social security legislation. The current positive attitudes of professionals in RTW development might be rooted in the extensive RTW legislation in Canada. Lack of professionals' involvement in RTW developments is found in settings with dearth of legislation, such as in the US [25]. Second, despite regulations and commitment regarding RTW, there can still be many problems in practice. More flexibility in arrangements and expertize in collaborative efforts for sickness absence is needed, which is in line with conclusions from research in various public health contexts [25, 43, 48-49]. To improve our understanding of implementation processes, future studies how bipartite representatives in the RTW policy process and other policymakers grasp the intention of involvement (e.g., important differences in arguments, what demands do they make on collaboration in RTW planning and expected outcomes) in this and other public health contexts is warranted. 


\section{Conclusions}

Bipartite representation in return-to-work policy process does not entirely delete bottlenecks in executing RTW policy. On the one hand, more room is needed allowing the professionals to get and keep quality RTW plans in place (regarding timing of involvement, short and finite time frames, and strict formalized plans from start reintegration - because RTW process are capricious, including unpredictable recovery and unforeseen health issues). On the other hand, enhanced professionalism is needed to complete the RTW mandate given. The findings of this study on executing RTW policy in the practice deepen those found in studies among workers who tried to re-integrate and one among the frontline managers who were involved in re-integration planning of (their) workers in the same setting $[16,17]$. The advances notwithstanding, how bipartite agreed-upon reformed DM policy will function cannot be predicted and might not have the expected results from various stakeholders' perspectives.

\section{Acknowledgments}

We are grateful to the participants of this study. The authors kindly acknowledge Dr. Jaime Guzman, M.D., MSc, FRCPC and Renée-Louise Franche, PhD, both former Occupational Health \& Safety Agency for Healthcare (OHSAH), BC, Canada who supervised data-collection in Canada. Sources of financial support in the form of a research fellowship came from former OHSAH, BC, Canada. Funding does not imply endorsement of the research findings.

\section{Conflict of Interest}

The authors declare that no competing interests or conflicting interests exist. 


\section{References}

1. Statistics Canada. 2009-2011. Available from: http://www.statcan.gc.ca/daily-quotidien/110525/dq110525e-eng.htm; http://www.statcan.gc.ca/pub/75-001-x/topics-sujets/topics-sujetseng.htm.

2. Kalisch DW, Aman T, Buchele LA. Social and Health Policies in OECD Countries: A Survey of Current Programmes and Recent Developments. Organization for Economic Co-Operation and Development (OECD). Labour Market and Social Policy Occasional Papers, No. 33, OECD Publishing. http://dx.doi.org/10.1787/720018345154; 2003.

3. OECD. Transforming disability into ability. Policies to promote work and income security for the disabled. Paris: OECD. 2003.

4. WHO (World Health Organization). The World Health Report 2006 - working together for health. WHO. 2006.

5. ILO (International Labour Organization). Code of Practice on managing disability in the workforce. Tripartite Meeting of Experts on the Management of Disability at the Workplace. ILO. 2001.

6. MacEachen E, Ferrier S, Kosny A, Chambers L. A deliberation on "hurt versus harm" logic in early return to work policy. Policy and Practice in Health and Safety. 2007;5(2):41-62.

7. MacEachen E, Kosny A, Ferrier S. Unexpected barriers in return to work: lessons learned from Ontario injured worker peer support group. WORK. 2007;29(2):155-64.

8. MacEachen E, Kosny A, Ferrier S, Chambers L. The 'toxic dose' of system problems: Why some injured workers don't return to work as expected. J Occup Rehabil. 2010;20(2):349-66.

9. Maiwald K, de Rijk, A, Guzman J, Schonstein E, Yassi A. Evaluation of a workplace disability prevention intervention in Canada: examining differing perceptions of stakeholders. J Occup Rehabil. 2011;21(2):179-89.

10. Tjulin A, MacEachen E, Ekberg K. Exploring the meaning of early contact in return-to-work from workplace actors' perspective. Disabil and Rehabil. 2011;33(2):237-145.

11. WorkSafeBC. Board of Directors Manual. 2003. http://www.worksafebc.com/about_us/assets/PDF/BOD_Manual_2005.pdf. Accessed 12 February 2013.

12. Workplace Safety and Insurance Board. 2010 Annual Report. Building trust through fairness and integrity. 2010. http://www.wsibontario.ca/PDF/OnlineAR_E_2010.pdf. Accessed 12 February 2013.

13. Franche RL, Baril R, Shaw WS, Nicholas $M$, Loisel P. Workplace-based return-to-work Interventions: optimizing the role of stakeholders in implementing and research. J Occup Rehabil. 2005;15(4):525-42.

14. Guzman J, Yassi A, Baril R, Loisel P. Decreasing occupational injury and disability: The convergence of systems theory, knowledge transfer and action research. WORK. 2008;30:229-39.

15. van Oostrom S, Anema JR, Terluin B, Venema A, De Vet HC, Van Mechelen W. Development of a workplace intervention for sick-listed employees with stress-related mental disorders: Intervention Mapping as a useful tool. BMC Health Services Research. 2007;7(127).

16. Westmorland MG, Buys N. A comparison of disability management practices in Australian and Canadian workplaces. WORK. 2004; 23, 31-41.]

17. Williams RM, Westmorland M. Perspectives on workplace disability management: A review of the literature. WORK. 2002; 19:87-93.

18. Maiwald K, Meershoek A, de Rijk AE, Nijhuis FJN. How policy on employee-involvement in work reintegration can yield its opposite: employee experiences in a Canadian setting. Disabil Rehabil. 2013;35(7):527-537.

19. Maiwald K, Meershoek A, De Rijk AE, Nijhuis FJN. How policy on manager involvement in work reintegration might instead put them out of action: Managers' experiences in a Canadian setting. WORK (Epub: July 2013, ahead of print).

20. Kosny A, MacEachen E, Ferrier S, Chambers L. The Role of Health Care Supporters in Long Term and Complicated Workers' Compensation Claims. J Occup Rehabil. 2011;21(4):582-90. 
21. Gardner BT, Pransky G, Shaw WS, Hong QN, Loisel P. Researcher perspectives on competencies of return-to-work coordinators. Disabil Rehabil. 2010;32(1):72-8.

22. James C, Southgate E, Kable A, Rivett DA, Guest M, Bohatko-Naismith J. The Return-To-Work Coordinator Role: Qualitative Insights for Nursing. J Occup Rehabil. 2011;21(2).

23. Shaw WS, Hong QN, Pransky G, Loisel P. A Literature Review Describing the Role of Return-to-Work Coordinators in Trial Programs and Interventions Designed to Prevent Workplace Disability. J Occup Rehabil. 2008;18(2):2-15.

24. Bernhard D, MacEachen E, Lippel K. Disability Management Experts and the impact of jurisdiction on practice. An Ontario Example. International Journal of Social Security and Workers Compensation. 2010;2(1):1-16.

25. Pransky G, Shaw WS, Loisel P, Hong QN, Désorcy B. Development and Validation of Competencies for Return to Work Coordinators. J Occup Rehabil. 2010;20(1):41-8.

26. Stone DA. Policy paradox: the art of political decision making. Revised ed. New York- London: WW Norton \& Company; 2002.

27. Lipsky M. Street-level Bureaucracy: Dilemmas of the Individual in Public Services. New York: Russel Sage Foundation; 1980.

28. Meershoek A, Krumeich A, Vos R. Judging without criteria? Sickness certification in Dutch disability schemes. Sociology of Health \& Illness. 2007;29(4).

29. Meershoek A, and Krumeich A. Multiculturalism and the Construction of Ethic Identities in Labour and Health Practices: Avoiding the Culturalistic Fallacy in Applied Research. Health Care Anal. 2009;17:17397.

30. van der Veen RJ. De sociale grenzen van beleid: een onderzoek naar de uitvoering en effecten van sociaal beleid [The social boundaries of policy: a study into the implementation and effects of social policy]. Leiden: Stenfert Kroese; 1990.

31. van der Veen RJ. De transformatie van wetgeving [The transformation of regulations]. In: Het bereik van de wet [The reach of the law]. Witteveen, Stout, Trappenburg, editors. Zwolle: Tjeenk-Willink; 1992.

32. Boeije H. Analysis in Qualitative Research. 1st ed. Thousand Oaks: Sage; 2010.

33. Hammersley M, Atkinson P. Ethnography: principles in practice. 3rd ed. London: Routledge; 2007.

34. Tedlock B. The observation of participation and the emergence of public ethnography. In: Denzin NK, Lincoln, YS, editors. Handbook of qualitative research. 3rd ed. Thousand Oaks: Sage; 2005. pp. 467-81.

35. Stake R. Qualitative Case Studies in Handbook of Qualitative Research. In: Denzin NK, Lincoln YS, editors. Handbook of qualitative research. 3rd ed. Thousand Oaks: Sage; 2005. pp. 443-66.

36. Denzin NK, Lincoln YS. Handbook of qualitative research. 3rd ed. Thousand Oaks: Sage; 2005.

37. Polit, DF, Beck, CT. Nursing research: principles and methods. Philadelphia PA: Lippincott Williams \& Wilkins: 2004.

38. Corbin J, Strauss A. Basics of qualitative research: techniques and procedures for developing grounded theory. 3rd ed. Thousand Oaks: Sage; 2008.

39. Higgins A, O'Halloran P, Porter S. Management of Long Term Sickness Absence: A systematic Realist Review. J Occup Rehabil. 2012;22:322-32.

40. Ståhl C, Müssener U, Svensson T. Implementation of standardized time limits in sickness insurance and return-to-work: Experiences of four actors. Disabil and Rehabil. 2012;34(16):1404-11.

41. Soklaridis S, Cassidy JD, van der Velde G, Tompa E and Hogg-Johnson S. The economic cost of return to work: An employer's perspective. WORK. 2012;43: 255-262.

42. Westmorland MG, Williams R, Strong S, Arnold E. Perspectives on work (re)entry for persons with disabilities: Implications for clinicians. WORK. 2002; 18:29-40.

43. Hoefsmit N, de Rijk A, Houkes I. Work resumption at the price of distrust: a qualitative study on return to work legislation in the Netherlands. BMC Public Health. 2013;13:153. 
44. Hoefsmit N, Houkes I, Nijhuis FJN. Intervention Characteristics that Facilitate Return to Work after Sickness Absence: A Systematic Literature Review. J Occup Rehab. 2012;22(4):462-77.

45. Vos R, Houtepen RH, Horstman K. Evidence based medicine and power shifts in health care systems. Health Care Analysis. 2002;10(4): 319-328.

46. Horstman K, Houtepen R. Vertrouwen, sturen of leren : een pragmatisch filosofisch perspectief op 'goed professioneel werk' [Trust, steering and learning: a pragmatic philosophic perspective on 'good professional work']. In: Goed werk: verkenningen van normatieve professionalisering [Good work: explorations of normative professional development]. G. Jacobs and R. Meij, editors. Amsterdam: SWP; 2008.

47. Loisel P, Durand M-J, Baril R, J G, Falardeau M. Interorganizational Collaboration in Occupational Rehabilitation: Perceptions of an Interdiscipinary Rehabilitation Team. J Occup Rehabil. 2005;15(4):581-90.

48. Anema JR, Schellart AJ, Cassidy JD, Loisel P, Veerman TJ, van der Beek AJ. Can cross country differences in return-to-work after chronic occupational back pain be explained? An exploratory analysis on disability policies in a six country cohort study. J Occup Rehabil. 2009;19:419-426.

49. De Rijk AE, Van Raak AJA, van der Made J. A New Theoretical Model for Cooperation in Public Health Settings: The RDIC Model. Qualitative Health Research. 2007;17(8):1103-6. 

Chapter 6

General discussion 


\section{Introduction}

In this thesis a bipartite agreed-upon RTW policy, that was implemented in BC Healthcare in Canada, is evaluated. Return to work (RTW), or work reintegration after work disability (WD) with sickness absence, is considered necessary to support workers' health and social inclusion. Several organizational policies, often referred to as disability management (DM), which focuses on early intervention and includes both the employer and worker, have been developed. A basic distinction in the policy process that is often made is that between agenda setting, policy formulation, policy implementation and policy evaluation [1] (see figure 1, introduction). Our research centers on the implementation phase. In policy formulation in BC Healthcare, various stakeholders (worker and employer representatives) had been involved to enhance practicability [2]. The aim of bipartite involvement in RTW policy formulation is to include the workplace and worker perspectives in the assumption that this results in policies that are more workable in practice [3-5]. The aim of this study was to investigate whether the BC Healthcare RTW policy is experienced as successful by the stakeholders. This was done by first getting more insight in the exact differences in perspectives of the stakeholders on the policy, including the designers. Second, detailed understanding of how the policy was experienced by receivers (workers) and deliverers (frontline managers, disability management staff and trade union representatives) was gained.

A qualitative approach was chosen to be able to study the perspectives in-depth and in context. We examined stakeholders' perspectives and investigated this from a social constructivist view.

Our research questions focused on how the stakeholders experience the RTW policy and these were addressed in four studies:

- What are the various stakeholders' appreciations of the BC Healthcare RTW policy? (study 1)

- How are the workers experiencing their new role in work re-integration trajectories and to what extent do they appreciate the policy? (study 2)

- How are the employers, that is the frontline managers or supervisors, experiencing their new role in work re-integration trajectories and to what extent do they appreciate the policy? (study 3 )

- How are the occupational health professionals, that is the disability management staff and trade union representatives, experiencing their new role in work reintegration trajectories and to what extent do they appreciate the policy? (study 4) 
In this last chapter, we start with a summary of the main findings. Next, we interpret these findings in the light of empirical research and theory. To conclude, we reflect on strengths and limitations of this study, and suggest recommendations for future research and practice.

\section{Main results}

In the first phase of this study we aimed to get a general overview of similarities and differences in perceptions of stakeholders on the bipartite agreed-upon RTW policy (chapter 2). In this phase of the study we included three types of stakeholders groups: First, designers of the policy. In our case study designers -at provincial level- are (former) Occupational Health and Safety Agency for Healthcare, BC and employer representatives (Health Employers Association of $\mathrm{BC}$ ) and worker representatives (BC Healthcare trade unions); Deliverers - at programming level in $\mathrm{BC}$ Healthcare- are occupational health staff (occupational health and safety director, programming staff) and management representatives and trade union representatives, and -at service level- workplace based physiotherapists; Receivers of the policy are the workers with incapacities themselves.

We identified that stakeholders' perceptions of causes for work disability differ, as do their preferred strategies for prevention. Designers proposed work-directed measures to change the workplace and work organizations, and individual-directed measures to change workers' behaviour. Deliverers targeted individual-directed measures however receivers were mostly seeking work-directed measures. To assess how the intervention was working, designers sought a wide range of outcome measures. Deliverers focused on measurable outcomes targeted at reducing work time-loss. Receivers perceived that this intervention offered short-term benefits yet fell short in ensuring sustainable return-to-work. This answers research question one.

Because of the experienced short coming of the RTW policy in this small rural setting, in the second phase of this study, we selected a large urban and considered provincial leading $\mathrm{BC}$ Healthcare setting.

In this setting, we first completed an in-depth study of the perspectives of receivers, that are workers with incapacities, on the RTW policy and what their practical experiences in coordinating RTW planning in meetings were (chapter 3 ). This study demonstrated that according to the workers the involvement procedures during policy making did not result in a better work re-integration practice. In the phase of reporting 
sickness absence, they had difficulties to find their way in the complexity of the procedures on how to report sick. In the phase of work re-integration planning and coordination, workers struggled they were expected to think along at times when they could not oversee their illness and/or recovery trajectory. In the phase of work re-integration plan execution, they find they were not able to make RTW, despite being committed and devoted to the plans. In addition, workers encountered a lack of recognition in that involvement or practical insights in work re-integration trajectories could develop over time yet they find those who were expected to offer support tend to be nonsupportive to get their perspective on the plan. Over time, according to the workers, they were being backed in a corner and did not feel in control of their work reintegration trajectory. This answers research question 2.

The deliverers we distinguished in the first phase included occupational health staff and trade union representatives. It appeared however, that frontline managers also played an important role as deliverer even though they have different tasks and responsibilities in the RTW process. Therefore, we made separate analyses for the frontline managers on the one hand and occupational health staff and trade union representatives on the other hand.

So, next, we completed an in-depth study of the perspectives of the frontline managers on the RTW policy and what their practical experiences in coordinating RTW planning in meetings were (chapter 4). This study demonstrated that according to the frontline managers the formal RTW procedures did not comply with the work that managers had to do. For starters, it was found that the managers viewed themselves as a linchpin between the workplace and the worker. Nevertheless, in the phase of preparing a work re-integration plan, the managers did not feel heard by the other stakeholders. In the phase of executing the work re-integration plan, the managers wrestled with worker's unexpected limitations and struggled to get the plans adjusted to deal with unforeseen issues. Such issues were for example work stress, when work demands exceeded the worker's ability to cope or control on their own in service delivery and RTW. In turn, managers felt that they became overextended to make RTW of workers with incapacities possible. Over time, managers argued, they could not get blamed for poorly following the RTW plan and felt they could not meet RTW and healthcare objectives at the same time. This answers research question 3.

Finally, we completed an in-depth study of the perspectives of the occupational health professionals (disability management staff and trade union representatives) on the RTW policy and what their practical experiences in coordinating RTW planning in meetings were (chapter 5). This study showed that giving everyone input in RTW planning insufficiently guaranteed that the plan was workable in practice according to the disa- 
bility management staff and trade union representatives. These stakeholders experienced four main problems regarding RTW: 1) timing and content of physician' medical advice cannot be trusted as a basis for plans; 2 ) legal status of the plans and thus needing workers' consent and managers' approval can create tension, conflict and delays; 3) limited input and thus little fruitful inference in meetings; and yet 4) the supporters can be called to account for plans (in spite of being empty handed and having little control). Over time, according to these stakeholders, the new directions in decisionmaking in RTW planning were in the way, and can even be counterproductive regarding increased tension between the stakeholders to achieve the RTW mandate. In particular in complex cases, these stakeholders might not know what to do to get workers and managers perspectives on the plan in RTW. Involving various stakeholders is a complex process that asks for space to precisely shape adjusting RTW planning to the situation, which is not a fixed moment in which all stakeholders must be at the table. This answers research question 4.

What we saw is that all the stakeholders who were expected to execute the reformed bipartite agreed-upon RTW policy struggled with it in practice. They found this policy not workable to effectively deal with capricious RTW process, including unpredictable recovery process and unexpected health issues in varying cases of RTW they met in practice.

The stakeholders perceived a lack of flexibility in arrangement regarding timing and involvement. This was because both the workers and managers experienced that the RTW process was unpredictable and their expectations that the occupational health professionals (and their employer, agencies) will support them to coordinate RTW in deliberation with them were unfulfilled. For example, in RTW planning, both the workers and frontline managers find it troublesome that RTW plans could not be modified on the basis of practical ideas and experiences. They felt that details were not worked out. To follow-up on the agreed-upon RTW plan, both groups found it bothersome that when RTW did not work as expected - for example when diverse, sudden and unexpected changes in a worker's capacities occurred - neither disability management staff nor trade union representatives took concrete action. Time and again, both the workers and frontline managers encountered that services (administrators) tended to be unresponsive to support them in RTW and they then felt unsubstantiated to complete their responsibilities in RTW in combination with the demand to meet other organizational objectives.

Also the disability management staff and trade union representatives experienced bottlenecks in implementing the reformed bipartite-agreed upon RTW policy. This 
group also perceived that more flexibility was needed to allow for getting and keeping quality plans in place regarding capricious RTW process, including unpredictable recovery and unforeseen health issues. This was because disability management staff and trade union representatives felt they could not truly fulfill their function to get the perspectives on the RTW plan.

Further, patient confidentiality made it, according to disability management staff and trade union representatives, impossible to discuss individual worker's health-related issues and limitations (medical proof of as well as perceived) to meet work demands with other stakeholders; trade union stewards who were supposed to advice on the workplace and OHS Regulations/collective agreements did not feel comfortable to point managers in the right direction; disability management staff who were expected to get the perspectives on the plan did not feel supported to come with possible solutions that could thwart workers' right for protection as well as chance funding/earning arrangements. Because influences by existing privacy rules, social hierarchy structures and judicial arrangements were too fickle, this group of deliverers did not feel wellequipped, actually, stifled to complete the RTW mandate given and combine this with the other organizational objectives.

\section{Key gained insight}

The idea was that bipartite involvement in policy formulation would result in policy that better fits practice, yet the execution of RTW policy still appears markedly hampered in the Canadian BC healthcare settings studied. In the next section, we interpret these findings in the light of empirical research and theory. Even though the findings of previous research suggests that the bipartite approach to RTW is having positive effects in terms of measurable RTW outcomes targeted at reporting sick for work, claim duration, worker' satisfaction and cost savings [6-9], the findings of this dissertation illustrate that the process is not working very well in terms of the implementation.

On the basis of our findings, we argue that the bipartite agreed-upon RTW policy which set to guarantee management and worker involvement is based on assumptions of the local setting which do not fit with how the reality is experienced. These assumptions include that rules on timing of involvement, short and finite time frames, and strict formalized plans from start work re-integration alone can steer the daily practices. These assumptions need to be reconsidered in policy processes. Firstly, because the RTW process is capricious, more flexibility in arrangement to support translation of work incapacities to actual workload is needed. Secondly, involving perspectives in 
RTW planning is intricate and does not automatically and simply come off the ground. Thirdly, RTW is a capricious process and the procedures/rules do not facilitate the worker, frontline managers, disability management staff and trade union representatives to integrate this crystallize (out) process in the local context. Fourthly, because these assumptions all combined ultimately set workers with incapacities up for failure to return-to-work and be part of the workforce (and society).

In our research setting (one Canadian province, healthcare sector), RTW policy is formulated by representative bodies of workers and employers. Explorative research [2] suggests that those bodies define the interest of workers respectively employers in a different way, than the stakeholders in the practical reality [10-13]. We saw that the RTW policy frustrates the practice and might stunt the prospect of workers with incapacities to RTW over time and can even blight the reality of recovery pace. In an attempt to guarantee workers' right for protection, the trade unions emphasized the importance of formal procedures to guide stakeholders through the work reintegration trajectory. Those procedures however, appear to hamper the process: they do not allow for adaptions needed in practice to accommodate individual workers. We have seen this problem in other situations as well. On the traditional assumptions of policy makers, Tjulin et al. [14]) showed with empirical research how early work reintegration policy can have unwanted effect in the Swedish setting of RTW. These scholars inferred that in practice, the expectation for workers to start early work reintegration activities before full health recovery became an unfair process, due to complex social relations conditions at the workplace and (possible) infringement on the workers' recovery process. In the Dutch setting, Meershoek et al.[15] demonstrated with empirical research how administrative procedures can have counterproductive effects in work re-integration. These authors concluded that, in practice, the duty for employers to work on re-integration of workers who reported ill easily becomes an empty letter due to formal procedures and control mechanisms.

RTW is a capricious process, including unpredictable recovery and unforeseen health issue. This capriciousness of RTW trajectories is difficult to cover in abstract rules and procedures. They are not general enough to give room to consider individual circumstances and adjust work re-integration trajectories to individual situations. We have seen this dilemma in other settings too. On room to operate, Kozny et al. [16], in the Canadian context, highlighted with empirical research how professional (which they named: healthcare providers) involvement in RTW planning can have null effect in the Canadian setting of work re-integration. These authors found that, in practice, the duty for occupational health professionals to get the workers' perspective on the RTW plan became a meaningless process, due to lack of influence in RTW planning and conflict- 
ing organizational systems. So to improve RTW, rules and procedures should be made less strict and detailed to create more room to effectively deal with capricious RTW process, including unpredictable recovery process and unexpected health issues in varying cases of RTW that professionals simply encounter in practice. Tiedtke et al. [17], in the Belgian context, demonstrated that professionals seek their own room to effectively deal with individual situations in variable trajectories.

However, if criteria are rather general and leave too much discretionary space, the risk of ad-hoc services increases [18]. In order to organize RTW trajectories and prevent mishandling and hampering of the RTW trajectory, managers (employers) and workers appeared to need support to improve their professionalism regarding four main tasks with respect to RTW process. First, the task of substantiating what a worker can or cannot do for work given his/her incapacities along with attuning the content of the RTW plan. Second, dealing with capriciousness in trajectories which includes unpredictable recovery and unforeseen health issues in which continual adjustment and attuning of the plan must be possible. Third, integrating differing perspectives of stakeholders which includes to consider both workers interest and managers interest. Four, handling power differences between the worker with his/her health complaints and the manager (employer). Therefore, occupational health professionals need to be thoroughly qualified and well equipped. Given the substantial struggles the deliverers in our study report, the DM staff as well as the trade union representatives and the managers, we can doubt whether that is the case in the $\mathrm{BC}$ healthcare setting. Loisel et al. [19], in the Canadian context, showed that RTW is complex and suggested that facilitation and adjusting RTW as well as dialogue and negotiation are skills needed by occupational health professionals. Pranzky et al. [20], in the US context, also demonstrated that RTW is complex but also contextual and proposed that dealing with power are skills needed by professionals in the work reintegration domain.

It seemed that representative bodies of worker and employer in policy process did not develop a shared understanding of the problems underlying the bottlenecks for addressing work disability namely the implementation in practice. Special focus on abstract or general rules, which gives space to executors of the policy through which they can operate more flexible, appears needed in the institutional/work context. Additionally, enhanced professionalism seems necessary to effectively deal with potential tension between workers and managers in RTW planning in order to complete the RTW mandate given. As our study shows, the managers cannot complete the responsibility of RTW planning alone. 
To enhance the quality of professionals' actions and reflective control over the quality of professional services the focus should not only be on increasing knowledge, but more on improving skills and competencies.

Therefore more attention is needed for schooling of professionals in the practical setting (on the job training; mentorship; supervision, and feedback) $[19,20]$. Once the professionals are at the site, peer review, inter-collegial meetings and reflection might be useful to optimize professionalism $[20,21]$.

\section{Strengths and limitations of this study}

The strengths of this study are that we involved various stakeholders at differing work sites in different geographic locations, and used in-depth inquiry to gain detailed insight in how the bipartite agreed-upon RTW policy functions in the practice. Further, the findings of the studies at various workplaces identified the different stakeholders were experiencing the same problems in RTW process. That strengthens our conclusions. Moreover, using both a theoretical framework to design this study and analyze the data supports trustworthiness of findings and gained detailed insight into implementation bottlenecks, that is, the bottlenecks in trying to execute the policy in practice in this setting at the time of this study. The selected methods to study the implementation in daily practice from stakeholders' perspectives were therefore relevant to understand the workings and consequences of BC Healthcare RTW policy developments in the Canadian context and provide tools as direction for further policy making.

The sample of interviewees involved in this large study may be seen as a limitation. Bias in case selection could not be avoided as the respondents were self-selected. Yet our methods ensured the selection of various stakeholder groups (workers, managers, occupational health professionals - DM staff, trade union representatives) and within these groups a highly diverse range of individual stakeholders. In addition, the various interviewees also reported good experiences in the execution of RTW policy and are therefore not a selective subsample of those with only negative experiences. Thus this purposive sample served our specific need to examine how RTW policy, that is a result of a bipartite process, functions from the stakeholders' perspectives. Saturation was not always possible in practice and might not have been reached on the total practice of RTW planning in the entire BC healthcare sector in Canada. There might be other bottlenecks in BC Healthcare. However that makes the bottlenecks we found not less relevant. Furthermore similar problems can be expected in other sectors; however, to identify the exact character of bottlenecks in other sections, extra research is needed (all context are different). Nonetheless, this study demonstrated that representative 
bodies of worker and employer in policy process may not automatically develop a shared understanding of the problems underlying the bottlenecks for addressing work disability namely the implementation in practice and highlighted that RTW effectiveness can be seen in a different light.

\section{Recommendations for future research}

A key recommendation could be made for future research with regard to bipartite policy formulation. This is to examine how RTW policy process works in different contexts. How and to what extent do policy makers leave enough discretion for practical circumstances?

Future studies to gain more precise insight in bottlenecks to implement RTW policy in practice may also be done. These studies could focus on specific themes: to distinguish between type of health problems (e.g., work-related injury/illness versus non-work health related issues, physical versus mental and psychological problems- as diagnosed by a physician); arranging problems over time (e.g., short-term disability claims versus long-term disability claims, chronic problems); employment status problems (e.g., regular versus temporary employment status); industry-related issues (e.g., specific to healthcare versus re-employment in another social service or industry); and in public and private schemes (public disability schemes versus compensation schemes versus private disability benefits).

How professionalism of work re-integration professionals gets done in particular towards competence is a question that needs further study. What works and how do professionals think about inclusive support in a variety of contexts?

\section{Recommendations for practice}

Two recommendations could be made for practice with regard to RTW policy adjustment. As mentioned, the results of this study suggest that managers and workers need professionals who can effectively deal with potential tension between workers and managers (because, as our study shows, the manager cannot complete the RTW planning alone) in order to complete the RTW mandate given. First, less strict rules allowing executors of the policy to operate more flexible could be demanded by government policy in particular with respect to timing of involvement, time frames, and formalizing plans to steer daily practices. Second, professional education in terms of 
thoroughly qualify and equip, actually, allowing professionals to complete their huge responsibility could be demanded by government policy. Professional education and training should not only focus on increasing knowledge but centering on optimizing skills and competencies regarding RTW support. Therefore more attention is needed for schooling in the practical setting (on the job training, mentorship, supervision and feedback space) $[15,16]$. In general, it has been shown that schooling could center possible themes in actual situations (in facilitation and adjust RTW [15, 16]; and dialogue and negotiation [15], plus dealing with power [16]). Once the professionals are at the site, peer review, inter-collegial meetings and reflection might be useful to optimize professionalism [16, 17]. 


\section{References}

1. Buse K, Mays N, Walt G, eds. The Health Policy Framework: Context, process and actors. Birkshire, England: Open University Press; 2005.

2. Occupational Health \& Safety Agency for Healthcare. Bipartite policy to formulate policy on work disability and return-to-work programs in the healthcare sector in BC. A progress report. Maiwald $\mathrm{K}$, Meershoek AM, eds. Vancouver, Canada; Occupational Health \& Safety Agency for Healthcare; 2010.

3. Franche R, Baril R, Shaw W, Nicholas M, Loisel P. Workplace-based return-to-work Interventions: optimizing the role of stakeholders in implementing and research. J Occup Rehabil. 2005;15(4):525-42.

4. Guzman J, Yassi A, Baril R, Loisel P. Decreasing occupational injury and disability: The convergence of systems theory, knowledge transfer and action research. Work. 2008;30(3):229-39.

5. Van Oostrom S, Anema J, Terluin B, Venema A, De Vet H, Van Mechelen W. Development of a workplace intervention for sick-listed employees with stress-related mental disorders: Intervention Mapping as a useful tool. BMC Health Serv Res. 2007;7:127.

6. Yassi A, Ostry A, Spiegel J, editors. Injury prevention and return to work: breaking down the two solitudes: Taylor \& Francis Books Ltd.; 2003.

7. Badii M, Keen D, Yu S, Yassi A. Evaluation of a comprehensive integrated workplace-based program to reduce occupational musculoskeletal injury and its associate morbidity in a large hospital. J Occup Environ Med.2006;48(11):1159-65.

8. Ouellette V, Badii M, Lockhart K, Yassi A. Worker satisfaction with a workplace injury prevention and return-to-work program in a large Canadian hospital: the importance of an integrated approach. Work. 2007;28:175-81.

9. Canada Benefits. Get well sooner: How overhauling Vancouver Coastal Health Authority's disability management program saved \$ 2.5 million. Benefits Canada. 2012. http://www.benefitscanada.com/wp-content/uploads/2012/02/BC0212-Strategy.pdf. Accessed Sep 202013.

10. Maiwald K, de Rijk A, Guzman J, Schonstein E, Yassi A. Evaluation of a Workplace Disability Prevention Intervention in Canada: Examining Differing Perceptions of Stakeholders. J Occup Rehabil. 2011;21(2):179-89.

11. Maiwald K, Meershoek A, de Rijk A, Nijhuis FJN. How policy on employee-involvement in work reintegration can yield its opposite: Employee experiences in a Canadian setting. Disabil Rehabil. 2013;35(7):527-37.

12. Maiwald K, Meershoek A, de Rijk AE, Nijhuis FJN. Policy on manager involvement in work reintegration: Managers' experiences in a Canadian setting. Work. (EPub: Ahead of print. Sep 04 2013).

13. Maiwald K, Meershoek A, de Rijk AE, Nijhuis FJN. Policy on professional support in work re-integration: Disability management staff and union representatives' experiences in a Canadian setting. (Submitted for publication and under peer- review).

14. Tjulin A, MacEachen E, Ekberg K. Exploring the meaning of early contact in return-to-work from workplace actors' perspective. Disabil Rehabil. 2011;33(2):237-145.

15. Meershoek A, Krumeich A, Vos R. Judging without criteria? Sickness certification in Dutch disability schemes. Sociol Health IIIn. 2007;29(4):497-514.

16. Kosny A, MacEachen E, Ferrier S, Chambers L. The Role of Health Care Providers in Long Term and Complicated Workers' Compensation Claims. J Occup Rehabil. 2011;21(4):582-90.

17. Tiedtke C, Donceel P, Knops L, H D, Dierckx de Casterle B, de Rijk A. Supporting Return-to-Work in the Face of Legislation: Stakeholders' Experiences with Return-to-Work After Breast Cancer in Belgium. J Occup Rehabil. 2012(22):241-51.

18. Van der Veen R. De sociale grenzen van beleid: een onderzoek naar de uitvoering en effecten van sociaal beleid [The social boundaries of policy: a study into the implementation and effects of social policy]. Leiden: Stenfert Kroese; 1990. 
19. Loisel P, Durand M-J, Baril R, Gervais J, Falardeau M. Interorganizational Collaboration in Occupational Rehabilitation: Perceptions of an Interdisciplinary Rehabilitation Team. J Occup Rehabil. 2005;15(4):581-90.

20. Pransky G, Shaw WS, Loisel P, Hong QN, Désorcy B. Development and Validation of Competencies for Return to Work Coordinators. J Occup Rehabil. 2010;20:41-8.

21. Eikenaar T, van Groenestijn M, de Rijk A, Meershoek A. Dutch work reintegration professionals" frames of reference. Eur J Pub Health, 22S2, 194-195. 2012. 

Summary

Samenvatting

Dankwoord

Curriculum Vitae

List of publications 



\section{Summary}

The aim of the study was to investigate whether a bipartite agreed-upon return to work policy in a healthcare setting in Canada is experienced as successful by the stakeholders.

Return to work (RTW), or work reintegration after work disability (WD) with sickness absence, is considered necessary to support workers' health and social inclusion. The ambition is to provide inclusive support to assist as many people as possible who have a disability to participate in the work process in a beneficial, integrative and sustainable way. To prevent mild symptoms developing into more severe and permanent ones and to allow access to appropriate RTW support when receiving a medical diagnosis is regarded as crucial.

Several organizational policies, often referred to as disability management, which focuses on early intervention and includes both the employer and worker, have been developed. The aim of bipartite involvement in RTW policy formulation is to include the workplace and worker perspectives in the assumption that this results in policies that are more workable in practice.

A basic distinction in the policy process that is often made is that between agenda setting, policy formulation, policy implementation and policy evaluation. Our research centers on the implementation phase.

The healthcare sector workforce faces a higher risk for WD compared to other industries. In policy formulation in the healthcare sector in British Columbia (BC), Canada, various stakeholders (worker and employer representatives) are involved to enhance practicability. In this thesis the bipartite agreed-upon RTW policy, that was implemented in the healthcare sector in British Columbia, Canada, is evaluated.

A qualitative approach was chosen to be able to study the perspectives in-depth and in context. We examined stakeholders' perspectives and investigated this from a social constructivist view.

Our research questions focused on how the stakeholders experience the RTW policy and these were addressed in four studies:

- What are the various stakeholders' appreciations of the BC Healthcare RTW policy? (study 1)

- How are the workers experiencing their new role in work reintegration trajectories and to what extent do they appreciate the policy? (study 2) 
- How are the employers, that is the frontline managers or supervisors, experiencing their new role in work reintegration trajectories and to what extent do they appreciate the policy? (study 3 )

- How are the occupational health professionals, that is the disability management staff and trade union representatives, experiencing their new role in work reintegration trajectories and to what extent do they appreciate the policy? (study 4).

Chapter 2 presents the study on local stakeholders' (designers, deliverers, receivers) perspectives on RTW and the RTW practice in general. This study identified that stakeholders' perceptions of causes for work disability differ, as do their preferred strategies for prevention. Designers (those who formulated the policy at provincial and organizational level) proposed work-directed measures to change the workplace and work organizations, as well as individual-directed measures to change workers' behaviour. Deliverers (occupational health professionals) targeted individual-directed measures however receivers (workers) were mostly seeking work-directed measures. To assess how the intervention was working, designers sought a wide range of outcome measures. Deliverers focused on measurable outcomes targeted at reducing work time-loss. Receivers (workers) perceived that this intervention offered short-term benefits yet fell short in ensuring sustainable return-to work.

Because of the experienced short coming of the RTW policy in this small rural setting, in the second phase of this study we selected a large urban and considered provincial leading BC Healthcare setting, and analyzed how their perceptions influenced policy implementation.

Chapter 3 presents the study at another healthcare setting in BC, Canada, on how various workers (receivers) experienced RTW policy, in particular input in decision making processes in RTW planning. This study demonstrated that according to the workers the involvement procedures during policy making did not result in a better reintegration practice. Workers had difficulties to find their way on how to report in sick, struggled they were expected to think along at times when they could not oversee their illness and/or recovery trajectory and find they were not able to make RTW. Workers encountered a lack of recognition of experienced difficulties in RTW and find those who were expected to offer support tend to be non-supportive to adjust the plan. Over time, they felt being backed in a corner and did not feel in control of their reintegration trajectory.

The deliverers we distinguished in the first phase included occupational health staff and trade union representatives. It appeared however, that frontline managers also 
played an important role as deliverer even though they have different tasks and responsibilities in the RTW process. Therefore, we made separate analyses for the frontline managers on the one hand and occupational health staff and trade union representatives on the other hand.

Chapter 4 presents a study on how a number of frontline managers or supervisors (deliverers) experienced RTW policy, in particular input in decision making processes in RTW planning. This study demonstrated that according to the frontline managers the formal RTW procedures did not comply with the work that managers had to do. For starters, it was found that the managers viewed themselves as a linchpin between the workplace and the worker. Nevertheless, in the phase of preparing a reintegration plan, the managers did not feel heard by the other stakeholders. In the phase of executing the reintegration plan, the managers wrestled with worker's unexpected limitations and struggled to get the plans adjusted to deal with unforeseen issues. Such issues were for example work stress, when work demands exceeded the worker's ability to cope or control on their own in service delivery and RTW. In turn, managers felt that they became overextended to make RTW of workers with incapacities possible. Over time, managers argued, they could not get blamed for poorly following the RTW plan and felt they could not meet RTW and healthcare objectives at the same time.

Chapter $\mathbf{5}$ presents a study on how different occupational health professionals, that is disability management staff and trade union representatives (deliverers), experienced RTW policy, in particular to bring varying worker and managers' perspectives forward; and on individual RTW plans. This study showed that giving everyone input in RTW planning insufficiently guaranteed that the plan was workable in practice according to the disability management staff and trade union representatives. These stakeholders experienced four main problems regarding RTW: 1) timing and content of physician' medical advice cannot be trusted as a basis for plans; 2) legal status of the plans and thus needing workers' consent and managers' approval can create tension, conflict and delays; 3) limited input and thus little fruitful inference in meetings; and yet 4) they can be called to account for plans (in spite of being empty handed and having little control). Over time, according to these stakeholders, the new directions in decision-making in RTW planning were in the way, and can even be counterproductive regarding increased tension between the stakeholders to achieve the RTW mandate. In particular in complex cases, these stakeholders might not know what to do to get workers and managers perspectives on the plan in RTW. Involving various stakeholders is a complex process that asks for space to precisely shape adjusting RTW planning to 
the situation, which is not a fixed moment in which all stakeholders must be at the table.

What we saw is that all stakeholders who were expected to execute the reformed bipartite agreed-upon RTW policy struggled with it in practice. They found this policy not workable to effectively deal with capricious processes, including unpredictable recovery process and unexpected health issues in varying cases of RTW they met in practice.

\section{Discussion and conclusion}

Chapter 6 provides an overview of the main results and a discussion of the results. As well, the strengths and limitations of this thesis are considered and recommendations for future policy and practice are provided. This study showed that in the specific setting of BC Healthcare the result of bipartite policy formulation does not support the practice that contains complex and contextual work disability problems according to the stakeholders. The results imply that the created RTW policy should permit more space allowing executors of the policy to operate more flexible to steer daily RTW practice. In addition, professionals should be more professional to complete their huge responsibility to achieve the return-to-work mandate given.

Early intervention is an important aspect of contemporary approaches to RTW support. To prevent mild symptoms developing into more severe and permanent ones and to allow access to appropriate return-to-work support when receiving a medical diagnosis is regarded as crucial. The expectation that workers and managers, together with occupational health professionals come to a full analysis of the problems underlying practical difficulties and, moreover, in accordance with each other settle on care and support services in early interventions might be too high.

In an attempt to guarantee workers' right for protection, the trade unions emphasized the importance of formal procedures to guide stakeholders through the RTW trajectory. Those procedures however, appear to hamper the RTW trajectories: they do not allow for adaptions needed in practice to accommodate individual workers in varying circumstances.

Therefore we conclude that a bipartite policymaking approach may not function and that might not get us very far for addressing work disability; however other studies in this and different contexts are needed.

In this thesis on the interpretation and transformation of rules regarding return to work, we demonstrate the limited reach of policy in practice due to various reasons which offer handles for policy makers to consider in policy formulation. In policy for- 
mulation a balance in programming must be found with respect to space on the one hand and enhanced professionalism on the other hand towards supporting early RTW, or work reintegration after work disability with sickness absence, which is considered necessary to support workers' health and social inclusion. 



\section{Samenvatting}

Is bipartiet overeengekomen arbeidsre-integratie beleid ook werkbaar? Een beleidsevaluatie gebaseerd op ervaringen van belanghebbenden in Canadese gezondheidszorginstellingen.

In dit proefschrift verkennen we of de verschillende belanghebbenden ervaren dat bipartiet overeengekomen arbeidsre-integratiebeleid in Canadese gezondheidszorgjnstellingen succesvol is.

Arbeidsre-integratie na ziekteverzuim wordt in Canada in toenemende mate als noodzakelijk beschouwd om de gezondheid van werknemers te bevorderen en hun voor de arbeidsmarkt te behouden, oftewel de sociale inclusie te bevorderen. De ambitie is om werknemers met uiteenlopende arbeidsbeperkingen zoveel mogelijk te ondersteunen zodat zij in staat zijn weer op de werkplek te functioneren en hen te motiveren richting arbeid. Een juiste medische diagnose wordt als cruciaal verondersteld om verergering van milde symptomen en blijvende beperkingen te voorkomen en om de juiste ondersteuning te kunnen selecteren.

'Disability management', het beleid in organisaties dat zich richt op werknemers met ziekte en beperkingen, is tegenwoordig gericht op snelle interventie. In de gezondheidszorg in British Columbia, Canada, is de keuze gemaakt om werkgevers en werknemers vertegenwoordigers te betrekken in de ontwerpfase van beleid, de zogenaamde bipartiete structuur. De gedachte hierachter is dat als belangentegenstellingen tussen werkgevers en werknemers al in de ontwerpfase van beleid overbrugd worden, de uitvoering beter zal verlopen.

Dit brengt ons naar waar deze dissertatie over gaat namelijk het evalueren van het bipartiet overeengekomen arbeidsre-integratiebeleid, dat werd geïmplementeerd in de gezondheidszorg in British Columbia, Canada. De gezondheidszorg is een geschikte sector om arbeidsre-integratiebeleid te onderzoeken omdat werknemers in de gezondheidszorg een groter arbeidsongeschiktheid risico lopen in vergelijking met andere sectoren.

In dit bipartiet overeengekomen beleid is overeengekomen dat de disability management medewerker verantwoordelijk is voor het opstellen van een re-integratieplan voor een individuele werknemer die zich heeft ziek gemeld. De disability management medewerker is verplicht dat te baseren op medisch advies en heeft tot taak om andere belanghebbenden (werknemer, werkgever, en vakbondvertegenwoordiger -in Canada is deze laatste groep betrokken bij arbeidsre-integratie) daarin te betrekken 
en met hen tot overeenstemming te komen over de koers van het plan. Vervolgens heeft de disability management medewerker tot taak te monitoren of het plan conform de afspraken wordt uitgevoerd waarin hij/zij is verplicht te (her-)overleggen met de belanghebbenden, indien gaandeweg wijzigingen van het plan nodig zijn.

Een basisonderscheiding van het beleidsproces die vaak gebruikt wordt is het opstellen van de beleidsagenda, ontwerpfase, implementatie van beleid en een beleidsevaluatie. Ons onderzoek richt zich op de implementatiefase van beleid, ofwel beleidsuitvoeringonderzoek.

Om gedetailleerd inzicht in de perspectieven van belanghebbenden met betrekking tot het bipartiete ontwikkelde arbeidsre-integratiebeleid te verkrijgen hebben we gebruik gemaakt van kwalitatieve onderzoeksmethoden. Daarbij werd een sociaalconstructivistische onderzoeksbenadering gehanteerd.

Onze onderzoeksvragen richtten zich op hoe de verschillende belanghebbenden het arbeidsre-integratiebeleid ervaren en daarvoor deden we vier studies:

- Hoe waarderen de verschillende groepen belanghebbenden het arbeidsreintegratiebeleid in de gezondheidszorgsector in British Columbia, Canada? (studie 1)

- Hoe beleven de werknemers hun nieuwe rol in arbeidsre-integratietrajecten en in hoeverre waarderen ze het nieuwe beleid? (studie 2)

- Hoe beleven de werkgevers, hier direct leidinggevenden of afdelingshoofden, hun nieuwe rol in arbeidsre-integratietrajecten en in hoeverre waarderen ze het nieuwe beleid? (studie 3)

- Hoe beleven de re-integratie 'professionals', hier disability management medewerkers en vakbondsvertegenwoordigers, hun nieuwe rol in arbeidsre-integratietrajecten en in hoeverre waarderen ze het nieuwe beleid? (studie 4).

Ten behoeve van de verkenning van de uiteenlopende betekenissen die de verschillende belanghebbenden toekennen aan het arbeidsre-integratiebeleid (beleidsmakers, beleidsuitvoerders, en 'de doelgroep') is een empirische studie uitgevoerd (hoofdstuk 2). De resultaten geven inzicht in de verschillende perspectieven op de oorzaak van arbeidsongeschiktheid, en op de benodigde oplossingen. Beleidsmakers, zo bleek uit de maatregelen die zij opstelden, vonden zowel de werkomgeving, aanpassingen op de werkplek en het (re-) organiseren van werkprocessen, als individuele gedragsverandering van belang. Beleidsuitvoerders (re-integratieprofessionals) zijn vooral gericht op verandering van het individu. De doelgroep (de werknemers) daarentegen vond juist maatregelen ter verandering van de werkomgeving, aanpassingen op de werkplek en het (re-)organiseren van werkprocessen van belang. Bij de bepaling van de effectiviteit van het arbeidsre-integratiebeleid richtten beleidsmakers zich op verschillende uitkomstmaten zoals ziekmelden, ziekteverzuimduur, kosten en tevredenheid. Beleidsuit- 
voerders richtten zich op het verminderen van de verzuimduur. De ervaringen van de doelgroep (de werknemers) waren dat de interventies wel oplossingen op de korte termijn boden maar tekortschoten met betrekking tot de benodigde ondersteuning van duurzame arbeidsre-integratie.

Gezien de ervaren tekortkomingen van het arbeidsre-integratiebeleid in de geselecteerde plattelands locatie, selecteerden we in het tweede deel van de studie een stedelijke locatie, die in de provincie British Columbia gezien wordt als meest toonaangevende locatie voor wat betreft de onderhandelingen over collectieve arbeidsovereenkomsten en arbeidsre-integratiebeleid in de gezondheidszorgsector. Ook in dit vervolgonderzoek hebben we de perspectieven van belanghebbenden op de implementatie van het bipartiet overeengekomen beleid geanalyseerd. We zijn daarin dieper ingegaan op de achtergronden van de perspectieven van de verschillende belanghebbenden.

Op de eerste plaats hebben we bestudeerd hoe het arbeidsre-integratiebeleid ervaren werd door de doelgroep (de werknemers) en hoe het uitvoeren en aanpassen van overeengekomen arbeidsre-integratieplannen ging (hoofdstuk 3). De resultaten laten zien dat volgens de werknemers de betrokkenheid van beleidsmakers vanuit beide groepen belanghebbenden in de ontwerpfase van het beleid niet leidde tot verbetering van de arbeidsre-integratiepraktijk. Werknemers wisten niet goed hoe ze zich moesten ziekmelden, worstelden met de verwachting om mee te denken op het moment dat ze hun ziekte en hersteltraject nog niet konden overzien en ze vonden dat arbeidsre-integratie op zo een manier niet haalbaar was. Werknemers kregen maar moeilijk erkenning voor de door hun ervaren problemen tijdens arbeidsre-integratie en vonden dat de re-integratieprofessionals die geacht werden hen te ondersteunen, het niet voor elkaar kregen de re-integratieplannen op een juiste manier aan te passen. $\mathrm{Na}$ verloop van tijd voelden werknemers zich in een hoek gedrukt en vonden ze dat ze geen invloed kregen op hun arbeidsre-integratietraject.

Op de tweede plaats hebben we bestudeerd hoe het arbeidsre-integratiebeleid ervaren werd door de werkgevers en hoe het uitvoeren en aanpassen van overeengekomen arbeidsre-integratieplannen ging (hoofdstuk 4). De resultaten laten zien dat volgens de werkgevers de arbeidsre-integratie procedures en het dagelijkse werk dat ze moeten doen niet aaneensluiten. Ten eerste herkenden we dat werkgevers zichzelf als spil zagen tussen de werknemer en de werkomgeving. Desondanks voelden de werkgevers zich in de voorbereidingsfase van een arbeidsre-integratieplan niet gehoord door de andere belanghebbenden. In de uitvoeringfase van een re-integratieplan worstelden de werkgevers met onverwachte arbeidsbeperkingen van de werknemer en hadden ze moeite om plannen aangepast te krijgen. Arbeidsbeperkingen waren bijvoorbeeld werkstress, wanneer de werkeisen de mogelijkheden van de werknemer om hier goed mee om te gaan of er controle over te krijgen te boven gingen. 
Het ging dan om eisen met betrekking tot het waarborgen van de kwaliteit van zorg in combinatie met het nakomen van een overeengekomen arbeidsre-integratieplan. Als gevolg hiervan voelden werkgevers zich overvraagd bij het mogelijk maken van arbeidsre-integratie van hun werknemers met arbeidsbeperkingen. De werkgevers beargumenteerden dat zij uiteindelijk niet de schuld zouden moeten krijgen als ze reintegratieplannen niet precies opvolgen en verder vonden zij dat de doelen arbeidsreintegratie en het leveren van goede gezondheidszorg zo niet goed verenigbaar waren.

Op de derde plaats hebben we bestudeerd hoe het arbeidsre-integratiebeleid ervaren werd door de re-integratieprofessionals, dus disability management medewerkers en vakbondvertegenwoordigers (beleidsuitvoerders) en hoe het uitvoeren en aanpassen van overeengekomen arbeidsre-integratieplannen ging (hoofdstuk 5). In de Canadese praktijk zorgen vakbondsvertegenwoordigers dat de rechten van werknemers in acht worden genomen door de werkgever. De resultaten laten zien dat volgens de re-integratieprofessionals het organiseren van overleg om inbreng te creëren hun onvoldoende garantie gaf dat de re-integratieplannen daadwerkelijk praktisch beter haalbaar waren. Deze belanghebbenden ondervonden vier typen problemen met betrekking tot arbeidsre-integratie: 1 ) de keuze van het tijdstip en de inhoud van medisch advies door artsen vormen geen betrouwbare basis voor de re-integratieplannen; 2) juridische 'status' van het plan en de daarvoor benodigde toestemming van de werknemer en akkoord van de werkgever kunnen spanning, conflict en vertraging opleveren; 3) beperkte inbreng en daarom weinig vruchtbare uitwisselingsmomenten; 4) ze kunnen ter verantwoording worden geroepen (ondanks dat ze met lege handen staan en weinig controle hebben). Na verloop van tijd, bleek meestal dat het gezamenlijk overeengekomen re-integratieplan niet aansloot op de veranderde situatie en grillige processen tijdens arbeids-re-integratie. Met name in complexe situaties wisten deze belanghebbenden niet wat ze moesten doen om de verschillende perspectieven van de werknemer en werkgever te verwerken in het re-integratieplan. Vervolgens kon, volgens deze belanghebbenden, het idee dat het aanpassen van het arbeidsreintegratieplan alleen op basis van gezamenlijke besluitvorming tussen werknemer en werkgever (en -onder begeleiding van re-integratieprofessionals) mag geschieden de re-integratie in de weg zitten en zelfs contraproductief zijn. Het betrekken van verschillende belanghebbenden is een complex proces waarbij beslissingsruimte nodig is (ook met betrekking tot het moment van aanpassing) om het plan zo in te vullen dat het bij de individuele situatie past, en dit conflicteert met de eis van een vast overlegmoment tussen alle belanghebbenden.

Kortom, de resultaten laten zien dat alle belanghebbenden die het hervormde bipartiet overeengekomen arbeidsre-integratiebeleid moeten uitvoeren, er in de praktijk mee worstelen. Zij vinden het nieuwe beleid onwerkbaar en niet effectief omdat het onvoldoende oog heeft voor de grillige processen tijdens verzuim en arbeidsre- 
integratie, zoals de onvoorspelbare herstelprocessen en onverwachte gezondheidsproblemen.

\section{Discussie en conclusie}

Hoofdstuk 6 geeft een overzicht van de belangrijkste bevindingen en bediscussieert de resultaten. Verder bespreken we de kracht en beperkingen van het onderzoek en komen aanbevelingen voor toekomstig onderzoek en voor de praktijk aan de orde. Deze studie laat zien dat in een specifieke locatie, namelijk de gezondheidszorgsector in Britisch Columbia, Canada, het bipartiet overeengekomen arbeidsre-integratiebeleid het uitvoeringsproces niet goed ondersteunt. Processen rondom ziekteverzuim en arbeidsongeschiktheid zijn volgens de belanghebbenden uiterst complex en contextgebonden, terwijl regels en procedures in het bipartiet-overeengekomen arbeidsreintegratiebeleid juist sterk gestandaardiseerd zijn. Het beleid geeft met andere woorden onvoldoende beslissingsruimte aan uitvoerders (en de doelgroep), terwijl beleidsuitvoerders flexibel moeten kunnen handelen, om de dagelijkse praktijk rond arbeidsre-integratie te kunnen sturen. Dat geeft de uitvoerders wel een grotere verantwoordelijkheid in het begeleiden van het arbeidsre-integratie proces. Om die flexibiliteit te kunnen hanteren is het dan ook nodig dat re-integratieprofessionals de professionaliteit van hun handelen verbeteren.

Vroeg interveniëren na ziekmelden is een belangrijk aspect van de huidige aanpak om arbeidsre-integratie te ondersteunen. Zoals reeds gezegd, wordt een juiste medische diagnose als cruciaal verondersteld om verergering van milde symptomen en blijvende beperkingen te voorkomen en om de juiste ondersteuning te kunnen bepalen. De verwachting dat werknemers en werkgevers, samen met disability management medewerkers en vakbondsvertegenwoordigers tot een volledige analyse van onderliggende praktische problemen kunnen komen en - in samenspraak met elkaar definitief regelen wat benodigde zorg en ondersteuning bij vroeg interveniëren behoeft is wellicht te hoog gegrepen.

In een poging om rechten van werknemers te beschermen, benadrukken werknemersvertegenwoordigers het belang van formele procedures. Deze procedures blijken echter het arbeidsre-integratietraject te hinderen: ze staan niet toe om in de praktijk benodigde aanpassingen te realiseren om gerichte ondersteuning van individuele werknemers in verschillende situaties mogelijk te maken.

Daarom concluderen wij dat een bipartiete aanpak van arbeidsre-integratie, waarbij zowel werkgevers als werknemers vertegenwoordigd zijn in de ontwerpfase van het beleid, niet goed genoeg functioneert en dat het onvoldoende helpt om grip en controle te krijgen op ziekteverzuim en arbeidsongeschiktheid. Vervolgonderzoek in 
deze en andere institutionele contexten is nodig om beter zicht te krijgen op hoe arbeidsre-integratie dan wel verbeterd kan worden.

In deze dissertatie is onderzocht hoe beleid in de praktijk geïnterpreteerd en getransformeerd wordt. Daarmee leveren wij handvatten voor beleidsmakers in de beleidsontwerpfase. In de beleidsontwerpfase zal een balans gevonden moeten worden tussen enerzijds het reguleren van het uitvoeringsproces en anderzijds het geven van ruimte aan beleidsuitvoerders (werkgevers en re-integratieprofessionals). Voor dat laatste is vertrouwen in re-integratieprofessionals (disability management professionals, vakbondsvertegenwoordigers) nodig; dergelijk vertrouwen kan worden bevorderd door de professionaliteit van het handelen te vergroten. Dat wil zeggen dat er aandacht moet komen voor scholing van re-integratieprofessionals, gericht op verheldering van en reflectie op verschillen in keuzes en argumenten in gezamelijke besluitvormingsprocessen in re-integratie begeleiding voor werknemers met een uiteenlopende arbeidsbeperking. Het op deze wijze aanpassen van beleid zou vervolgens een steuntje in de rug kunnen zijn om het doel van arbeidsparticipatie te bereiken, wat als noodzakelijk wordt beschouwd om de gezondheid van werknemers en sociale inclusie te bevorderen. 


\section{A word of thanks}

My doctoral thesis is completed. I am very grateful for all the support so many wonderful people gave me to make the right decisions to take on and finalize this ambitious project.

First of all, I would like to thank all the people who shared their return-to-work experiences and views for my studies which took place in British Columbia, Canada. I also would like to thank the various organizations who agreed to support this project in the Netherlands and Canada: the Maastricht University in the Netherlands; (former) Occupational Health and Safety Agency for Healthcare (OHSAH), Interior Health, Vancouver Coastal Health, and various healthcare trade unions - British Columbia Nurses Union, Health Sciences Association, Health Employees Union in Canada.

Verder wil ik graag mijn (co-)promotores bedanken. Angelique de Rijk, bedankt dat jij dit project in Canada aan wilde gaan en mij steunde om dit ook af te maken. Jouw vakkennis, analytische scherpte en schrijfvaardigheid plus aanhoudend scherp oog voor benodigde puntjes op de $i$ verhoogden de kwaliteit van mijn werk. Dat ik over de jaren heen preciezer en geduldiger ben geworden heb ik o.a. aan jou te danken. Agnes Meershoek, bedankt voor jouw inzet voor dit proefschrift. Jouw vakkennis, analytische scherpte en taalkunde naast blijvende aandacht voor diepte inzicht waren onontbeerlijk voor de goede afronding van dit project. Dank voor je geduld en relativeringsvermogen, ook als dingen even niet helemaal liepen zoals gehoopt. Frans Nijhuis, bedankt dat jij als hoogleraar dit werk ondersteunde. Jouw vakkennis, ervaring en rust tijdens overlegmomenten waren bijzonder waardevol. Ik ben je zeer dankbaar voor je blijvende betrokkenheid.

Andere academici op de UM wil ik ook graag bedanken. Anja Krumeich, jij liet me kennis maken met kwalitatieve evaluaties en een specifieke 'stakeholder benadering' tijdens mijn jaar in Maastricht. Rob de Bie en Ilse Mesters, dank voor de begeleiding van mijn Health Sciences Research Master project in Canada -wat de basis vormde voor mijn promotietraject.

Veel dank aan de leescommissie: IJmert Kant, Han Anema, Klasien Horstman, Inge Houkes en Ellen MacEachen voor het beoordelen van dit proefschrift. Ellen, thank you 
for reviewing my thesis and helpful comments. Dank aan Hans Bosma en Lode Godderis voor deelname aan de corona.

To complete my studies, I worked in Canada and the Netherlands. Many thanks to the (former) Occupational Health \& Safety Agency for Healthcare (OHSAH), BC, Canada for supporting my work and partially funding my studies. Jaime Guzman, thank you for supervising my studies at OHSAH and being co-author in my first publication. You encouraged me to turn my master-level project into a doctorate study, thank you! ReneeLouise Franche, thank you for supervising my studies at OHSAH. Eva Schonstein, Annalee Yassi, thank you for introducing me to (former) OHSAH and being co-authors in my first publication. To my former colleagues at (former) OHSAH (Georgia Pomaki, Philip Mah, Noushin Khushrushahi, Al Kozlowski, Eleanor Murray), thank you Disability Prevention team for supporting my work and welcoming me when visiting Vancouver. Noushin, thank you for conducting some interviews with healthcare workers and typing them out! Aan mijn collega's van de Universiteit Maastricht, afdeling Sociale Geneeskunde, dank dat jullie geinteresseerd waren in mijn project en mij de mogelijkheid hebben geboden om van verschillende werkplekken en faciliteiten gebruik te maken. Isel van Noppen en Arnold van Alphen, ook dank hiervoor! Katarina Putnik, Daniëlle Groffen, Yvonne Goertz, Nicole Hoefsmit (allen Socmed) en Lineke van Hal, Corine Tiedtke, Gonnie Klabbers, Yvette Bartholomee (ex-SocMed medewerkers), onze contactmomenten waren altijd waardevol. Nicole, hartstikke fijn en dank dat je mijn paranimf wilt zijn! I would also like to thank all my Work Disability Prevention CIHR Strategic Training Program colleagues. This international program, including the opportunity for summer coursework and international knowledge exchange activities as well as the professional contacts and friendships made still inspire my work!

Dank aan vrienden, familie en gezin. Marjolein Selis en Frenk Peeters, dat deze promotie vanuit Canada en bij de UM is gelukt heb ik echt aan jullie te danken. Dank voor jullie steun en vooral ook jullie ongelooflijke gastvrijheid, etentjes, mooie muziek, filmavonden etcetera wanneer ik in Maastricht was, soms met gezin en al. lk heb veel met jullie gelachen en dit promotietraject nooit vol kunnen houden zonder jullie! Dankjewel Marjolein dat je mijn paranifm wilt zijn. My dear friends in Canada, thank you for helping me cope and control spells of cabin fever. Mijn lieve vriendinnen in Nelson, Canada, dank voor de uitstapjes, chocolaatjes, oliebollen - kortom gezelligheid! Mijn lieve vriendinnen in Nederland, dank dat jullie contact bleven houden en dank voor de gezellige afspraken tijdens mijn werkbezoeken in Nederland.

Lieve moeder en $\mathrm{HJ}$, bedankt voor jullie lieve steun en luisterend oor de afgelopen jaren. Dat jullie voor de kinderen zorgden, en dat heel graag deden, als ik naar naar 
Maastricht vertrok, was geweldig! Lieve pa, het is toch ergens goed gekomen dat ik niet direct een simpel antwoord verwacht op een lastige vraag. Dank voor onze gezamelijke uitjes de afgelopen jaren! Lieve Michiel, dank voor je expertise een mooie website (www.workhealthconnexion.com) voor mijn opstartende bedrijfje te lanceren!

Mijn allerliefste Sophie en Sabien, wat ik nou precies deed voor werk, behalve veel achter de computer zitten en dan ook nog eens heel ongezellig boven, was niet zo makkelijk aan jullie uit te leggen. Maar gelukkig, het boek wat ik aan het schrijven was is klaar en nu te zien. Verder komt er een reisje en feest in Nederland aan plus weer een familiebezoekje- allemaal leuke dingen. Ik ben zo blij dat jullie er zijn en geniet heel veel van jullie! My dearest George, at times you were not so sure what to think of me doing a PhD or how to value it. But you kept supporting me and jumped in when I felt rather overwhelmed to complete this journey. I treasure all you did, enjoy our now and look forward to our future! 



\section{Curriculum vitae}

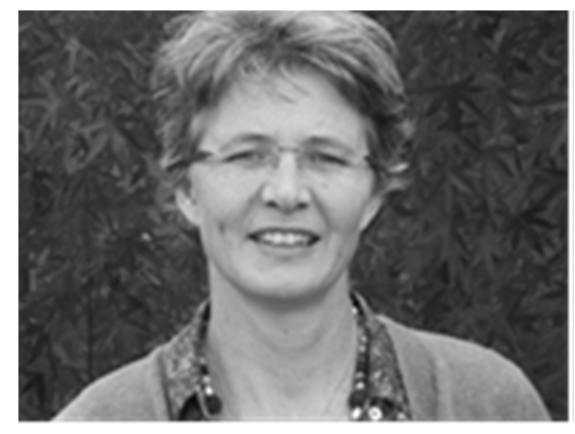

Karin Maiwald was born on July $15^{\text {th }} 1964$ in The Hague, the Netherlands. She studied Physiotherapy (full-time) at the 'Stichting Paramedische Academie "De Uithof", Utrecht, the Netherlands (now called: University of Applied Sciences, Utrecht) (BPT degree in 1986) and Psychology (part-time) at the University of Utrecht, the Netherlands (propedeuse/first year degree in 1988). She

held several (freelance) jobs as a Physiotherapist in the Netherlands before moving to Canada in 1988 to gain work experience abroad in the public healthcare sector in British Columbia. In 1991/92 she travelled on her pedal-bicycle in Australia, New Zealand, and Europe. In 1992 she started her own private physiotherapy clinic in British Columbia (BC), Canada, which she successfully sold in 2003. Karin held several (freelance) jobs as a physiotherapist in the public and private sector in 2003/04. During her work career and business experience, Karin gained further administrative experience through several positions on the Board Physiotherapy Association of BC (PABC), including Chair Business Affairs Committee and Executive Director, as well as being a member of the Professional Development Advisory Committee (PABC), and Health Care Practitioner Representative for Hearing Panels of the Medical Services Commission, Ministry of Health, Legislation and Professional Regulation, BC, Canada. In 2005 she moved to the Netherlands to study Health Sciences at the Maastricht University, the Netherlands, during which she developed a research proposal to examine the perceptions and experiences of stakeholders with return-to-work programming in the healthcare sector in British Columbia, Canada and in 2006 she completed this study in collaboration with the Occupational Health \& Safety Agency for Healthcare (OHSAH), BC (MPhil degree in 2006, specialisation Social Sciences). In 2007 she was offered a junior research position at $\mathrm{OHSAH}, \mathrm{BC}$ to help coordinate return-to-work programming development in collaboration with a BC healthcare organization. In 2008 Karin was offered a two-year Research Fellowship with OHSAH, BC in order to develop a research proposal and start a PhD-project to expand her qualitative research in the $\mathrm{BC}$ healthcare sector. In that same year, she was granted a Scholarship to do an international two year PhD/Post doc level Work Disability Prevention CHIR Strategic Training Program at the University of Sherbrooke, Montreal, Canada (Diploma degree in 2011). 
She further joined the department of Social Medicine, Maastricht University, the Netherlands as an external (honorary) PhD candidate in 2008. Her PhD project (based in Canada) led to several publications in international peer reviewed journals as well as various presentations at (international) conferences and organizations. Karin helped develop a bachelor skills training responsive evaluation, part of the training practicing policy skills for local public health contexts, Maastricht University, the Netherlands in which students practice the methods of responsive evaluation on the basis of her qualitative research conducted in Canada. In 2010, Karin together with fellow team members was awarded the Synthesis Activity Project, Work Disability Prevention CIHR Training Program, University of Toronto, Dalla Lana School of Public Health, Canada (where the WDP CIHR Training is currently being held). In 2012, she helped organize and coordinate a Pre-Conference Student Day that focused on promoting knowledge transfers between research and practice-and back again, part of the Canadian Association for Research on Work \& Health (CARWH) Conference, Vancouver, BC. In 2013 she held a term-certain position as an Advisor, Partnerships in Prevention, Workplace Health \& Safety at Interior Health/Northern Health, BC, Canada. Her research interests lie in the field of work disability prevention, disability management in workplace settings (return-to-work policy), stakeholders perspectives, (political) policy processes and legislation, multidisciplinary decision making in return-to-work planning and occupational health professional development, and international differences in this regard. She recently launched her own company Work-Health Connexion, supporting disability management (return-to-work policy) development in organizations. 


\section{List of publications}

\section{Journal articles}

Maiwald K, Meershoek A, de Rijk AE, Nijhuis FJN. Policy on professional support in work re-integration: Disability management staff and union representatives' experiences in a Canadian setting (Submitted for publication and under peer- review).

Maiwald K, Meershoek A, de Rijk AE, Nijhuis FJN. Policy on manager involvement in work re-integration: Managers' experiences in a Canadian setting. WORK: A Journal of Prevention, Assessment \& Rehabilitation. (EPub Ahead of print. DOI 10.3233/WOR-131727, September 04, 2013).

Maiwald K, Meershoek A, de Rijk A, Nijhuis FJN. How policy on employee-involvement in work reintegration can yield its opposite: Employee experiences in a Canadian setting. Disabil Rehabil. 2013;35(7):527-537.

Maiwald K, de Rijk A, Guzman, J, Schonstein E, Yassi A. Evaluation of a Workplace Disability Prevention Intervention in Canada: Examining Differing Perceptions of Stakeholders. J Occup Rehabil. 2011;21(2):179189.

\section{Reports (in Canada)}

Maiwald K, and Meershoek A. Bipartite policy to formulate policy on work disability and return-to-work programs in the healthcare sector in BC: Preliminary Findings. 2010. Occupational Health \& Safety Agency for Healthcare (OHSAH), BC.

Maiwald K, Meershoek A, Khushrushahi N, Franche R-L. How Healthcare Employees Experience Policy on Return-to-Work after Reporting Sick from Work: Preliminary Findings. 2010. Occupational Health \& Safety Agency for Healthcare (OHSAH), BC.

\section{Presentations (in Canada \& the Netherlands)}

Maiwald K, Meershoek A, de Rijk A, Nijhuis FNJ. Responsive evaluation in a Canadian healthcare setting. In: Bachelor Health Sciences, module Public Health Policy, Maastricht University. May 8, 2014. Maastricht University, the Netherlands. Lecture.

Maiwald K, Meershoek A, de Rijk A, Nijhuis FNJ. Bipartite agreed-upon policy for return to work: experiences, unintended consequences and opportunities in a Canadian setting. Second Scientific Conference on Work Disability Prevention and Integration Conference. Oct 22-24, 2012. University Medical Center Groningen, Groningen, the Netherlands. Conference presentation.

Maiwald K, Meershoek A, de Rijk A, Nijhuis FNJ. How bipartite policy on work reintegration can have excluding consequences: experiences from workers and management in a Canadian setting. Canadian Association for Research on Work \& Health Conference. May 31- June 1, 2012. Vancouver, BC, Canada. Research poster. 
Maiwald K, Meershoek A, de Rijk A, Nijhuis FNJ. How bipartite policy on work reintegration can have excluding consequences: experiences from workers and management in a Canadian setting. BC Environmental and Occupational Health Research Network AGM and Spring Conference. May 30, 2012. Vancouver, BC, Canada. Research poster.

Maiwald K, Meershoek A, de Rijk A, Nijhuis FNJ. How policy on employee-involvement in work reintegration can yield its opposite: employee experiences in a Canadian setting. January 11, 2012. Faculty of Medical Sciences, Dept. of Health Sciences, Community \& Occupational Medicine, University Medical Center Groningen, the Netherlands. Seminar.

Maiwald K, Meershoek A, de Rijk A, Nijhuis FNJ. How policy on employee-involvement in work reintegration can yield its opposite: employee experiences in a Canadian setting. October 4, 2011. Institute for Work \& Health, Toronto, ON, Canada. Plenary meeting presentation.

Maiwald K, Meershoek A, de Rijk A, Nijhuis FNJ. How policy on employee-involvement in work reintegration can yield its opposite: employee experiences in a Canadian setting. In: Community Forum "Work reintegration: 'Disability management' practices involving the injured worker. What is the idea? What is the result?". September 29, 2011. Injured Workers Group Consultants, Toronto, ON, Canada. Forum presentation and discussion.

Maiwald K, Meershoek A, Khushrushahi N, Franche R-L. Study 1: Exploring RTW policy experiences in practice. Canadian Institutes of Health Research, Work Disability Prevention Strategic Training Program. June 7, 2010. University of Toronto, Toronto. ON, Canada. Seminar.

Maiwald K, de Rijk A, Guzman J, Schonstein E, Yassi A. The practice of a work place intervention: A qualitative program evaluation from an innovative point of view. Workplace Health, Safety and Wellness Conference. September 14-15, 2009. Kelowna, BC, Canada. Conference presentation.

Maiwald K, Guzman J, Mesters I, de Rijk A, Schonstein E, de Bie R, Yassi A. Stakeholders' Perspectives on a Disability Prevention Intervention for Healthcare Workers in British Columbia, Canada. Canadian Institutes of Health Research, Work Disability Prevention Strategic Training Program. June 5, 2009. University of Sherbrooke. Montreal, QC, Canada. Seminar.

Maiwald K, Guzman J, Mesters I, de Rijk A, Schonstein E, de Bie R, Yassi A. Surfacing Theoretical and Practical Perspectives on a Disability Prevention Intervention for Healthcare Workers in British Columbia, Canada. In: Master Work \& Health, module Collaboration in (Occupational) Health Care. Maastricht University. January 16, 2009. Maastricht University, the Netherlands. Lecture.

Maiwald K, Guzman J, Mesters I, de Rijk A, Schonstein E, de Bie R, Yassi A. Surfacing Theoretical and Practical Perspectives on a Disability Prevention Intervention for Healthcare Workers in British Columbia, Canada. January 15, 2009. Department of Social Medicine. Maastricht University, the Netherlands. Seminar.

Maiwald K, de Rijk A, Mesters I, Schonstein E, de Bie RA, Yassi A. Surfacing the Theoretical Framework of a Work Disability Prevention Program for Healthcare Workers in British Columbia, Canada. The $5^{\text {th }}$ Provincial PEARS Meeting. Oct 6, 2008. Vancouver, BC, Canada. Annual meeting presentation and discussion. 
Maiwald K, Mesters I, de Bie RA, Guzman J, Schonstein E, Yassi A. Surfacing the Program Theory of a Disability Prevention Program for Healthcare Workers in British Columbia, Canada. Occupational Health and Safety Conference Canadian Association for Research on Work \& Health. June 15-17, 2008. Montreal, QC, Canada. Conference presentation.

Maiwald K, Nijhuis FNJ, de Rijk A, Meershoek A, Guzman J. A Responsive Evaluation of Work Disability Prevention for Healthcare Workers in British Columbia, Canada: An Evaluation from Stakeholders' Perspective. Canadian Institutes of Health Research, Work Disability Prevention Strategic Training Program. June 10, 2008, University of Sherbrooke. Montreal, QC, Canada. Seminar.

Maiwald K, Mesters I, de Bie RA, Guzman J, Schonstein E, Yassi A. Surfacing the program theory of an injury and disability prevention program for healthcare workers in BC. International Commission on Occupational Health Conference on Health Care Worker Health. October 26-28, 2007. Vancouver, BC, Canada. Research poster.

Maiwald K, Mesters I, de Bie RA, Guzman J, Schonstein E, Yassi A. Surfacing the program theory of an injury and disability prevention program for healthcare workers in BC. Workplace Health, Safety and Wellness Conference. September 17-18, 2007. Kelowna, BC, Canada. Research poster. 
